
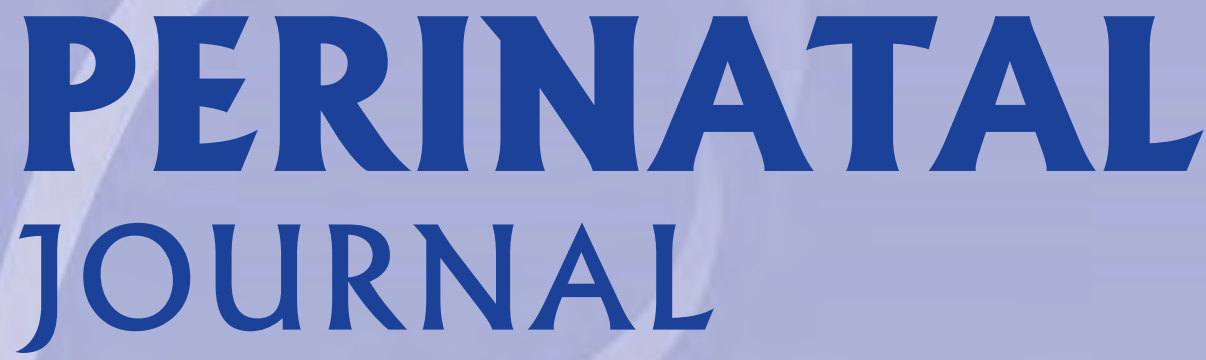

www.perinataldergi.com

Volume 22 | Supplement | October 2014

\title{
11th Congress of
}

the Mediterranean Association for

\section{Ultrasound in Obstetrics and Gynecology}

9th-12th October 2014, Belek, Antalya, Turkey

9th Congress of Obstetrical and Gynecological Ultrasonography

Abstracts

The Official Publication of

Perinatal Medicine Foundation

Turkish Perinatology Society

Turkish Society of Obstetrics and Gynecology

deomed。 


\title{
PERINATAL JOURNAL
}

\author{
www.perinataljournal.com \\ The Official publication of Perinatal Medicine Foundation, \\ Turkish Perinatology Society and \\ Turkish Society of Ultrasound in Obstetrics and Gynecology
}

\begin{abstract}
Description
Perinatal Journal, the official publication of Perinatal Medicine Foundation, Turkish Perinatology Society and Turkish Society of Ultrasound in Obstetrics and Gynecology, is an international online open access peer-reviewed scientific journal (e-ISSN 1305-3124) published triannually in English. The manuscripts which are accepted for publication in the Perinatal Journal are published as a parallel publication of Turkish version in "Perinatoloji Dergisi" (p-ISSN:13005251, e-ISSN:1305-3132). Translation in to Turkish language is provided by the publisher as free of charge for authors. This is automatically accepted by the authors of manuscripts at the time of submission.
\end{abstract}

The journal mainly includes original clinical and experimental research articles, case reports, reviews, editorial and opinion articles, and a letters column. Perinatal Journal can be read by perinatologists, obstetricians, gynecologists, radiologists, pediatricians, sonographers, midwives, radiographers, and scientific members of other related areas.

\section{Aim and Scope}

Perinatal Journal aims to create an interdisciplinary scientific platform for sharing and discussing topics on perinatal medicine and to share its experience with international scientific community.

\section{Copyright}

Periantal Journal does not officially agree with the ideas of manuscripts published in the journal and does not guarantee for any product or service advertisements in its content. Scientific and legal responsibilities of published articles belong to their authors. Materials such as pictures, figures, tables etc. sent with manuscripts should be original or if they were published before written approval of copyright holder should be sent with manuscript for publishing together.

All published materials will become the sole property of, and will be copyrighted by Perinatal Journal. Therefore, "Acknowledgement of Authorship and Transfer of Copyright Agreement" are requested in addition to manuscripts that are to be assessed. Acknowledgement of Authorship and Transfer of Copyright Agreement form is available online at wuw.perinataljournal.com. No payment is done for manuscripts under the name of copyright or others approved for publishing in the journal and no publication cost is charged; however, reprints are at authors' cost.
To promote the development of global open access to scientific information and research, the journal provides copyrights of all online published papers (except where otherwise noted) for free use of readers, scientists, and institutions (such as link to the content or permission for its download, distribution, printing, copying, and reproduction in any medium, without any changing and except the commercial purpose), under the terms of CC BY-NC-ND 3.0 License (www.creativecommons.org/licenses/by-nc-nd/3.0), provided the original work is cited. To get permission for commercial purpose please contact the publisher.

\section{Conflicts of Interest}

The authors should disclose all issues concerning financial relationship, conflict of interest, and competing interest that may potentially influence the results of the research or scientific judgment. All financial contributions or sponsorship, financial relations, and areas of conflict of interest should be clearly explained in the cover letter to the Editor-inChief at the time of submission, with full assurance that any related document will be submitted to the journal when requested. For the details of journal's "Conflicts of Interest Policy" please visit unw.perinataljournal.com.

\section{Publication Info}

Ownership: On behalf of the Perinatal Medicine Foundation Cihat Şen

Managing Editor: Murat Yayla

Administrative Office: Cumhuriyet Cad. 30/5 Elmadağ, Taksim 34367 Istanbul

Due the Press Law of Turkish Republic dated as June 26, 2004 and numbered as 5187 , this publication is classified as a local periodical. Perinatal Journal is published by Deomed Publishing (Copyright (C) 2014, Perinatal Medicine Foundation).

Publication Coordinator: Ilknur Demirel English Editor: Fikret Yeșilyurt

Graphic Design: Tolga Erbay

Page Layout: Nurgül Özcan

Press: Birmat Matbaacılık, Yüzyıl Mahallesi MASSIT 1. Cad. No: 131 Bağcılar, Istanbul, Tel: (0212) 62905 59-60

Printed on acid-free paper (October 2014). 


\section{PERINATAL JOURNAL}

www.perinataljournal.com

\section{Volume 22 | Supplement | October 2014}

Editor-in-Chief

Cihat Şen

Istanbul, Turkey

\section{Associate Editors}

Murat Yayla

Istanbul, Turkey

Oluş Api

Istanbul, Turkey

\section{Advisory Board}

Abdallah Adra, Beyrut, Lübnan

Arif Akșit, Eskişehir, Türkiye

Aris Antsaklis, Atina, Yunanistan

Saadet Arsan, Ankara, Türkiye

Abdel-Latif Ashmaig, Hartum, Sudan

Alev Atış-Aydın, istanbul, Türkiye

Ahmet Baschat, Baltimore, MD, ABD

Ahmet Başaran, Konya, Türkiye

Yeșim Baytur, Manisa, Türkiye

Lous Cabero-Roura, Barselona, ispanya

Manuel Carrapato, Porto, Portekiz

Jose M. Carrera, Barselona, Ispanya

Julene Carvalho, Londra, Ingiltere

Rabih Chaoui, Berlin, Almaya

Frank Chervenak, New York, NY, ABD

Bülent Çakmak, Tokat, Türkiye

Filiz Çayan, Mersin, Türkiye

Ebru Çelik, Malatya, Türkiye

Vincenzo D'Addario, Bari, Italya

Nur Danişmend, İstanbul, Türkiye

Cansun Demir, Adana, Türkiye

Jan Deprest, Leuven, Belçika

Ebru Dikensoy, Gaziantep, Türkiye

Gian Carlo DiRenzo, Perugia, Italya

Tony Duan, Shanghai, Çin

Joachim Dudenhausen, Berlin, Almanya

Alaa Ebrashy, Kahire, Misır

Elif Gül Yapar Eyi, Ankara, Türkiye

Ali Gedikbaşı, istanbul, Türkiye

Ulrich Gembruch, Bonn, Almanya

Anne Greenough, Londra, Ingiltere

Gökhan Göynümer, İstanbul, Türkiye

Arif Güngören, Hatay, Türkiye

Melih A.Güven, Istanbul, Türkiye

Joseph Haddad, Paris, Fransa

Davor Jurkovic, Londra, Ingiltere

Oliver Kagan, Tübingen, Almanya

Ömer Kandemir, Ankara, Türkiye

Burçin Kavak, Elazığ, Türkiye

Ischiro Kawabata, Osaka, Japonya

Selahattin Kumru, Düzce, Türkiye

Names are in alphabetical order.
Asım Kurjak, Zagrep, Hırvatistan Nilgün Kültürsay, İzmir, Türkiye Malcome Levene, Leeds, Ingiltere Narendra Malhotra, Agra, UP, Hindistan Giampaolo Mandruzzato, Trieste, Italya Alexandra Matias, Porto, Portekiz Ratko Matijevic, Zagrep, Hirvatistan Israel Meizner, Tel Aviv, Israil Mohammed Momtaz, Kahire, Misır Giovanni Monni, Cagliari, Italya Ercüment Müngen, İstanbul, Türkiye Kypros Nicolaides, Londra, Ingiltere Lütfü Önderoğlu, Ankara, Türkiye Soner Recai Öner, İzmir, Türkiye Okan Özkaya, Isparta, Türkiye Alexander Papitashvilli, Tiflis, Gürcistan Ibrahim Polat, Istanbul, Türkiye Ritsuko Pooh, Osaka, Japonya Ruben Quintero, Tampa, FL, ABD Nebojsa Radunovic, Belgrad, Sirbistan Guiseppe Rizzo, Roma, italya Roberto Romero, Detroit, MI, ABD Levent Saltık, Istanbul, Türkiye Haluk Sayman, İstanbul, Türkiye Mekin Sezik, Isparta, Türkiye Yunus Söylet, İstanbul, Türkiye Milan Stanojevic, Zagrep, Hirvatistan Florin Stomatian, Cluj, Romanya Jiri Sonek, Dayton, $O H, A B D$ Turgay Şener, Eskişehir, Türkiye Stephen Robson, Newcastle, Ingiltere Alper Tanrıverdi, Aydın, Türkiye Ebru Tarım, Adana, Türkiye Neslihan Tekin, Eskişehir, Türkiye Ilan Timor-Tritsch, New York, NY, ABD Seyfettin Uludağ, İstanbul, Türkiye Liliana Voto, Buenos Aires, Arjantin Miroslaw Wielgos, Varşova, Polonya Simcha Yagel, Tel Aviv, İsrail Ahmet Yalınkaya, Diyarbakır, Türkiye Ivica Zalud, Honolulu, HI, ABD

The Official Publication of Perinatal Medicine Foundation, Turkish Perinatology Society and Turkish Society of Ultrasound in Obstetrics and Gynecology

Correspondence: Perinatal Journal, Perinatal Medicine Foundation,

Cumhuriyet Cad. 30/5 Elmadağ, Taksim 34367 Istanbul, Turkey

Phone: (0212) 2255215 • Fax: (0212) 2252322 e-mail: editor@perinataljournal.com

www.perinataljournal.com 


\section{Coverage}

The manuscripts should be prepared for one of the following article categories which are peer-reviewed:

- Clinical Research Article

- Experimental Study

- Case Report

- Technical Note

- Letter to the Editor

In addition, the journal includes article categories which do not require a peer review process but are prepared by the Editorial Board or consist of invited articles, titled as:

- Editorial

- Viewpoint Article

- Review Article

- Abstracts

- Announcements

- Erratum

\section{Manuscript Evaluation}

All submissions to Perinatal Journal must be original, unpublished, and not under the review of any other publication. This is recorded by the system automatically with the IP number, the date and time of submission. On behalf of all authors the corresponding author should state that all authors are responsible for the manuscripts. The name, date, and place of the relevant meeting should be stated if the submission is a work that was previously presented in a scientific meeting.

Following the initial review, manuscripts which have been accepted for consideration are reviewed by at least two reviewers. The Editors of the journal decide to accept or reject the manuscript considering the comments of the reviewers. They are authorized to reject or revise the manuscript, to suggest required corrections and changes upon the comments and suggestions of reviewers, and/or to correct or condense the text by permission of the corresponding author. They have also the right to reject a manuscript after authors' revision. Author(s) should provide additional relevant data, documents, or information upon the editorial request if necessary.

\section{Ethical Issues}

All manuscripts presenting data obtained from studies involving human subjects must include a statement that the written informed consent of the participants was obtained and that the study was approved by an institutional ethics board or an equivalent body. This institutional approval should be submitted with the manuscript. Authors of case reports must submit the written informed consent of the subject(s) of the report or of the patient's legal representatives for the publication of the manuscript. All studies should be carried out in accordance with the World Medical Association Declaration of Helsinki, covering the latest revision date. Patient confidentiality must be protected according to the universally accepted guidelines and rules. Manuscripts reporting the results of experimental studies on animals must include a statement that the study protocol was approved by the animal ethics committee of the institution and that the study was conducted in accordance with the internationally accepted guidelines, including the Universal Declaration of Animal Rights, European Convention for the Protection of Vertebrate Animals Used for Experimental and Other Scientific Purposes, Principles of Laboratory Animal Science, and the Handbook for the Care and Utilization of Laboratory Animals. The authors are strongly requested to send the approval of the ethics committee together with the manuscript. In addition, manuscripts on human and animal studies should describe procedures indicating the steps taken to eliminate pain and suffering.

The authors should also disclose all issues concerning financial relationship, conflict of interest, and competing interest that may potentially influence the results of the research or scientific judgment. All financial contributions or sponsorship, financial relations, and areas of conflict of interest should be clearly explained in the cover letter to the Editor-in-Chief at the time of submission, with full assurance that any related document will be submitted to the journa when requested. For the details of journal's "Conflict of Interest Policy" please read the PDF document which includes "Conflicts of Interest Disclosure Statement".

Perinatal Journal follows the ethics flowcharts developed by the Committee on Publication Ethics (COPE) for dealing with cases of possible scientific misconduct and breach of publication ethics. For detailed information please visit www.publicationethics.org.

\section{Manuscript Preparation}

In addition to the rules listed below, manuscripts to be published in Perinatal Journal should be in compliance with the Uniform Requirements for Manuscripts Submitted to Biomedical Journals published by International Committee of Medical Journal Editors (ICMJE) of which latest version is available at www.icmje.org.

Authors are requested to ensure that their manuscript follows the appropriate guidelines such as CONSORT for randomized controlled trials, STROBE for observational studies, STARD for diagnostic accuracy studies, and PRISMA for systematic reviews and meta-analyses, for the study design and reporting if applicable.

\section{Authorship and Length of Texts}

The author(s) must declare that they were involved in at least 3 of the 5 stages of the study stated in the "Acknowledgement of Authorship and Transfer of Copyright Agreement" as "designing the study", "collecting the data", "analyzing the data", "writing the manuscript" and "confirming the accuracy of the data and the analyses". Those who do not fulfill this prerequisite should not be stated as an author.

Original research articles base on clinical or experimental studies. The main text should not exceed 2500 words (max. 16 pages) and there should be a maximum 6 authors

Case reports should illustrate interesting cases including their treatment options. The main text should not exceed 2000 words (max. 8 pages) and there should be a maximum 5 authors.

Viewpoint articles: Only by invitation and should be no more than 2000 words long (max. 8 pages).

Review articles: Only by invitation and should be no more than 4000 5000 words long (max. 20 pages).

Technical notes aims to present a newly diagnostic or therapeutic method. They should not exceed 2000 words (max. 8 pages) and include a maximum of 10 references.

Letters to the Editor should be no more than 500 words long (max. 2 pages) and include a maximum of 10 references.

\section{Sections in the Manuscripts}

Manuscripts should be designed in the following order: title page, abstract, main text, references, and tables, with each typeset on a separate page:

Page 1 - Title page

Page 2 - Abstract and key words

Page 3 and next - Main text

Next Page - References

Next Page - Table heading and tables (each table should be placed in separate pages)

Next Page - Figure legends and figures (each figure should be placed in separate pages)

Last Page - Appendices (patient forms, surveys etc.)

Title page

This page should only include the title of the manuscript, which should be carefully chosen to better reflect the contents of the study. No anusual abbreviations should be used in the title of the manuscript. A short title as running heading not exceeding 40 characters should be given which is desired to appear on top part of continuing pages when journal is published. 


\title{
Instructions for the Authors
}

\author{
www.perinataljournal.com
}

\section{Abstract page}

Abstracts should not contain any abbreviation and references. They should be prepared under following designs.

- Abstracts of research articles should be max. 250 words and structured in four paragraphs using the following subtitles: Objective, Methods, Results, and Conclusion. Following the abstract, each abstract page should include max. 5 key words separated with comma and written in lower cases.

- Abstracts of case reports should be max. 125 words and structured in three paragraphs using the following subtitles: Objective, Case, Conclusion. Following the abstract, each abstract page should include max. 3 key words separated with comma and written in lower cases.

- Abstracts of review articles should be max. 300 words and presented not structured in one paragraph. Following the abstract, each abstract page should include max. 5 key words separated with comma and written in lower cases.

- Abstracts of technical notes should be max. 125 words and structured in three paragraphs using the following subtitles: Objective, Technique, Conclusion. Following the abstract, each abstract page should include max. 3 key words separated with comma and written in lower cases.

\section{Main text:}

The sections in main text are defined according to the manuscript type.

- In research articles, main text should consist of sections titled as "Introduction, Methods, Results, Discussion and Conclusion". Each title may have subtitles. The categories of subtitles should be clearly defined.

The Introduction section should include a brief summary of the base of the work and clearly states the purpose of the study.

The Methods section should contain a detailed description of the material, the study design and clinical and laboratory tests, and statistical methods used. A statement regarding the ethical issues should also be given in this section.

The Results section should provide the main findings of the study. Data should be concisely presented, preferably in tables or graphs.

The Discussion section should mainly rely on the results derived from the study, with relevant citations from the most recent literature.

The Conclusion section should briefly and claearly present the conclusions derived from the results of the study. It should be in compliance with the aim of the work and and point out its application in clinical practice.

- In Case Reports, main text should be divided with the titles "Introduction, Case(s), Discussion". Reported case(s) should be introduced clearly including the case story, and the results of laboratory tests should be given in table format as far as possible.

- The text of the reviews articles should follow the "Introduction" and be organized under subtitles which should clearly define the text's context categorization. The Reviews are expected to include wide surveying of literature and reflect the author's personal experiences as far as possible.

- The text of the technical note type of articles should be divided into "Introduction, Technic, Discussion". The presented technic should be defined briefly under the related title, and include illustrations or figures as soon as possible.

- Letters to the Editor should not have titled sections. If there is a citation about a formerly published article within the text, reference(s) should be provided.

\section{References}

References used in the text should be directly related to the topic, as recent as possible and in enough numbers. They should be numbered in square brackets in the order in which they are mentioned in the text including Tables and Figures. Citation order should be checked carefully.

Only published articles or articles in press can be used in references. Unpublished data including conference papers or personal communications should not be used. Papers published in only electronic journals or in the preprint or online first issues of the electronic versions of conventional periodicals should be absolutely presented with DOI (digital object identifier) numbers.
Journal titles should be abbreviated according to the Index Medicus. All authors if six or fewer should be listed; otherwise, the first six and "et al." should be written.

Direct use of references is strongly recommended and the authors may be asked to provide the first and last pages of certain references. Publication of the manuscript will be suspended until this request is fulfilled by the author(s).

The style and punctuation should follow the formats outlined below:

- Standard journal article: Hammerman C, Bin-Nun A, Kaplan M. Managing the patent ductus arteriosus in the premature neonate: a new look at what we thought we knew. Semin Perinatol 2012;36:130-8.

- Article published in an only electronic journal: Lee J, Romero R, Xu Y, Kim JS, Topping V, Yoo W, et al. A signature of maternal anti-fetal rejection in spontaneous preterm birth: chronic chorioamnionitis, anti-human leukocyte antigen antibodies, and C4d. PLoS ONE 2011;6:e16806. doi:10.1371/ journal.pone.0011846. 112-9.

- Book: Jones KL. Practical perinatology. New York: Springer; 1990. p.

- Chapter in a book: Sibai BM, Frangieh AY. Eclampsia. In: Gleicher N, editors. Principles and practice of medical therapy in pregnancy. 3rd ed. New York: Appleton\&Lange; 1998. p. 1022-7

\section{Figures and tables}

All illustrations (photographs, graphics, and drawings) accompanying the manuscript should be referred to as "figure". All figures should be numbered consecutively and mentioned in the text. Figure legends should be added at the end of the text as a separate section. Each figure should be prepared as a separate digital file in "jpeg" format, with a minimum 300 dpi or better resolution. All illustrations should be original. Illustrations published elsewhere should be submitted with the written permission of the original copyright holder. For recognizable photographs of human subjects, written permission signed by the patient or his/her legal representative should be submitted; otherwise, patient names or eyes must be blocked out to prevent identification. Microscopic photographs should include information on staining and magnification.

Each table should be prepared on a separate page with table heading on top of the table. Table heading should be added to the main text file on a separate page when a table is submitted as a supplementary file.

\section{Submission}

For a swift peer review, Perinatal Journal operates a web-based submission, peer review and manuscript tracking system. Authors are required to submit their articles online. Details of how to submit online can be found at www.perinataljournal.com.

\section{Submission Checklist}

The following list will be useful during the final check of a manuscript before submission:

1. Manuscript length (max. 4000 words for research articles)

2. Number of authors (max. 6 authors for research articles)

3. Title page (no anusual abbreviations)

4. Abstracts (max. 250 words for research articles)

5. Key words (max. 5 keys for research articles)

6. Main text (subtitles)

7. References (listed according to the rules of ICMJE)

8. Figures and tables (numbering; legends and headings; copyright info/permission)

9. Cover letter

10. Acknowledgement of Authorship and Transfer of Copyright Agreement (undersigned by all authors)

11. Conflicts of Interest Disclosure Statement (if necessary) 


\section{1th Congress of the Mediterranean Association for Ultrasound in Obstetrics and Gynecology \\ 9th-12th October 2014, Belek, Antalya, Turkey \\ 9th Congress of Obstetrical and Gynecological Ultrasonography \\ Abstracts}

Program Schedule

Oral Presentations

(OP-01 - OP-12)

Poster Presentations

(PP-01 - PP-114)

Author Index

SE59 


\section{1th Congress of the Mediterranean Association for Ultrasound in Obstetrics and Gynecology 9th-12th October 2014, Belek, Antalya, Turkey 9th Congress of Obstetrical and Gynecological Ultrasonography Program Schedule}

\begin{tabular}{|c|c|}
\hline \multicolumn{2}{|c|}{ October 9th, Thursday } \\
\hline 09:00-10:00 & Registration \\
\hline 10:00 & $\begin{array}{l}\text { Basic ultrasound examination / Chairs: Murat Yayla, Burcu Ülkümen } \\
\text { Tips for the adjustment of ultrasound machine } \\
\text { S. Öner }\end{array}$ \\
\hline 10:15 & $\begin{array}{l}\text { Evaluation of the cervix-uterus- tubes-ovaries and pelvis } \\
\text { B. Tekin }\end{array}$ \\
\hline 10:30 & $\begin{array}{l}\text { Ultrasound evaluation of pelvic floor } \\
\text { Ö. Yeniel }\end{array}$ \\
\hline 10:45 & $\begin{array}{l}\text { Cephalopelvic disproportion by ultrasound } \\
\text { A. Güngören }\end{array}$ \\
\hline 11:00 & $\begin{array}{l}\text { Standards for first trimester ultrasound examination } \\
\text { M. Yayla }\end{array}$ \\
\hline 11:15 & $\begin{array}{l}\text { Prediction model for preeclampsia } \\
\text { F. Çayan }\end{array}$ \\
\hline 11:30-11:45 & Discussion \\
\hline $11: 45-12: 45$ & Live demonstration \\
\hline 13:30 & $\begin{array}{l}\text { First trimester examination / Chairs: Reem Abu-Rustum, Özlem Moraloğlu } \\
\text { Fetal anatomical evaluation in the first trimester } \\
\text { R. Abu-Rustum }\end{array}$ \\
\hline 13:45 & $\begin{array}{l}\text { TAD/BPD at } 11-14 \text { wks in the diagnosis of spina bifida } \\
\text { G. Haddad }\end{array}$ \\
\hline 14:00 & $\begin{array}{l}\text { Serum and US markers altered in pregnancies after ART? } \\
\text { O. Gliozheni }\end{array}$ \\
\hline 14:15 & $\begin{array}{l}\text { First trimester markers for aneuploidy: what makes changes? } \\
\text { O. Özkaya }\end{array}$ \\
\hline 14:30 & $\begin{array}{l}\text { Ultrasound markers for spina bifida in first trimester } \\
\text { G. Göynümer }\end{array}$ \\
\hline
\end{tabular}




\begin{tabular}{|c|c|}
\hline $14: 45$ & $\begin{array}{l}\text { Four-year period after screening the first three months of routine diagnostic procedures and results } \\
\text { R. N. Ergin Bayık }\end{array}$ \\
\hline $14: 50$ & $\begin{array}{l}\text { Prenatal diagnosis of the acute meconium peritonitis secondary to ileum volvulus perforation: } \\
\text { A case report } \\
\text { K. E. Karaşahin }\end{array}$ \\
\hline $14: 55$ & $\begin{array}{l}\text { Pentalogy of Cantrell: a case report } \\
\text { A. Akberova }\end{array}$ \\
\hline $15: 00-15: 15$ & Discussion \\
\hline \multirow[t]{2}{*}{$15: 15-16: 00$} & Live demonstration: CNS \\
\hline & Coffee \\
\hline $16: 15$ & $\begin{array}{l}\text { Urogynecology: pelvic floor / Chairs: Gökhan Göynümer, Murat Muhçu } \\
\text { Pelvic floor anatomy by ultrasound } \\
\text { A. Sivaslıoğlu }\end{array}$ \\
\hline $16: 30$ & $\begin{array}{l}\text { Ultrasound techniques and landmark for pelvic floor } \\
\text { D. Uysal }\end{array}$ \\
\hline $16: 45$ & $\begin{array}{l}\text { Ultrasound evaluation of anterior compartment defects } \\
\text { G. A. Santoro }\end{array}$ \\
\hline $17: 00$ & $\begin{array}{l}\text { Ultrasound evaluation of pelvic floor after surgery } \\
\text { A. Sivas/ığlu }\end{array}$ \\
\hline $17: 15$ & $\begin{array}{l}\text { Ultrasound evaluation of posterior compartment defects } \\
\text { G. A. Santoro }\end{array}$ \\
\hline \multirow[t]{2}{*}{$17: 30-17: 45$} & Discussion \\
\hline & Opening ceremony \\
\hline $17: 45$ & Welcome by the president / MEDUOG \& OJUD \\
\hline $18: 00$ & $\begin{array}{l}\text { Future of perinatal imaging } \\
\text { Asım Kurjak }\end{array}$ \\
\hline $18: 30$ & $\begin{array}{l}\text { Chromosomal abnormalities: ultrasound? - fDNA? } \\
\text { Cihat Şen }\end{array}$ \\
\hline 19:00 & Reception \\
\hline
\end{tabular}

\section{October 10th, Friday}

$08: 30$

09:00

09:15
Obstetric ultrasound-1 / Chairs: Vincenzo D'Addario- Syed Gilani

IUGR: Past, present and future

G. Mandruzzato

Prediction of adverse pregnancy outcome

E. Barrabes

Umbilical artery-signal of life

S. Gilani

Ultrasonographic prediction of obstetrical bleedings

A. Yalınkaya 


\begin{tabular}{|c|c|}
\hline 09:30 & $\begin{array}{l}\text { Ultrasound diagnosis of placenta accreta: yes we can } \\
\text { G. Cali }\end{array}$ \\
\hline 09:45 & $\begin{array}{l}\text { Ultrasonografic prediction of uterine rupture } \\
\text { M. Kurdoğlu }\end{array}$ \\
\hline \multirow[t]{2}{*}{ 10:00-10:15 } & Discussion \\
\hline & Coffee \\
\hline $10: 45$ & $\begin{array}{l}\text { Fetal neurosonograhy / Chairs: Ebru Tarım, Giuseppe Cali } \\
\text { Early human development studied by HD-3D sonography } \\
\text { A. Kurjak }\end{array}$ \\
\hline $11: 00$ & $\begin{array}{l}\text { Does fetal neuro-risk mean neonatal neuro-risk? } \\
\text { M. Stanojevic }\end{array}$ \\
\hline 11:15 & $\begin{array}{l}\text { NTD and fetal surgery as an option } \\
\text { A. Gedikbaşı }\end{array}$ \\
\hline $11: 30$ & $\begin{array}{l}\text { Cystic anomalies of the posterior fossa } \\
V . D^{\prime} \text { Addario }\end{array}$ \\
\hline 11:45 & $\begin{array}{l}\text { Cortex abnormalities } \\
\text { U. Dilek }\end{array}$ \\
\hline $12: 00$ & $\begin{array}{l}\text { US screening in OB/GYN when by who and how } \\
\text { A. Antsaklis }\end{array}$ \\
\hline $12: 15-12: 30$ & Discussion \\
\hline \multirow[t]{2}{*}{$12: 30-13: 30$} & MEDUOG: Board and General Assembly \\
\hline & Lunch \\
\hline $14: 00$ & $\begin{array}{l}\text { Fetal heart ve thorax / Chairs: Cihat Şen, Kaouther Dimassi } \\
\text { Effective use of obstetrics ultrasound for fetal heart? } \\
\text { O. Api }\end{array}$ \\
\hline $14: 15$ & $\begin{array}{l}\text { Stenosis, atresia and hypoplastic heart } \\
\text { O. Uzun }\end{array}$ \\
\hline $14: 30$ & $\begin{array}{l}\text { Fetal heart defects: diagnostic tips and perinatal management } \\
\text { C. Şen }\end{array}$ \\
\hline $14: 45$ & $\begin{array}{l}\text { Fetal arrhythmias: diagnosis and management } \\
\text { O. Uzun }\end{array}$ \\
\hline $15: 00$ & $\begin{array}{l}\text { CCAM, sequestration, hydrothorax: fetal intervention } \\
\text { E. Çelik }\end{array}$ \\
\hline $15: 15$ & $\begin{array}{l}\mathrm{CDH} \text { diagnosis and prognostic factors } \\
T \text {. Şener }\end{array}$ \\
\hline $15: 30-15: 45$ & Discussion \\
\hline $15: 45-16: 45$ & Live demonstration: Heart \\
\hline $16.45-17.45$ & Live demonstration: Doppler \\
\hline
\end{tabular}




\section{October 11th, Saturday}

\section{$08: 30$}

08:45

09:00

09:15

09:30

09:45

09:50

09:55

09.55

\begin{tabular}{l} 
10:00-10:15 \\
\hline $10: 45$ \\
$11: 00$
\end{tabular}

$11: 15$

$11: 30$

\begin{tabular}{ll} 
11:30 & Ultrasound evaluation of infertile cases \\
B. Tiraş & $\begin{array}{l}\text { Endometrial pathologies in infertility and Doppler USG } \\
\text { E. Çalışan }\end{array}$ \\
\cline { 2 - 2 } 12:00 & 3D ultrasonography in congenital uterine anomalies \\
& A. Athanasiadis
\end{tabular}

Ultrasound management of twins pregnancy

K. Dimassi

Monochorionic twin pregnancy: TTTS

A. Khalil

Monochorionic twin pregnancy: sIUGR

A. Khalil

Timing and methods of delivery in twins

i. Polat

Selective intrauterine growth restriction in monochorionic twins: pathophysiology, diagnostic approach and management dilemmas Kaouther Dimassi

A rare case of ectopic pregnancy in meso-ovarium

Ö. D. Gündüz

K. Dimassi

Discussion

\section{Coffee}

Ultrasound evaluation of pelvic pain

E. Oral
Twin pregnancy / Chairs: Abdallah Adra, Bülent Çakmak

Methods of screening and prenatal diagnosis in twins

G. Monni

Use of ultrasound in the delivery room for the diagnosis of fetal head engagement

Gynecological Doppler-1 / Chairs: Cansun Demir, Apostolos Athanasiadis

12:15-12:30 Discussion

12:00-13:00 OJUD Board and General Assembly

Lunch

$\begin{array}{ll} & \text { Gynecological Doppler-2 / Chairs: Tugan Beşe, Ertan A } \\ \text { 14:00 } & \text { Benign uterine pathologies and Doppler ultrasound }\end{array}$

A. Özsaran 


\begin{tabular}{|c|c|}
\hline $14: 15$ & $\begin{array}{l}\text { Benign ovarian-tubal pathologies and Doppler ultrasound } \\
\text { S. Topuz }\end{array}$ \\
\hline $14: 30$ & $\begin{array}{l}\text { Cervix pathologies and Doppler ultrasound } \\
T \text {. Beşe }\end{array}$ \\
\hline $14: 45$ & $\begin{array}{l}\text { Malign uterine pathologies and Doppler ultrasound } \\
\text { I. Dünder }\end{array}$ \\
\hline $15: 00$ & $\begin{array}{l}\text { Malign ovarian tumours and Doppler ultrasound } \\
\text { F. Demirkıran }\end{array}$ \\
\hline $15: 15$ & $\begin{array}{l}\text { Gestational throphoblastic diseases and Doppler ultrasound } \\
\text { A. Karateke }\end{array}$ \\
\hline \multirow[t]{2}{*}{$15: 30-15: 45$} & Discussion \\
\hline & Coffee \\
\hline $16: 00$ & $\begin{array}{l}\text { Fetal anomaly / Chairs: Giovanni Monni, Ercüment Cengiz } \\
\text { Second trimester markers for aneuploidy } \\
\text { F. Abdeljawad }\end{array}$ \\
\hline $16: 15$ & $\begin{array}{l}\text { Challenging diagnosis of the fetal abdominal cyst } \\
\text { A. Adra }\end{array}$ \\
\hline $16: 30$ & $\begin{array}{l}\text { Antenatal detection of umbilical cord abnormalities } \\
\text { N. Radunovic }\end{array}$ \\
\hline $16: 45$ & $\begin{array}{l}\text { Fetal syndromes and diagnostic ultrasound } \\
\text { A. Kurjak - S. Zabutovic }\end{array}$ \\
\hline $17: 00$ & $\begin{array}{l}\text { Abnormal pathology of the kidney } \\
\text { M. Chaabane }\end{array}$ \\
\hline $17: 15$ & $\begin{array}{l}\text { Obstructive uropathy: diagnosis and fetal intervention } \\
\text { C. Demir }\end{array}$ \\
\hline $17: 30$ & Discussion \\
\hline
\end{tabular}

\section{October 12th, Sunday}

$08: 30$

Obstetric ultrasound-2 / Chairs: Zehra Kurdoğlu, Neşe Gül Hilali

Importance of placental examination

A. Tanriverdi

08:45 Hyperechogenic bowel: is it a matter?

E. Dikensoy

09:00

Hyperechogenic kidney?

E. Tarım

09:15

Macrosomia: diagnosis and obstetric management

S. Uludağ

09:30

Case presentations: what is your diagnosis?

M. A. Güven 


\begin{tabular}{|c|c|}
\hline 09:45 & $\begin{array}{l}\text { Ultrasound and practising in obstetrics: where is malpractice? } \\
\text { M. Sezik }\end{array}$ \\
\hline \multirow[t]{2}{*}{$10: 00-10: 15$} & Discussion \\
\hline & Coffee \\
\hline $10: 30$ & $\begin{array}{l}\text { Obstetric ultrasound-3 / Chairs: Soner Recai Öner, Burçin Kavak } \\
\text { Craniofacial malformations } \\
\text { E. G. Yapar Eyi }\end{array}$ \\
\hline $10: 45$ & $\begin{array}{l}\text { Fetal kidney abnormalities: diagnosis and management } \\
\text { D. Arıkan }\end{array}$ \\
\hline 11:00 & $\begin{array}{l}\text { Preterm delivery: screening and management by TAS/TVS } \\
\text { A. Atış Aydın }\end{array}$ \\
\hline $11: 15$ & $\begin{array}{l}\text { Skeletal dysplasias } \\
\text { S. Kumru }\end{array}$ \\
\hline 11:30 & $\begin{array}{l}\text { Fetal abdominal wall defects } \\
\text { F. Koyuncu }\end{array}$ \\
\hline $11: 45$ & $\begin{array}{l}\text { Ectopia cordis and omphalocele: a case report } \\
\text { B. Artunç Ülkümen }\end{array}$ \\
\hline $11: 50$ & $\begin{array}{l}\text { Term } 2 \text { and 3-dimensional ultrasound in low-risk population with a different formula } \\
\text { comparison of estimated fetal weight } \\
\text { I. Özer }\end{array}$ \\
\hline $11: 55$ & $\begin{array}{l}\text { Sonographic cervical length and biochemical markers in spontaneous preterm birth (SPTB) } \\
\text { up to } 14 \text { days from sampling } \\
\text { M. H. Lega }\end{array}$ \\
\hline $12: 00$ & $\begin{array}{l}\text { Undergraduate medical education in Turkey in the obstetric and gynecologic ultrasound training } \\
\text { M. Sezik }\end{array}$ \\
\hline $12: 05$ & $\begin{array}{l}\text { Ultrasound evaluation of fetal nasal bone In singleton pregnancies } \\
B \text {. Artunç Ülkümen }\end{array}$ \\
\hline $12: 10$ & $\begin{array}{l}\text { Umbilical artery Doppler in preeclamptic pregnancy and neonatal sepsis } \\
\text { M. Sezik }\end{array}$ \\
\hline $12: 15-12: 30$ & Discussion \\
\hline $12: 30-13: 00$ & $\begin{array}{l}\text { Rational drug use } \\
\text { G. Göynümer }\end{array}$ \\
\hline & Closing \\
\hline
\end{tabular}




\title{
11th Congress of the Mediterranean Association for Ultrasound in Obstetrics and Gynecology 9th-12th October 2014, Belek, Antalya, Turkey 9th Congress of Obstetrical and Gynecological Ultrasonography
}

\author{
Oral Presentations
}

(OP-01 - OP-12)

\section{OP-001}

Comparison of the estimated fetal weight measurements by 2 and 3 dimensional ultrasound at term pregnant women

Hasan Energin, Elif Gül Yapar Eyi

Zekai Tabir Burak Women's Health Education \& Research Hospital, Ankara, Turkey

Objective: To analyze the 2-dimensional and 3-dimensional ultrasound estimation of fetal weight in terms of measurements and the accuracy of the formulas used in the comparison of these measurements.

Methods: 165 pregnant women who were delivered at Zekai Tahir Burak Women's Health Education and Research Hospital were included in the study. Informed consent was obtained from participants and the study was approved by the Hospital Ethics Committee. Pregnant women who participated in the study were selected according to the following criteria: being at 37-42 weeks of gestation without any pregnancy complications and delivering within 48 hours of ultrasonographic measurements. 2D and 3D ultrasound measurements were performed by the same physician (H.E.). Estimated fetal weights $(\mathrm{EFW})$ were calculated from registered biometric values of the $2 \mathrm{D}$ and $3 \mathrm{D}$ images of thigh processed EFW programme and Viewpoint PIA 's were calculated. The most widely used 2D measurements EFW Hadlock I (BPD, AC, FL), Hadlock II (BPD, HC,AC, FL), Shepard (BPD, AC) formulas were used to estimate fetal weight. In terms of $3 \mathrm{D}$ measurements, EFW were calculated from the formulas of Lee I (TVol), Lee II (TVol, AC), Lee III (TVol, AC, BPD). Statistical analysis of the study was carried out by SPSS 17 (SPSS, Chicago,IL USA). The difference between the EFW from the different formulas and the birthweight at delivery was obtained and analyzed by using paired sample t-test.

Results: Estimated fetal weights for all formulas significantly correlated with birthweights. In comparison of the infant birth weights and estimated fetal weights for each formula, no statistically significant difference was detected for Lee I, Hadlock II, Hadlock I; whereas there was significant difference for Lee II, Lee III, Shephard. P values of Lee I, Hadlock II and Hadlock I were 0667,0.526, 0.016) respectively.

Conclusion: Ultrasonographicestimation of fetal weight has been widely used in labor wards. Estimation of fetal weight by 3-D ultrasound including soft tissue volume appears to be more accurate in Lee I formula than the other 2 and $3 \mathrm{D}$ formulas in low risk term pregnant women delivered within 48 hours of measurement.

Keywords: 2D ultrasound, 3 D ultrasound, fetal weight. 


\section{OP-002}

\section{Prenatal diagnosis of the acute meconium peritonitis secondary to ileum volvulus perforation: a case report}

Ugur Keskin $^{1}$, Kazım Emre Karaşahin ${ }^{1}$, Mustafa Öztürk ${ }^{3}$, Cüneyt Atabek ${ }^{2}$, Suzi Demirbağ ${ }^{2}$, Ali Ergün ${ }^{1}$

${ }^{1}$ Department of Obstetrics and Gynecology, Gulhane Military Medical Faculty, Ankara, Turkey; ${ }^{2}$ Department of Pediatric Surgery, Gulhane Military Medical Faculty, Ankara, Turkey; ${ }^{3}$ Department of Obstetrics and Gynecology, Etimesgut Military Hospital, Ankara, Turkey

We present an unusual case different than previously described prenatal cases, with very early diagnosis and surgical intervention following delivery. A 40-year-old gravida, showed the presence of cystic structure in the fetal abdomen consistent with intestinal dilatation. At 32th week control ultrasound showed the collapse of the bowel dilatation and the presence of hyperechogenic fluid in the fetal abdomen. A C-Section was performed. The clinical importance of this report is that the meconium peritonitis (MP) may be diagnosed in the acute phase with typical ultrasound features, and should be considered in the differential diagnoses of cases presented with reduced fetal movements. It looks as if the morbidity and mortality in Meconium peritonitis cases depend upon the gestational age, and our case report may aid to manage similar cases for defining the appropriate delivery time and treatment option after prenatal diagnosis of the problem.

Keywords: Meconium peritonitis, prenatal diagnosis, ultrasonography.

\section{OP-003}

\section{Obstetrical and gynecological ultrasound training during graduate medical education in Turkey}

\section{Mekin Sezik}

Department of Obstetrics and Gynecology, Faculty of Medicine, Siileyman Demirel University, Isparta, Turkey

Objective: Use of ultrasonography in obstetrics and gynecology is ever increasing. Physicians generally acquire competency in ultrasonography during postgraduate years. However, acquaintance and core competency at a certain level during graduate education at medical school may be important. The present study aims to analyze the obstetrics and gynecology curricula of various medical schools in Turkey, concerning the current context of graduate obstetrical/gynecological ultrasound training.

Methods: This is a cross-sectional descriptive study. Curricula of 10 medical schools (at Abant İzzet Baysal, Akdeniz, Atatürk, Başkent, Dicle, Ege, Hacettepe, Istanbul, Karadeniz Teknik, and Süleyman Demirel Universities) randomly assigned from distinctive geographical regions in Turkey were retrieved from their websites. Theoretical and practical subject titles on obstetrics and gynecology during graduate education were probed. This included searches through online curricular texts with the keywords "USG", "ultrasound", and "ultrasonography". Titles in the retrieved curricula pertaining to obstetri$\mathrm{cal} /$ gynecological ultrasonography were analyzed.

Results: There was no subject title on gynecological ultrasonography in any of the analyzed curricula. Half of the academic programs $(n=5)$ included a 1-hour theoretical lecture on "obstetrical ultrasonography". Titles on practical training ("pregnancy/gynecological ultrasound and follow-up" and "ultrasonographic cyst aspiration") were present only in 2 of the curricula.

Conclusion: Graduate education aiming competency in obstetrical/gynecological ultrasonography seems limited according to the present sample including 10 representative medical schools in Turkey.

Keywords: Competency in ultrasonography, curriculum evaluation, graduate medical education.

\section{OP-004}

\section{Umbilical artery Doppler waveform and newborn sepsis in preeclamptic pregnant women}

Mekin Sezik ${ }^{1}$, Hülya Toyran Sezik ${ }^{2}$

${ }^{1}$ Department of Obstetrics and Gynecology, Faculty of Medicine, Siileyman Demirel University, Isparta, Turkey; ${ }^{2}$ Private Isparta Hospital, Isparta, Turkey

Objective: Although there is data showing that the presence of absent or reversed end-diastolic velocity (AREDV) in umbilical artery Doppler (UAD) of preeclamptic pregnant women increases the risk of neonatal sepsis, no study thoroughly has investigated if this effect is independent from the week of gestation or not. In this study, our aim was to investigate the importance of AREDV for predicting neonatal sepsis during severe preeclampsia.

Methods: A total of 284 pregnant women who had UAD data for prenatal period and resulted with live births after severe preeclampsia during a five-year period were included in the study. The correlation between AREDV and the diagnosis of neonatal sepsis confirmed by laboratory was evaluated by chisquare tests and logistic regression analysis.

Results: Neonatal sepsis rate was found significantly higher in those with AREDV ( $\mathrm{n}=34)$ than those without AREDV $(\mathrm{n}=250)(17.6 \%$ vs. $4 \%, \mathrm{p}=0.006)$. However, it was found that there was no such effect in the logistic regression model where preeclampsia beginning date was included (adjusted odds ratio $=3.07, \mathrm{CI}=0.97-9.63, \mathrm{p}=0.055)$. 
Conclusion: AREDV presence in preeclamptic pregnant women increases neonatal sepsis risk; however, this correlation seems to be associated with sepsis rate increase in the earlyonset disease.

Keywords: Doppler, preeclampsia, sepsis.

\section{OP-005}

\section{Fetal nasal bone assessment in low risk singleton pregnancies between 20-24 weeks}

Burcu Artunç Ülkümen, Halil Gürsoy Pala, Faik Mümtaz Koyuncu, Yıldız Uyar, Yeşim Baytur

Perinatology Division, Department of Obstetrics and Gynecology, Celal Bayar University School of Medicine, Manisa, Turkey

Objective: In this study, the evaluation of the mean values in the nasal bone (NB) measurements of low-risk Turkish population is aimed.

Methods: Between June 2014 and July 2014, 92 singleton pregnancies, who admitted to perinatology outpatient clinic for 20-24 week fetal anomaly screening, are included in the study. NB lengths, fetal biometric measurements, gestational week and parity characteristics are analysed. All measurements are performed with transabdominal ultrasound (Voluson 730, RAB 3.5-MHz prob). Pregnancies with fetal structural anomalies or chromosomal anomalies are excluded.

Results: Mean maternal age was $28.08 \pm 5.62$ (minimum 17, maksimum 43; median 29); mean gravida was $2.36 \pm 1.42$ (minimum 1, maksimum 6; median 2); mean parity was 0.82 \pm 0.99 (minimum 0 , maksimum 3; median 1); mean gestational week was $20.49 \pm 2.29$ (minimum 20, maksimum 23; median 21); fetal NB length was $6.2 \pm 0.9 \mathrm{~mm}$ (minimum 4.4 $\mathrm{mm}$, maksimum $8.3 \mathrm{~mm}$; median $6.1 \mathrm{~mm}$ ). NB length was correlated with the gestational week $(\mathrm{r}=0.232)$.

Conclusion: Fetal NB can be assessed during 10 gestational week. Fetal position, maternal obesity, ultrasound image quality are main effecting factors. NB length can be differ according genetic and racial characteristics, which are important for making diagnosis of NB hypoplasia.

Keywords: Nasal bone, second trimester screening, singleton pregnancy.

\section{OP-006}

\section{Ectopia cordis and omphalocele: case report}

Burcu Artunç Ülkümen, Halil Gürsoy Pala, Yıldız Uyar, Yeşim Baytur, Faik Mümtaz Koyuncu

Perinatology Division, Department of Obstetrics and Gynecology, Celal Bayar University School of Medicine, Manisa, Turkey
Objective: Ectopia cordis is a rare anomaly with an incidence of 0.8/100,000 births. As the heart can be located outside the thorax, it can be located also in cervical region due to a defect at the upper sternum or it can be also a part of Cantrell's Syndrome. Intracardiac anomalies may be associated with ectopia cordis. Besides, abdominal wall defects, cranial or face abnormalities, cleft palate and lip, chromosomal anomalies may also accompany with ectopia cordis.

Case: A 31 year old, primigravid pregnant woman was referred to our perinatology outpatient clinic with suspicion of fetal anomaly. Ultrasonographic examination revealed 1112 week fetus. Anterior thoraco-abdominal Wall defect and extra-thoracic located heart were seen. Omphalocele sac with approximately $4 \mathrm{~cm}$ was also seen. The patient had no systemic disease. There was no evidence of tertogen exposure during the perinatal period. Family history was unremarkable; there was no newborn with structural or chromosomal anomaly. Karyotype analysis was triploidy. The perinatology council explained the prognosis of the anomaly and the couple wanted to terminate the pregnancy. Written and verbal informed consent were obtained from the couple and the pregnancy was terminated. Postabortal examination revealed that fetal heart was located outside the thorax with concominant omphalocele sac. Postmortem autopsy was not performed, because the family refused to have an autopsy.

Conclusion: The embryonic development of thorax and abdominal wall is completed at 8-9 gestational weeks. Any midline fusion defect during this period results in various anomalies ranging from ectopia cordis to complete viscreal evisseration. Ectopia cordis can be diagnosed with ultrasonography during early pregnancy. It is important, because termination of pregnancy should be offered to the couple due to poor prognosis.

Keywords: Ectopia cordis, omphalocele.

\section{OP-007}

\section{The pentalogy of Cantrell: a case report}

Aygun Akberova,, Semir Köse, Sabahattin Altunyurt

Department of Obstetrics and Gynecology, Hospital of Dokuz Eylul University, Izmir, Turkey

The pentalogy of Cantrell has been defined by the frontal face defect of midline supra-umbilical abdomen, lower end defect of sternum, absence of pericardium diaphragm, absence of frontal surface of diaphragm and various intracardiac anomalies. Cantrell's syndrome was first reported by Cantrell, Haller and Ravitch in a series of 5 cases. It is a rare syndrome seen in 1/65,000-1/200,000 births.

Keywords: Ectopia cordis, pentalogy of Cantrell. 


\section{OP-008}

\section{Selective intrauterine growth restriction in monochorionic twins: pathophysiology, diagnostic approach and management dilemmas}

Kaouther Dimassi ${ }^{1}$, Meriem Ajroudi ${ }^{1}$, Asma Hamdi ${ }^{2}$, Dalenda Chelli' ${ }^{2}$, Amel Triki ${ }^{1}$, Mohamed Faouzi Gara ${ }^{1}$

${ }^{1}$ Department of Obstetrics and Gynecology, Mongi Slim Hospital, La Marsa, Tunisia; ${ }^{2}$ Department A of Gynecology and Obstetrics, Tunisian Maternity and Neonatology Center, Rabta, Tunis, Tunisia

Objective: Selective intrauterine growth restriction (sIUGR) in monochorionic $(\mathrm{MC})$ twins is associated with a substantial increase in perinatal mortality and morbidity for both twins. Clinical evolution depends on the combination of the effects of placental insufficiency in the IUGR twin with inter-twin blood transfer through placental anastomoses.

Case 1: It is about a 30 years old women with a Spontaneous monochorionic twin pregnancy. A selective intrauterine growth restriction type 2 was diagnosed at 22 WA with a persistent absent diastolic flow in the umbilical Doppler of the twin with IUGR. The evolution was marked by the deterioration of the Doppler waveforms and the appearance of a reversed end-diastolic flow at $29 \mathrm{WA}$. Then, because of the faltering growth and the appearance of A reverse atrial flow in the Ductus venosus, a cesarian section was performed at 32 WA. Birth weights were respectively $1200 \mathrm{gr}$ and $1800 \mathrm{gr}$ for the twin with IUGR and the larger twin. The latest died of a hyaline membrane disease after 5 days.

Case 2: It is about a Spontaneous monochorionic diamniotic twin pregnancy with a diagnosis of a type 2 sIUGR at 26 WA. Monitoring was regular and based on the study of fetal growth, and Doppler waveforms. The evolution was marked by a persistent absent diastolic flow in the umbilical Doppler of the twin with sIUGR and the conservation of growth in both twins. Delivery was scheduled at 34 WA. The birth weights were of $1300 \mathrm{~g}$ and $1700 \mathrm{~g}$. At the age of 6 mouths, the pediatric exam did not revealed any brain injury for both twins.

Conclusion: SIUGR is a common condition associated with $\mathrm{MC}$ pregnancy. It is increasingly considered to be an important complication of MC twins, with potentially significant risks of intrauterine fetal demise or neurological adverse outcome for both twins. Introduction of skilled sonographic evaluation, a better understanding of different Doppler patterns and of the anatomy of MC placenta, together with the development of fetoscopic techniques have all contributed to a deeper scientific understanding of this condition.

Keywords: Intra uterine growth restriction, monochorionic, twins, Doppler waveforms.

\section{OP-009}

\section{First trimester screening driven diagnostic procedures and outcomes: 4 year experience}

\author{
Rahime Nida Ergin Bayık ${ }^{1}$, Murat Yayla
}

${ }^{1}$ Department of Gynecology and Obstetrics, Faculty of Medicine, Bahçeşehir University, Istanbul, Turkey; ${ }^{2}$ Department of Gynecology and Obstetrics, International Hospital, Istanbul, Turkey

Objective: In this study we aimed to present the distribution of the risk results detected by routine first trimester combined screening and screening driven procedures together with the demographic and clinical properties of the patients.

Methods: Data of the routine first trimester combined screening of singleton pregnancies performed between 2008 and 2011 were evaluated in this cross-sectional and retrospective study. Patients had test after NT measurements within the same day. Screening driven procedures like cordocentesis and amniocentesis were re-evaluated for their indications, frequencies and karyotype results. Patient groups of cordocentesis and amniocentesis were compared for perinatal prognosis.

Results: A total of 1109 patients were included for data analyses. Mean maternal age of screened pregnant women was $31.07 \pm 3.73$ years. Mean values of related biochemical parameters were as: $\mathrm{fBhCG}: 1.26 \pm 0.94 \mathrm{MoM}$ and PAPP-A $1.16 \pm 0.65 \mathrm{MoM}$. When a cut off value of $1 / 250$ is chosen for combined test detected risk, screening was positive in 3,15\% of the patients (35/1109). In addition, 22 cases were performed invasive procedures irrespective of combined test and when second tirmster screening was taken into account 19 more patients were performed invasive procedures (A total of $6,4 \%)$. In $7.4 \%$ of the patients, abnormality was present in the karyotype analysis. These were; Trisomy $21 \quad(\mathrm{n}=3)$, Trisomy $18(\mathrm{n}=2)$, mosaic XXY $(\mathrm{n}=2)$, inversion -inv9 (p11q12)- $(\mathrm{n}=1)$ and triploidy $(\mathrm{n}=1)$. Abnormality in the karyotype analysis was more frequent in the patinets with positive first trimester combined screening compared to patients performed invasive procedures solely for maternal age, anxiety, second trimester screening or positive sonographic screening alone. Invasive procedures resulted an outcome of rate of approximately $13 \%$ chromosomal abnormality and pregnancy termination in approximately $10 \%$. No abnormality necessitating pregnancy termination was encountered in invasive procedures performed due to anxiety of doctor or mother.

Conclusion: Though false positive rate of routine first trimester combined screening test is $3,1 \%$ in our study, total rate of invasive procedures exceeds the double of this rate $(6.4 \%)$. An old habit of the anxiety related to maternal age 
increases rate of invasive procedures. When procedures performed with indications of NT alone or biochemical test alone, are taken into account this rate further increases.

Keywords: First trimester screening, amniocentesis, cordocentesis.

\section{OP-010}

\section{A rare form of ectopic pregnancy on mesoovarium: case report}

Alev Atis, Ozge Deniz Gunduz, Arzu Kublay, Tolga Karacan, Ali Gedikbasi

Department of Obstetrics \& Gynecology, Kanuni Sultan Suleyman Training \& Research Hospital, Istanbul, Turkey

Objective: Broad ligament pregnancy also termed as intraligamentous pregnancy is a rare form of ectopic pregnancy. Incidence is reported as 1 in 300 ectopic pregnancies.

Case: A 34-year-old, multigravida with 3 previous cesarean section before presented at 8 weeks gestation with intermittent suprapubic pain and vaginal bleeding. She had undergone three cesarean sections before. An abdominal ultrasound examination showed free fluid and $3 \times 4 \mathrm{~cm}$ left adnexal mass in her abdomen. She was hospitalized for follow-up examination and ,-hcg level was: 10290, the next day she had the symptoms of acute abdomen and a fall in hematocrit level so she was taken for laparotomy with the diagnosis of ectopic pregnancy under general anestesia. Perop she was found to have a ruptured $3 \times 4 \mathrm{~cm}$ bleeding site from left mesoovarium. It was found to be an intraligamenter pregnancy,primary abdominal pragnancy. After removal of the lesion, $\beta$-hcg levels decreased. Hystopathological confirmation was done.

Conclusion: A broad ligament pregnancy is an extremely rare condition; a rare form of ectopic pregnancy, and one type of abdominal pregnancy. The diagnosis is seldom established before surgery. We suggest the use of clinical and ultrasonographic findings for the suspicion of pregnancy in the broad ligament because of high incidence of mortality in case of delay in diagnosis.

Keywords: Ectopic, intraligamenter pregnancy.

\section{OP-011}

\section{Sonographic cervical length and biochemical markers in spontaneous preterm birth (SPTB) up to $\mathbf{1 4}$ days from sampling}

Marija Hadzi Lega ${ }^{1}$, Ana Daneva Markova', Milan Stefanovic ${ }^{2}$

${ }^{1}$ University Clinic of Gynecology and Obstetrics, Skopje, Macedonia; ${ }^{2}$ University Clinic of Gynecology and Obstetrics, Nis, Serbia
Objective: The aim of this study was to determine the relationship between sonographic cervical length, fetal fibronectin (fFN), phIGFBP-1 (Actim partus test), cytokines (IL-6, IL-2R and TNF-alpha) and spontaneous preterm birth (SPTB) up to 14 days from sampling.

Methods: Patients were recruited in period of 6 months from September 2013 untill March 2014 with symptoms or complaints suggestive of preterm labor Consenting women were treated according to usual hospital protocol, with addition of vaginal swabs taken for fetal fibronectin, phIGFBP1(Actim partus test) and cervicovaginal IL6, IL2R and TNFalpha. The outcome variable was occurrence of preterm delivery within 14 days from the day of hospital admission.

Results: Thirty six patients (62.07\%) were delivered within 14 days from admission. The fetal fibronectin test is a significant predictor of preterm delivery. Patients with a positive fetal fibronectin test have an OR of 6.429 (95\% CI 1.99120.758) to deliver prematurely. The patients that gave birth within 14 days of admission were also statistically more likely to have a positive phIGFBP-1 test $(\mathrm{p}=0.02)$. All but one pregnant women that remained pregnant after 14 days of admission had a serum level of IL-2R below $500 \mathrm{U} / \mathrm{mL}$ and the difference in concentrations between the two groups is statistically significant $(\mathrm{p}=0.044)$. The patients that were delivered within 14 days of admission in our study group had an average cervical length of $18.78 \pm 5.8 \mathrm{~mm}$, which is significantly lower than the average cervical length $(23.87 \pm 6.36)$ of patients that remained pregnant after 14 days $(\mathrm{p}=0.0028)$. Our results indicated that the cervical length significantly correlates with the concentration of IL- 6 in the CVF (Spearman's coefficient $\mathrm{R}=-0.382, \mathrm{p}<0.05$ ), i.e. there is a negative indirect correlation between the two parameters, which means that increased IL- 6 concentrations in the CVF mean shortening of the cervix and vice-versa. Cervical length also correlated with a positive phIGFBP-1 test i.e. patients with a positive test had an average cervical length of $18.5 \pm 4.63 \mathrm{~mm}$, which is significantly lower than patients with a negative test $-23.43 \pm 7.39 \mathrm{~mm}(\mathrm{p}=0.003)$.

Conclusion: The studied biochemical markers in our study were only moderately successful in the prediction of preterm delivery. Further research is required in terms of the evaluation of cost-benefit of using such test to prevent subsequent unnecessary interventions in the low-risk group, as well as achieve the benefits from such intervention in the high-risk groups of patients.

Keywords: Preterm labor, cervical length, predictive value. 


\section{OP-012}

\section{Use of ultrasound in the delivery room for the diagnosis of fetal head engagement}

Kaouther Dimassi, Sana Mtimet, Anis Dhouaibia, Anissa Ben Amor, Cyrine Belghith, Amel Triki, Mohamed Faouzi Gara

Department of Obstetrics and Gynecology, Mongi Slim Hospital, La Marsa, Tunisia

Objective: The Assessment of fetal head engagement by digital examination is highly subjective even though this method remains the gold standard. Ultrasound could be a new way to specify the fetal head engagement with objective and reproductible measurements.

Methods: We conducted a prospective longitudinal study on a serie of 100 patients and compared the clinical assessment of fetal engagement to the ultrasound measurements. Ultrasound examination was performed in the delivery room. The probe was placed on the ano-vulvar area. The measure used was: distance perineum - external table of fetal head bone.

Results: The ultrasound measures of the distance [perineum external table of fetal head bone] went from 13 to $75 \mathrm{~mm}$; and the measures of the distance [perineum- succedaneum bump] went from 22 to $68 \mathrm{~mm}$. We tried to retain a value threshold of the distance [perineum - external table of fetal head bone] above which the diagnosis of engagement would be countered. The threshold so proposed is of $55 \mathrm{~mm}$ with a positive predictive value in $98,63 \%$, a sensibility in $86.74 \%$ and specificity in $94.11 \%$.

Conclusion: Transperineal ultrasound is a simple and easy method to define fetal head engagement by measuring the distance between perineum and fetal head. This new tool can be very useful in the delivery room when clinical examination is inconclusive hampered, for example, by a succedaneum bump.

Keywords: Ultrasoud, engagement, labor. 


\section{Poster Presentations}

\section{(PP-01 - PP-114)}

\section{PP-001}

\section{First trimester imaging of fetal anterior wall defect by three-dimensional Doppler sonography} Mekin Sezik

Department of Obstetrics and Gynecology, Faculty of Medicine, Siileyman
Demirel University, Isparta, Turkey

Objective: Differentiation between omphalocele and gastroschisis during late first trimester is of importance. A diagnosis of omphalocele requires meticulous search for chromosomal and cardiac abnormalities, whereas gastroschisis is rarely associated with severe additional anomalies. We used three-dimensional color Doppler techniques for early differentiation of these two conditions.

Case: A 20-year-old G1P0 woman was seen at 13 weeks' gestation. A fetal anterior wall defect was present. Three-dimensional color Doppler clearly demonstrated the lateral course and insertion of the umbilical cord and sac-free intestinal loops. Tomographic ultrasound imaging (TUI) aided the definitive diagnosis of gastroschisis.

Conclusion: Three-dimensional color Doppler techniques such as TUI may be useful for differentiation of omphalocele and gastroschisis during late first trimester.

Keywords: Gastroschisis, omphalocele, three-dimensional ultrasonography.

\section{PP-002}

\section{Fetal gender-specific difference for placental volume assessed with 3D-ultrasonography}

Burcu Artunç Ülkümen, Halil Gürsoy Pala, Yıldız Uyar, Faik Mümtaz Koyuncu, Yeşim Baytur

Division of Perinatology, Department of Obstetrics and Gynecology, Celal Bayar University School of Medicine, Manisa, Turkey

Objective: The aim of this study was to evaluate the effect of fetal gender in placental volume and placental mean gray value assessed by three-dimensional (3D) ultrasonography.

Methods: This case-control prospective study consisted of 60 healthy singleton pregnancies, 29 of which were male fetuses and 31 of which were female fetuses which were matched for gestational age, maternal age and parity. Placental volume and placental volumetric mean gray values were evaluated. Umbilical artery and fetal middle cerebral artery (MCA) Doppler indices were calculated.

Results: Placental volume was $296.93 \pm 108.08$ and $399.12 \pm$ $135.08 \mathrm{~cm}^{3}$ in male and female group, respectively $(\mathrm{p}=0.012)$. Mean gray value of the placenta was $39.68 \pm 7.83$ and 39.27 \pm 7.22 in male and female group, respectively $(\mathrm{p}=0.863)$. Umbilical artery PI was $1.03 \pm 0.21$ and $1.00 \pm 0.24$ in male and female group $(\mathrm{p}=0.761)$ and MCA PI was $1.84 \pm 0.85$ and $2.16 \pm 0.67$ in male and female group, respectively $(\mathrm{p}=0.197)$.

Conclusion: Female fetuses have larger placental volumes which may contribute to get better through the adverse maternal environmental conditions.

Keywords: Placental volume, 3D ultrasonography, genderspecific difference.

\section{PP-003}

\section{A comparison of maternal outcomes in complicated vaginal and cesarean deliveries}

Elif Ağaçayak ${ }^{1}$, Serdar Başaranoğlu², Senem Yaman Tunç ${ }^{1}$, Mehmet Sait İçen ${ }^{1}$, Fatih Mehmet Fındık', Sibel Sak ${ }^{3}$, Talip Gül ${ }^{1}$

${ }^{1}$ Department of Obstetrics and Gynecology, Dicle University School of Medicine, Diyarbakur, Turkey; ${ }^{2}$ Department of Obstetrics and Gynecology, İdil State Hospital, Şırnak, Turkey; ${ }^{3}$ Department of Obstetrics and Gynecology, Sedef Medical Center, Diyarbakur, Turkey

Objective: The purpose of this study was to compare general characteristics, laboratory data and maternal outcomes of patients who experienced complications in the first 24 hours after a normal vaginal delivery or cesarean section. This way, we intended to determine the results of complications in these patients.

Methods: Data of patients referred from the peripheral care centers to our tertiary care center in the first 24 hours after a vaginal delivery or cesarean section due to the presence of various complications were screened retrospectively from 2009 to 2013. Clinical and demographic characteristics, results of physical examinations, laboratory parameters (complete blood count, liver and kidney function tests, electrolyte levels and coagulation parameters), indications for cesarean section, mortality rates, maternal morbidities, including 
blood transfusion requirements, surgical and medical treatments administered in our clinic as well as operations performed in other care centers were noted.

Results: A total of 330 patients were included in this study. Of these patients, 285 constituted the postoperative group (C-sections) whereas 45 constituted the postpartum (vaginal deliveries) group. There was no statistically significant difference between the two groups in gravidity, parity, age, vital signs, results of liver and kidney function tests, hemoglobin levels, white blood cell counts and live birth rates. In addition, no significant difference was found between the two groups in maternal morbidity and mortality rates. Although the two groups' hemoglobin and INR values were not significantly different from each other, fresh blood transfusion required in our hospital was significantly higher in the postoperative group compared to the postpartum group (p:0.003). In the postoperative group, hysterectomy was performed in 18 patients $(6.3 \%)$ and hypogastric artery ligation was performed in 16 patients $(5.6 \%)$. In the postpartum group, on the other hand, 'hysterectomy + hypogastric artery ligation' was performed in 4 patients $(8.8 \%)$ and 'hypogastric artery ligation' was performed in one patient $(2.2 \%)$ (p:0.001). Requirement of relaparotomy was significantly higher in the postoperative group (p:0.007)

Conclusion: In the early follow-up, it was found that complicated cesarean sections and vaginal deliveries had similar maternal morbidity and mortality rates, without any advantage of one group to the other. With this in mind, mode of delivery should be selected according to the overall health status of the patient and indications for cesarean section. However, it should also be mentioned that higher requirement of hysterectomy and relaparotomy emerged as an undesirable condition among the postoperative patients in this study. Therefore, larger studies are needed to determine both short term and long term effects of mode of delivery on maternal and neonatal morbidity and mortality rates.

Keywords: Cesarean sections, vaginal deliveries, maternal complications.

\section{PP-004}

\section{Ultrasound in firearm injuries in pregnancy}

Kazim Emre Karasahin, Ibrahim Alanbay, Ugur Keskin, Mustafa Ulubay, Ulas Fidan, Murat Dede, Mufit Cemal Yenen

\section{Department of Obstetrics\&Gynecology, Gulhane Military Medical Academy, Ankara, Turkey}

Objective: We aimed to evaluate the subject of using diagnostic ultrasound and other radiological methods for firearm injury in pregnant women The military conflicts and terror- ism is on the rise in our times. Mass casualty situations are encountered more frequently, nowadays, involving civilians and also pregnant women, therefore injuries with military weapons tend to increase in daily practice, with another increasing contribution being the violence against women using firearms.

Methods: The literature on the subject was searched using Clinical Keys ${ }^{\circledast}$ and PubMed ${ }^{\circledR}$. The evaluation of firearm injuries during pregnancy is critical. The extent of the injury and fetal involvement should be well evaluated and documented. The projectile should be identified,localized and recovered for ballistic investigation.

Results: There are limited literature on the subject. However some guidelines are formed. In the pregnant trauma patient, ultrasound is often easily accessible in an emergency department and can provide crucial information.

Conclusion: Although ultrasound is the primary tool of diagnosis for obstetricians, additional radiological investigations including computer tomography or plain $\mathrm{X}$ rays may aid in diagnosis, and should be ordered without hesitation when necessary, especially in life threathening conditions involving high speed penetrating projectile injuries to the abdomen. As stated in the guidelines(2):"Concern about possible effects of highdose ionizing radiation exposure should not prevent medically indicated maternal diagnostic X-ray procedures from being performed. During pregnancy, other imaging procedures not associated with ionizing radiation should be considered instead of X-rays when possible." Viability of the fetus can also be assessed and documented using fetal biometry and possible vascular injuries to both fetus and placenta can be assessed by using color doppler. 3D/4D ultrasound may also be utilized to surface scan the fetus for any possible injury when there is suspected uterine penetrating injury, this is of course, when the mother and fetus is stable. It should be remembered that ultrasound is unreliable for detecting placental abruption but it may be helpful to exclude placenta previa and demonstrate significant hemorrhage.

Keywords: Pregnancy, firearm, injury.

\section{PP-005}

\section{Abnormalities of the hands in the fetus: the place of ultrasound diagnostic}

Stevan Milosevic, Mirjana Bogavac, Mileva Orelj Popic, Ljiljana Mladenovic Segedi, Sladjana Koledin

Department of Obstetrics and Gynecology, Clinical Center of Vojvodina, University of Novi Sad Medical Faculty, Novi Sad, Serbia

Introduction: The incidence of skeletal system anomalies is 30-35/100,000 deliveries. Thanks to sonography, antenatal 
diagnosis is possible in large number of skeletal anomalies. By careful examination, it is possible to notice number, form and movement disorders of hands and feet as well as fingers and toes. Prenatal diagnosis includes ultrasound examinations and prenatal invasive diagnostic methods. Anomalies of the hand may be associated with triploidy and trisomy of 13,18 and 21 chromosome.

Objective: Our aim was to present case of prenatally diagnosed fetal malformation-abnormal development of the right hand and the importance of ultrasound diagnosis in the decision to end a pregnancy.

Methods: Case of pregnant women in 21 week of gestation (WG) was presented, where the ultrasound diagnosis of fetal anomalies was set (malformation of fetal hand) which was promptly interrupted by inducing abortion.

Results and Case: During ultrasound examination (3D) in $21 \mathrm{WG}$, in patient P.K. 25 years old, it was established pregnancy with anomalous development of the right hand-the thumb has two phalanges, missing index finger, and there is only a part of the upper phalanx of the middle finger and the little and ring fingers have two phalanges. During ultrasound examinations movements of the wrist were normal. The rest of the morphology of the fetus looked normal. From history data patient states only hiperemesis symptoms in the first trimester of pregnancy. After signing the informed conset, under ultrasound control amniocentesis was performed and obtained $20 \mathrm{ml}$ of clear amniotic fluid, which is sent to the cytogenetic testing. Analysis of amniotic fluid cells showed normal female karyotype 46,XX. Analysis was performed from two flasks on 16 metaphases. After reviewing the medical records-the ultrasound findings, the Ethics Commission of the Department of Gynecology and Obstetrics in Novi Sad made the decision to terminate the pregnancy.The patient was admitted to the Clinic of Gynecology and Obstetrics, Clinical Center of Vojvodina for abortion (registration number 3169/2014 in case history). Pregnancy is completed by induction of abortion with the use of 2 Prepidil gel and application of Prostin 15M. Extraction of the fetus was performed and instrumental revision of the uterus. Antibiotic therapy and therapy with uterotonics was administered. At autopsy confirmed the ultrasound diagnosis of these anomalies. On follow up after induced abortion ultrasound examinations showed normal uterine findings.

Conclusion: A case report shows the importance of 3D ultrasound as a reliable method for prenatal diagnosis of abnormalities of the skeletal system, careful antenatal fetal testing with the application of cytogenetics and off associated disorders and timely completion of pregnancy. Prenatal diagnostics today necessitates a multidisciplinary approach and thus prevent the birth of children with anomalies which are burden not only for their families, but also for whole society.

Keywords: Prenatal diagnosis, fetal skeletal system anomalies, 3D ultrasound.

\section{PP-006 \\ Placentomegaly with acute chorionitis: case report}

İlay Öztürk Gözükara' ${ }^{1}$, Arif Güngören' ${ }^{1}$ Kenan Dolapçıoğlu', Hasan Gökçe', Raziye Keskin Kurt', Oya Soylu Karapınar', Ali Ulvi Hakverdi ${ }^{1}$

${ }^{1}$ Department of Obstetrics \& Gynecology, Faculty of Medicine, Mustafa Kemal University, Hatay, Turkey; ${ }^{2}$ Department of Pathology, Faculty of Medicine, Mustafa Kemal University, Hatay, Turkey

Objective: Placentomegaly is enlargement of placenta with 2 standard deviation from mean values. A placental thickness of $>40 \mathrm{~mm}$ at term is associated with gestational diabetes, intra uterine infections and hydrops fetalis.

Case: A 16-year-old women, gravidity 1 with 23 weeks pregnancy was reffered to as placentomegaly. Her blood type was A Rh positive. There was single, alive and anatomically normal fetus with 23 week biometric measurement in her ultrasonographical exam. Cervical dilation with $3 \mathrm{~cm}$ and $80 \%$ effacement was found in clinical exam. Placental thickness was $6 \mathrm{~cm}$ and measured from cord insertion as a perpendicular to uterine wall. Placenta has occupied nearly whole part of uterine cavity and fetus located on one side because of placenta. She delivered a $530 \mathrm{gr}$, male, dead fetus by spontaneous vaginal way. Acute chorionitis and fibrinoid necrosis were found in histo-pathological evaluation of placenta. Placentomegaly might be result of hydrous fetalis, placental bleeding, eritroblastosis fetalis, intrauterine infections (e.g. syphilis), chromosomal abnormality, molar pregnancy, chorioangioma of placenta. Increased placental thickness was associated with maternal mortality and fetal anomaly furthermore it was a predictor for LGA infants. Placentomegaly was accompanied with acute chorionitis in our case. However exact etiology of acute chorionitis could not found.

Keywords: Placentomegaly, acute chorionitis.

\section{PP-007}

\section{One sided upper extremity amputation related to amniotic band syndrome: a case report}

Emre Ekmekçi, Seçil Kurtulmuş, Sefa Kelekçi

Department of Perinatology, School of Medicine, Izmir Katip Celebi university, Izmir, Turkey

Amniotic band syndrome anomalies is a syndrome that is caused premature rupture of amniotic membranes and results 
a broad spectrum of fetal anomalies. Syndrom can result various anomalies in a wide spectrum caused by a simple band construction, ranging from major craniofascial visceral defects and fetal demise. In this syndrome various malformations can be seen but most effected parts are extremities. Prognosis is related to severity of anomalies and involvement of the organs. 19 years old, gravisy 1, parity 0, 16 weeks pregnant patient according to the last menstrual period was referred to our clinic because of non visulation of right upper extremity. There was no significant features in the patient's history. Ultrasonographic measurements of gestation was consistent with gestational age. She had no history of previous operation and additional systemic disease.There was no history of consanguineous marriage and drug use. First trimester screening test was not avaliable. There was not sufficient information about first-trimester nuchal thickness on the 11-14 week scan. In the fetal anatomical scan, on the right upper extremity distal radius and ulna were observed absent from 1/2 part. The left upper extremity and both lower extremities were normal. Fetal echocardiographic examinations were normal. In anatomical scan no additional anomalies were detected. The patient was recommended to karyotyping and amniotic fluid sampling for prenatal diagnosis by amniocentesis was performed. Without waiting the result of karyotyping, the case was discussed in the council and she were offered the option of pregnancy termination. With the request of the patient, pregnancy was terminated vaginally. At the macroscopic appearance of abortion material, the $1 / 2$ part of distal radius and ulna on the right extremity were amputated. At the right forearm amputation level, a thin amniotic membrane fold that could not be visualised on ultrasound was observed that was wraping right forearm very hard and the other part of it was attached to left parietal bone on cranium and that caused a 3-4mm defection cranium. Any other gross anomalies was not observed. Fetal amniotic band was confirmed in the autopsy examination and the diagnosis of the right forearm amputation due to the amniotic band syndrome was confirmed. In amniotic band syndrome complications of upper and lower extremities are frequently observed but may also cause visceral anomalies. Amniotic bands are structures that are very difficult to be select on the ultrasound but can be determined in case of detection of abnormalities of the extremities with a more careful examination. But like in our case, an amniotic band that is so tightly wraping the limb may not be displayed in ultrasonography. Like in our case, other cranial structures and organs can have deformations together with limb amputations by the advancement of gestational age.

Keywords: Amniotic band syndrome, fetal amputation.

\section{PP-008}

\section{An unusual cause of isolated fetal ascites; fetal ovarian cyst rupture}

\author{
Emre Ekmekci, Seçil Kurtulmuş, Sefa Kelekçi
}

Department of Perinatology, School of Medicine, Izmir Katip Celebi University, Izmir, Turkey

Fetal ascites can be recognized as a symptom of fetal hydrops, which arise in response to numerous etiologic factors. In contrast, the causes of primary isolated fetal ascites are unclear. Most cases of isolated fetal ascites progress to hydrops fetalis only a bit can resolve spontaneously. In female newborns, ovarian cysts are frequently seen abdominal masses. Usually they are not symptomatic and resolve spontaneously. However, they are rarely symptomatic and they have no clinical significance. A 34-year-old woman, gravity 2, parity 0 , abortion 1 is referred to our clinic at 32 weeks of gestation because of fetal intraabdominal cystic formation. She had an unremarkable prenatal course until this week. In the 32 weeks ultrasonography fetal biometric measurements were compatible with gestational age, amniotic fluid volume was in normal limits. In ultrasonography, we detected a $15 \mathrm{~mm}$ spheric cystic formation on the left lower side of fetal abdomen. The cystic formation was not related with renal structures and bladder. In Doppler sonography, we did not determine intracystic blood supply. Because the fetus is female and had no accompanying genitourinary and gastrointestinal abnormalities primarily suggested us an ovarian cyst. Patient was called for a new visit two weeks later. In the 34th week, ultrasonography fetal growth was compatible with 34 weeks and amniotic fluid was in normal limits again. Only abdominal circumference was measured as $99 \%$ for this week because of fetal intraabdominal fluid. In fetal abdomen, a widespread fluid accumulation was observed. Ovarian cyst on the left fetal ovary was regressed and was measured $14 \mathrm{~mm}$ with an ellipsoid shape. Intestines were floating in this fluid. Fetal thorax was normal and hydrothorax was notdetermined. We did not observe any edema in subcutaneous tissue and we evaluated as primary fetal ascites even so we performed an assessment about hydrops fetalis. Hemogram, HbA1c, VDRL, TORCH screening, Parvovirus B-19 screening, indirectcoombs test and anticardiolipin IgM and IgG studies were performed for the patient. Karyotyping recommended to patient. However, patient did not accept karyotyping. All screenings were evaluated normal. Fetal echocardiography was normal. Patient was called for a visit two weeks later again. Onthe next examination in the 36th weeks of pregnancy, fetal ultrasonography was completelynormal. We have not observed any fetal ovarian cyst and fluid in fetal abdomen was completelyregressed. Patient had a 3400gr healthy baby on the 40th weeks of her pregnancy. No abnormal finding determined in postnatal abdominal ultrasonography. Fetal ovarian cyst rupture should be evaluated as an etiological factor in isolatedfetal ascites cases. 
Evaluation of fetal ovaries is difficult and generally cannot be differentiated from the other pelvic structures. However,when anabdominal detected cystic formation is presented, fetal ovaries should be kept in mind.

Keywords: Fetal ascites, fetal ovarian cyst rupture.

\section{PP-009}

\section{The prenatal diagnosis of lymphangiomas and outcomes}

$\underline{\text { Resul Arisoy }}^{1}$, Emre Erdogdu ${ }^{1}$, Pinar Kumru ${ }^{1}$, Oya Demirci ${ }^{1}$, Hatip Aydin ${ }^{2}$, Semih Tugrul ${ }^{1}$

${ }^{1}$ Department of Perinatology, Zeynep Kamil Maternity and Children's Diseases Training and Research Hospital Istanbul, Turkey; ${ }^{2}$ Department of Genetics, Zeynep Kamil Maternity and Children's Diseases Training and Research Hospital, Istanbul, Turkey

Objective: Our aim was to evaluate ultrasound findings and perinatal outcome after prenatal diagnosis of lymphangiomas

Methods: We searched the archives of our ultrasound database at our center for cases with a prenatal diagnosis of the lymphangioma in the period from 2008 to 2013. We described maternal, fetal and perinatal variables for all cases.

Results: Seven fetuses were diagnosed in our center as having the lymphangioma between 2008 and 2013. All cases were diagnosed during the second and third trimesters with the average gestational age of $24 \pm 4$ weeks. The average diameter of lymphangioma were $58.4 \pm 22.5 \mathrm{~mm}$ at time of diagnosis. Four of the seven fetuses $(57.1 \%)$ had lymphangioma in the neck. Three of the seven fetuses $(42.9 \%)$ had lymphangioma in locations other than fetal neck. Fetal karyotyping was normal in all cases. Two of these fetuses was terminated. No abnormal doppler finding or hydrops were detected in the antenatal follow-up of remaining five cases. Cesarean section was performed due to dystocia for all cases.

Conclusion: The risk of chromosomal abnormalities is very low in pregnancies with isolated lymphangioma. The outcome of pregnancies with lymphangioma is generally favorable and prognosis depends on their locations and size.

Keywords: Chromosomal abnormalities, lymphangioma, perinatal outcome.

\section{PP-010}

\section{The prenatal diagnosis and outcome of fetal intra-abdominal cysts}

Pınar Kumru, Resul Arısoy, Emre Erdogdu, Oya Demirci, Elif Tozkır, Sevcan Arzu Arıkan, Mesut Polat, Semih Tugrul

Department of Perinatology, Zeynep Kamil Maternity and Children's Diseases Training and Research Hospital, Istanbul, Turkey
Objective: The aim of this study is to evaluate the ultrasound findings and perinatal outcome after prenatal diagnosis of fetal abdominal cysts.

Methods: Fetuses diagnosed with abdominal cysts between 2008 and 2013 were retrospectively analysed. Cysts arising from renal system and bowel dilatation were excluded. We described maternal, fetal and perinatal variables for all cases

Results: Eighteen fetuses that are 3 males (16.7\%), 15 females $(83.3 \%)$ with fetal abdominal cyst were diagnosed. The mean gestational age at diagnosis of a fetal abdominal cyst was $26.78 \pm 6.75$ weeks. The mean diameter of fetal abdominal cyst was $39.81 \pm 20.47 \mathrm{~mm}$ at diagnosis. There were 15 liveborn cases and two intrauterine deaths. One case was terminated due to multiple anomalies. Fetal abdominal cyst was resolved in four cases during antenatal period. Surgery was required in six cases (40\%). Overall spontaneous mortality was 3/17 (17.7\%), of which two cases were intrauterine and one case was postoperative.

Conclusion: Ultrasound is not sufficient to detect the origin of fetal abdominal cysts. But the apperance and location of the cyst, fetal gender, presence of peristaltism in the cyst, presence of thick muscular wall and additional fetal anomalies are important of the diagnosis and pre-postnatal management of the cyst.

Keywords: Fetal abdominal cyst, ultrasound.

\section{PP-011}

\section{2nd trimester cervical ectopic pregnancy: case report}

Salih Burçin Kavak ${ }^{1}$, Ebru Kavak ${ }^{2}$, Özgür Arat ${ }^{1}$, Ekrem Sapmaz ${ }^{1}$, Raşit İlhan ${ }^{1}$, Selçuk Kaplan

${ }^{1}$ Department of Obstetrics and Gynecology, School of Medicine, Firat Medical Center, Firat University, Elazı̆̆, Turkey; ${ }^{2}$ Department of Obstetrics and Gynecology, Special Medical Park Hospital, Elazı̆̆, Turkey

Introduction: The incidence of cervical ectopic pregnancy varies between $1 / 2,500$ and 1/10,000. Cervical ectopic pregnancy is life-threatening, and one of the rarest forms of ectopic pregnancy. Sonographic diagnosis of cervical pregnancy has several challenges. The relationship between endometrial cavity and gestational sac should be considered carefully. Since it is seen rarely and one of the most significant reasons of mortality, we aimed to present a case of a cervical ectopic pregnancy diagnosed at 23 weeks of gestation.

Case: Twenty-nine-year-old case with second pregnancy had no remarkable history except a previous cesarean delivery. The case who regularly visited external center for follow-up during current pregnancy admitted to our clinic with the pre-diagnosis of $22 \mathrm{~W} 2 \mathrm{D}$ pregnancy oligohydramnios and diastolic flow 
loss. The case who had 22W2D pregnancy according to early USGs had fetus competible to 19 weeks of gestational age in the USG performed. The case was followed up weekly with the diagnosis of oligohydramnios + IUGR (AC: 18W, FL: $20 \mathrm{~W}$ ) and diastolic flow loss. Placenta was low-lying and no clear relationship with cervix was established. The patient had normal results for first trimester combined test in her history, no rupture of membrane was described and there was no remarkable characteristic in the TORCH panel. The patient who refused vaginal examination was called for control. The patient came one week later and fetal cardiac activity was not seen in the ultrasonography. Fetal abdominal circumference was compatible with $18 \mathrm{~W} 4 \mathrm{D}$. She was diagnosed with 23W1D oligohydramnios, intrauterine fetal death, transverse presentation, and previous $1 \mathrm{C} / \mathrm{S}$. In the USG, fundus was observed as empty and in postpartum appearance. Fetus was observed around isthmic area. So it was suspected of servical ectopic pregnancy. The patient was hospitalized and applied laparotomy after preoperative evaluation. The abdomen was entered by epigastric and hypogastric incisions. The diagnosis of cervical ectopic pregnancy was confirmed by the laparotomy. In order to prevent possible severe bleeding, it was decided to apply Infrarenal Aorta occlusion. The aorta was suspended from Aorta bifurcation level by the consultant cardiovascular surgery physician. Double J catheters were placed on both ureters together with cystoscopy by consultant urologist. Also tourniquet was applied by Penrose over isthmic region. $1 \mathrm{cc}$ heparin was administered and the aorta was clamped 2 minutes later. First the bladder was dissected. Just below the isthmus on the front side of uterus, fetus and its attachments were delivered by opening $3 \mathrm{~cm}$ transverse incision. Fetus was $240 \mathrm{~g}, 20$ $\mathrm{cm}$ and male. Placenta and its attachments were cleaned. Intracervical foley condom was placed. It was inflated by 300 cc SF. Aorta clamp was opened. The procedure took about 25 minutes. One foley drain was placed into Douglas. Bleeding was checked. The case was taken to her bed in the unit with stable findings.

Conclusion: The diagnosis of servical ectopic pregnancy is generally limited with the first trimester cases in the literature. In cases referring at advanced weeks of gestation, prioritized evaluation of uterine fundus and fetus localization is essential to prevent delays in diagnosis.

Keywords: 2nd trimester, cervical ectopic pregnancy.

\section{PP-012}

\section{Edward syndrome: a case report}

Sevcan Arzu Arınkan, Resul Arısoy, Emre Erdoğdu, Oya Demirci, Oya Pekin, Mesut Polat, $\underline{\text { Murat Muhcu }}$

Maternal Fetal Medicine Department, Zeynep Kamil Women and Children Diseases Research and Training Hospital, Istanbul, Turkey
Objective: Edward syndrome, is the second common autosomal trisomy and most of the cases are lost during their first year of life because of severe cardiac pathologies. We aimed to present a case of Edward syndrome which is prenatally diagnosed and to discuss the management in these cases.

Case: A 35-year-old gravida 2, para 1 patient was referred to our clinic at 17 weeks gestation. A detailed ultrasound scan was revealed that alobar holoprosencephaly, proboscis, hypotelorism, polydactyly and midfacial cleft palate-lip. Parents were informed about the fetal prognosis and termination of pregnancy was put forward as an option. Karyotype analysis was performed.

Conclusion: Edward syndrome can include holoprosencephaly and midfacial defects. Karyotype analysis should be performed and termination of pregnancy should be offered as an option for these cases.

Keywords: Edward syndrome, trisomy 18, prenatal diagnosis.

\section{PP-013}

\section{Prenatal diagnosis of right aortic arch and aberran left subclavian artery anomalies: a case report}

Şebnem Erol Türkyılmaz', Gürcan Türkyılmaz ${ }^{2}$, Resul Arısoy ${ }^{1}$, Emre Erdoğdu ${ }^{1}$, Oya Demirci ${ }^{1}$, Oya Pekin', Pinar Kumru', Murat Muhçu

${ }^{1}$ Perinatology Clinic, Zeynep Kamil Training and Research Hospital, Istanbul, Turkey; ${ }^{2}$ Obstetrics and Gynecology Clinic, Beykoz State Hospital, Istanbul, Turkey

Objective: İt's aimed to present a case of right aortic arch and aberran left subclavian artery anomalies which is prenatally diagnosed, and to discuss the managment of the case.

Case: A 29-year-old, gravida 2, parity 1 patient was refered to our clinic because of high risk of Edward syndrome in triple aneuploidy screening test. Detailed fetal ultrasonography and fetal echocardiography performed. Right aortic arch and aberran left subclavian artery anomalies were detected. No additional anomaly was detected during the examinations of other systems. Cordosentesis was performed to patient. Normal karyotype was detected and Di George syndrome microdelesyon was not identified. Pregnancy follow-up was continued and at 39 . week of gestation a healty 3240 gr male infant was delevered by vajinal delivery.

Conclusion: Karyotype analysis and the other associated syndromes should be evaluated and a detailed ultrasonography examination should be performed in fetuses which right aortic arch and left subclavian artery were diagnosed. The prognosis for isolated right aortic arch and aberran left subclavian artery anomailes are good. 
Keywords: Aberran left subclavian artery, prenatal diagnosis, right aortic arch.

\section{PP-014}

\section{Sirenomelia at twin pregnancy: Case Report}

Selçuk Yazıcı', Mine İslimye Taşkın², Eda Üreyen ${ }^{2}$, Tanju Çelik ${ }^{4}$, Şenol Öztürk ${ }^{4}$, Betül Eser ${ }^{3}$, Ertan Adalı ${ }^{2}$

${ }^{1}$ Department of Pediatrics, School of Medicine, Ballkesir University, Balkesir, Turkey; ${ }^{2}$ Department of Obstetrics and Gynecology, School of Medicine, Bahkesir University, Balkesir, Turkey; ${ }^{3}$ Department of Mecial Genetics, School of Medicine, Balkesir University, Balıkesir, Turkey; ${ }^{4}$ Bebcet Uz Child Disease and Pediatric Surgery Training And Research Hospital, Izmir, Turkey

Objective: Sirenomelia is a rare congenital anomaly $(1 / 600,000-1,000,000)$ evaluated in the major form of caudal regression syndrome. It is characterized by a variety of anomalies. Sirenomelia is mostly fatal. Here we aimed to present a case with sirenomelia which diagnosed in the 2 nd trimester in twin pregnancy.

Case: 32-year-old woman,gravida3, para 2, was referred to our outpatient clinic at the gestational age of 32 weeks and 5 days with fetal anomaly in twin pregnancy. She had no history of drug or alcohol abuse and no family history of fetal malformations. Ultrasound examination confirmed of 32 weeks and 5 days diamniotic, viable fetuses. The measurements of the first fetus were consistent with 33 weeks of pregnancy. The measurements of the second fetus were consistent with 32 weeks of pregnancy. In the second fetus severe oligohydramnios, fused lower extremities and a single umbilical artery were detected at ultrasonographic examination. Kidneys were not identified by ultrasonoraphic examination and ultrasonoraphic examination showed absent bladder. At 37 weaks of gestation the patient delivered first baby weighing $3000 \mathrm{gr}, 48 \mathrm{~cm}$ and second baby weighing $2000 \mathrm{gr}, 38 \mathrm{~cm}$ with elective cesarian section. At the first baby's apgar scores were 9,10 at one and five minutes and at the second baby's apgar scores were 6,8 at one and five minutes. On the physical examination, second baby's lower extremities were fused. The external genitalia had not developed except for a small bud. The anus was not open, it had a single umbilical artery. At the sixth hour of delivery the baby was accepted as exitus.Postnatal ultrasound revealed multicystic dysplastic horseshoe kidneys and absence of the bladder. Cytogenetic analysis revealed a normal male fetus $(46, \mathrm{XY})$.

Conclusion: Sirenomelia is a rare congenital anomaly. Diagnosis of sirenomelia at second trimester can be difficult because of oligo-hydramnios due to renal agenesis. During the first trimester the amniotic fluid volume is usually normal, unrelated to the fetal urine production. Therefore, anatomic survey of the fetus during first trimester or early second trimester can provide early prenatal diagnosis. An early diagnosis of this lethal condition is important in order to allow prenatal counseling for possible pregnancy termination.

Keywords: Sirenomelia, congenital anomalies, oligohydramnios.

\section{PP-015}

\section{The effect of anhydramnios and/or ceserian section history on duration of medical abortion}

Oya Soylu Karapınar, Arif Güngören, Kenan Dolapçığlu, Raziye Keskin Kurt, Dilek Benk Şilfeler, Hanifi Şahin, Ali Ulvi Hakverdi

Department of Gynecology and Obstetrics of, Faculty of Medicine, Mustafa Kemal University, Hatay, Turkey

Objective: We aimed to determine that if anhydramnios and ceserian section history affect the duration of abortus in medical abortus cases with various indications and compare them with cases which have normal amnion fluid and vaginal birth history.

Methods: This study was a retrospectively designed study. Patients who were admitted to our clinic because of medical abortion between January 2010-December 2013 were included in this study. A total of 32 pregnant women with anhydramniosis as study group and 67 pregnant women who had normal amnion fluid as control group were included in this study. Control group`s abortus indications were spina bifida, hydrocephalus, encephalocele, anencephaly, hydrops fetalis, multiple anomalies, heart anomalies(hypoplastic left heart), down syndrome, Beta thalassemia, sickle cell anemia and cystic hygroma. Patients' age, gravida, parity, gestational age, previous delivery route, duration of abortus were recorded. Misoprostol were used for medical abortion as follows: 200 mcg po and $200 \mathrm{mcg}$ vaginal twice a day in patients who had prior ceserian section history and $200 \mathrm{mcg}$ po and $200 \mathrm{mcg}$ vaginal three times a day in patients who had prior vaginal birth history. After medical abortion, revision curettage was performed in necessary cases.

Results: While the mean age of patients was $28.10 \pm 5.72(15-$ $47)$, the mean gestational age was $17.94 \pm 3.40$ (10-27) weeks. $62(\% 62.6)$ of patients had previous vaginal delivery and 28 $(\% 28.3)$ of them had previous ceserian section history. 9 (\%9.1) patients were primigravida. 78 (\%78.8) patients had revision curettage after medical abortion. While the mean duration of abortion in anhydramnios group was $71.93 \pm$ $47.51 \mathrm{~h}$, it was $79.08 \pm 52.62 \mathrm{~h}$ in control group. There was no statistically significiant difference between two groups according to duration of abortion $(\mathrm{p}=0.516)$. While the mean 
duration of abortion was $69.95 \pm 31.24 \mathrm{~h}$ in Patients having prior history of vaginal birth, it was $87.07 \pm 74.38 \mathrm{~h}$ in patients having prior history of ceserian section. Primigravid patients had the mean duration of abortion of $91.77 \pm 68.06 \mathrm{~h}$. There were no statistically significiant difference in duration of abortion according to previous delivery route $(\mathrm{p}=0.220)$.

Conclusion: There was no statistically significiant difference between anhydramnios group and control group according to duration of abortion. In addition to that parity and previous delivery route did not seem to affect the duration of abortus.

Keywords: Medical abortion, anhydramniosis, ceserian section history.

\section{PP-016}

\section{A case of non-immune hydrops fetalis and intrauterine transfusion}

Emre Ekmekci ${ }^{1}$, Seçil Kurtulmuș ${ }^{1}$, Serpil Aydoğmuş² Sefa Kelekçi ${ }^{1}$

${ }^{1}$ Perinatology Clinic, School of Medicine, Izmir Katip Celebi University, Izmir, Turkey; 'ynecology and Obstetrics Department, School of Medicine, Izmir Katip Celebi University, Izmir, Turkey

Hydrops fetalis is excessive accumulation of fluid in extravascular compartmans which causes fluid collection in fetal body spaces and generalised soft tissue edema. Non immun hydrops fetalis is a high mortality rate disease that can be caused by chromosomal abnormalities cardiacanomalies, arrhythmia, fetalanemia and TORCH infections. In her first prenatal visit the patient who had gravida 2, paritiy 1 referred to our clinic to perform a combine test on her 12th week of pregnancy. Her blood type was A Rh positive and there was no consanguinity with her husband. Her combined test result was $1 / 10,000$. One month later, fetal caryotyping by amniocentesis was performed when fetal intestinal hyperechogenity and intracardiac echogenic focus in the left venticule were observed in the 17 th week of pregnancy. TORCH screening was made and it was negative. Fetal caryotype was normal, fetal echocardiography was normal. In 27 th week of pregnancy the fetus is examined again and it was observed that intestinal hyperechogenicity is persisted and additionally intraabdominal accumulation of fluid is found. Nuchal fold is measured as $8.3 \mathrm{~mm}$. Enddiastolic reverse flow was diagnosed in umbilical artery. Scalp was edematous and skin thickness was measured as $8 \mathrm{~mm}$. Cardiomegaly was observed in fetal echocardiography. A systolic regurgation flow with the peak velocity of $117 \mathrm{~cm} / \mathrm{sec}$ was measured in tricuspid valve. Indirect coombs test was negative. Parvovirus test was negative. Any additional abnormality was not observed in the anatomic examination. After five-day period of test results span, fetal hydrops advanced excessive acid accumulated in the abdomen, plevral effusion started and skin edema improved. Daily $25 \mathrm{mg}$ Digoxine was prescribed. Fetal heart rate was $188 / \mathrm{min}$ and peak systolic velocity in MCA was measured $53 \mathrm{~cm} / \mathrm{sec}(1.57 \mathrm{MoM})$ suggesting fetal anemy. Because of fetal anemy intrauterin transfusion was planned. $250 \mathrm{cc}, 0 \mathrm{Rh}$ negative irradiated and locosyte filtered CMV negative, \%80 hematocryte erithrocyte suspension was prepared. The fetal hematocryte before transfusion was 21 . İntravasculer fetal transfusion was made by $180 \mathrm{cc}$ eriytrocyte suspension. After transfusion fetal hematocryte was 54 and increased, the peac systolic velocity in MCA was $0.82 \mathrm{MoM}$ and it was decreased and fetal tacycardia was regressed. The daily $25 \mathrm{mg}$ Digoxin therapy was continiued. After transfusion, in the first 20-hour period, fetal heart rate was normal. But in the 21st hour, it was observed that fetal heart beats was negative. After than, pregnancy was terminated through vagina. The etiology is usually unknown in NIHF. In INHF cases, after a detailed anatomic scan and fetal echocardiography evaluation for the fetal anemy should be made. Subgroup $\mathrm{Rh}$ incompatibility or any other etiolgic factors can be the cause of the fetal anemy. As in our case if hydrops occurs the prognosis in fetal anemy is poor even if the tratment is performed.

Keywords: Hydrops fetalis, intrauterine transfusion.

\section{PP-017}

\section{A rare case of spina occulta}

Narjess Karmous, Kaouther Dimassi, Helmi Temessek, Thouraya Ammouss, Raouina Radhouani, Amel Triki, Mohamed Faouzi Gara

Department of Obstetrics and Gynecology, Mongi Slim Hospital, La Marsa, Tunisia

Introduction: Diastematomyelia, also termed split cord malformation (SCM), is a rare form of occult spinal dysraphism characterized by the cleft in spinal cord. Prenatal diagnosis is possible bu ultrasonography (US), and fetal MRI can be used to diagnose the type of diastelatommyelia precisely. This anomaly can be isolated or associated with other dysraphism, segmental anomalies of the vertebral bodies, or visceral malformations. In isolated diastematomyelia, the skin is intact ant the prognosis excellent.

Objective: We present a case of SCM with low attached spinal cord and a lipoma of the conus diagnosed in our institution as well as a review of the literature in order to determine the prognodis of isolated case of this unusual condition.

Case: Routine US in a 22 weeks pregnant woman revealed a spinal abnormality of the fetus. There was a intra spinal hyper echogenicity opposite the third lumbar vertebra, with a mature 
posterior vertebral integrated and intact skin surface. It was difficult to see the spinal cord due to acoustic shadowing. MRI was performed during the 33rd week of gestation and confirmed the presence terminal SCM and low attached spinal cord. After the vaginal delivery at term, the child's development was normal. The MRI was done after 2 months, it confirmed the prenatal diagnosis: there was no cerebral abnormalities, there was a spinal dysraphism consisting on a law attached spinal cord associated to a lumbar diastematomyelia and a spinal lipoma of the terminal conus. We classified this SCM type 2 with good prognosis.

Conclusion: Prenatal knowledge of spinal cord anomalies is important for prenatal counseling as well assurgical treatment. Since MRI shows these lesions better and with less interobserver variation than US, in patients with suspected spinal anomalies, either diagnosed on US or based on clinical and laboratory criteria, fetal MRI should be used prior to further management.

Keywords: Spina occulta, diastematomyelia, lipoma of the conus.

\section{PP-018}

\section{Prenatal diagnosis of giant sacrococcygeal teratoma}

Onur Erol, Özgür Özdemir, Bekir Sttkı İsenlik, Selahattin Kumru

Antalya Training and Research Hospital, Antalya, turkey

Objective: Sacrococcygeal teratomas constitute more than half of all fetal tumors, their incidence is only 1:40,000 live births, with a female-to-male ratio of $4: 1$. They originate during embryonic development when the primitive streak fails to differentiate among mesodermal, ectodermal and endodermal tissues in the embryonic disc. Characteristics of the neoplasm include internal calcifications, haemorrhage, necrosis of the tumour and degeneration of the cystic neoplasm.The effects of the mass may lead to dystocia and preterm labour. The highly vascular tumour may result in high-output cardiacfailure and eventually foetal hydrops. Advances in ultrasonography have enabled accurate early diagnosis of sacrococcygealteratomas when they present in the form of cystic, solid, or mixed masses that form starting in the sacral region and protrude toward the perineum or buttocks. However, cystic sacrococcygeal teratomas may be erroneously diagnosed as anterior sacral meningomyelocele, especially when they present as posterior cystic masses.

Methods: We present a case of solid-cystic sacrococcygeal teratoma that was diagnosed in the 18 week of pregnancy by means of two-dimensional ultrasonography in association with color Doppler.
Case: A 34-year-old patient, gravida 2 para 1, with 18 weeks of gestation has presented for routine fetal examination. The ultrasonographic examination revealed a bulky mass $(89 \mathrm{x} 59 \mathrm{x}$ $67 \mathrm{~mm}$ ) at the sacral area that was predominantly solid and had a few cystic components with internal flow seen on color Doppler. No other fetal abnormalities were detected. The patient and her husband were counseled about the prognosis. The patient was referred for fetal surgery. Before this process, a new ultrasound examination revealed fetal demise. The parents opted for termination of pregnancy. The postnatal macroscopic findings confirmed the prenatal diagnosis.

Conclusion: Advances in ultrasonography have enabled accurate early diagnosis of sacrococcygeal teratomas. Ultrasound scans are also necessary to monitor the tumor size, extension into adjacent structures, tumor vascularity, evidence of cardiac failure, determining time and mode of delivery.

Keywords: Fetal anomaly, prenatal diagnosis, sacrococcygeal teratoma.

\section{PP-019}

\section{A case of non-immun hydrops fetalis due to a giant chorioangioma}

Seçil Karaca Kurtulmus ${ }^{1}$, Emre Ekmekci ${ }^{1}$, Serpil Aydoğmuş ${ }^{2}$, Alkım Yildırım², Sefa Kelekçi ${ }^{1}$

${ }^{1}$ Perinatology Clinic, Izmir Katip Celebi University School of Medicine, Izmir, Turkey; ${ }^{2}$ Department of Gynecology and Obstetrics, Izmir Katip Celebi University School of Medicine, Izmir, Turkey

Chorioangiomas are found in approximately $0.5 \%-1.0 \%$ of placentas. Large $(\geq 5 \mathrm{~cm})$ or multiple chorioangiomas have been reported to occur at a rate of 1: 3500 to $1: 16,000$ births. Most of them are small in size and have generally no clinical significance. However, large chorangiomas $(>5 \mathrm{~cm})$ are often associated with polyhydramnios, preterm labor, hydrops, fetal hemolytic anemia, fetal thrombocytopenia, cardiomegaly, intrauterine growth restriction, placental abruption and preeclampsia. Large hemangiomas probably act as arteriovenous shunts and cause complications. 29 year old G2P1 womean was referred to our clinic because of developing hydrops on her 27th week of pregnancy. Detailed sonographic examination was performed. Fetal biometry was consistent with gestational age. On sonographic examination, excessive accumulation of fluid in fetal abdomen, fetal thorax and fetal subcutaneous tissue, cardiomegaly, pericardial effusion and hepatosplenomegaly were observed. A well-defined echogenic mass measured $93 \mathrm{~mm}$ x $100 \mathrm{~mm}$, different from the rest of the placenta was stated bulging on the fetal side, near the placenta. The anatomic sonogram of fetal heart and other fetal organs were normal. The peak systolic velocity in 
fetal aorta and pulmonary artery were high, suggesting hyperdynamic circulation. The peak systolic velocity in the fetal MCA was $72 \mathrm{~cm} / \mathrm{sec}(2.04 \mathrm{MoM})$ suggesting fetal anemia. Diagnosis of hydrops fetalis and fetal anemia due to huge chorioangioma was made and intrauterin fetal transfusion was planned. Before fetal transfusion chordosynthesis was performed; fetal hematocryte was $24 \% .32 \mathrm{ml}$ radiated $\mathrm{CMV}$ negative, $0 \mathrm{Rh}$ negative eriythrocyte suspension was transfered. After transfusion fetal hematocryte was measured as $33 \%$ and fetus was monitorized with cardiotocogram. Six hours after transfusion recurrent late decelarations occured and the pregnancy was terminated via C/S. 1100 gr female baby was delivered. The 1 st minute apgar score was 5 and the 5 th minute apgar score was 2 . Despite agressive cardiopulmonary resucitation the baby was dead 1 hour after birth. A lobular mass measuring $90 \mathrm{~mm} \times 100 \mathrm{~mm}$ that attached to the fetal surface of placenta with a pedicle was noted. The diagnosis of chorioangioma was made with pathological examination. Chorioangioma is usually treated with expectant management, as the majority of tumors are asymptomatic and small. In situations in which maternal or fetal complications necessitate intervention, there are several possible treatments. However, most of these cases have a dismal poor prognosis. Possible interventions include serial fetal transfusions, fetoscopic laser coagulation of vessels supplying the tumor, chemosclerosis with absolute alcohol, and endoscopic surgical devascularization. Large placental chorioangiomas are rare and the prognosis is bad when a big tumor causes fetal hemodynamic changes with NIHF. The overall prognosis is somewhat dependent on the presence and / or development of hydrops fetalis.

Keywords: Chorioangioma, fetal hydrops.

\section{PP-020}

\section{Alobar holoprosencephaly: a case report}

Seçil Karaca Kurtulmuș ${ }^{1}$, Emre Ekmekci', Serpil Aydoğmuş ${ }^{2}$, Alkım Yıldırım², Sefa Kelekçi ${ }^{1}$

${ }^{1}$ Perinatology Clinic, Atatiurk Training and Research Hospital, Faculty of Medicine, İmir Katip Çelebi University, İzmir, Turkey; ${ }^{2}$ Department of Obstetrics and Gynecology, Atatiirk Training and Research Hospital, Faculty of Medicine, İmir Katip Çelebi University, İzmir, Turkey

Alobar holoprosencephaly is a rare and severe congenital brain anomaly which is caused by developmental defect in the fore brain associated with non-disjunction of both hemispheres and ventricles during embryonic period. Depending on the severity of non-disjunction, holoprosencephaly can be classified as alobar, semilobar or lobar. Alobar holoprosencephaly is the most severe form and results with monoventricular cavity formation, fusion of thalami and non-development of corpus callosum, falx cerebri, optical paths and olfactory structures. Its ethiology is multifactorial, and chromosomal anomalies or monogenic defects are the major reasons with the rate of 40 $50 \%$. The patient with gravida 1 and parity 0 was referred to our clinic at 30 weeks of gestation due to lateral ventriculomegaly. There was no risk factor in the medical history of the patient. The result of combined screening test was normal. In her ultrasonography, composite lateral ventricular and monoventricular appearances were observed. Bilateral thalamic fusion was detected. Vermian agenesis was found. Interorbital length was measured as $10.6 \mathrm{~mm}$ and hypotelorism was observed. Median cleft was seen on the midline of upper lip. The results of the evaluation of other systems and fetal cardiac screening were normal. Fetal karyotyping was carried out by cordocentesis and karyotyping was resulted as normal. The patient was discussed at our council and the patient was informed about the progress of the pregnancy. The termination of pregnancy was offered as an option to the patient and she accepted the termination option. After the fetocide, the pregnancy was terminated vaginally. Postpartum median cleft lip and hypothelorism were confirmed. Since the family did not approved, fetal autopsy could not be performed. The diagnosis of HPE is established primarily when monoventricular structure, fusioned thalami and cavum septum pellucidum cannot be observed. Various brain anomalies and facial anomalies are frequently concomitant. In our case, we have presented an alobar holoprosencephaly case diagnosed by the presence of monoventricular structure, fusioned thalami, vermian agenesis and cleft lip.

Keywords: Alobar holoprosencephaly, cleft lipt, vermian agenesis.

\section{PP-021}

\section{Prenatally diagnosed fetal gallbladder stone: a case report}

$\underline{\text { Süreyya Demir }}{ }^{1}$, Bülent Demir ${ }^{1}$, Faruk Demir ${ }^{2}$, Selçuk Atalay ${ }^{1}$, Gülser Bingöl ${ }^{1}$, Barış Akcan², Emel Ataoğlư ${ }^{3}$, Ahmet Çetin ${ }^{1}$

${ }^{1}$ Department of Obstetrics and Gynecology, T.R. Ministry of Health Haseki Training and Research Hospital, Istanbul, Turkey; ${ }^{2}$ Pediatrics Department, Faculty of Medicine, Adnan Menderes University, Aydin, Turkey; ${ }^{3}$ Pediatrics Department, T.R. Ministry of Health Haseki Training and Research Hospital, Istanbul, Turkey

Objective: Fetal gallbladder stone is seen quite rarely. Its incidence rate is approximately $1 / 2000$. Together with the increase of the use obstetric ultrasonography in clinical practice, there has been an increase in the number of cases diagnosed with fetal gallbladder stone. Our aim is to present the case diagnosed with prenatal gallbladder stone.

Case: Twenty-year-old, foreign woman who had no prenatal follow-up referred to our clinic with the complaints of pain and water-breaking. In the obstetric US performed, it was 
found that she was at 38 weeks of gestation which was her first pregnancy, her placenta was at anterior position, had sufficient amnion fluid and the presentation was breech type. NST was evaluated as reactive. In the measurement at AC transverse plane, an appearance consistent with single hyperechogenic stone in the gallbladder was observed. The patient delivered $3230 \mathrm{~g}$ female baby with 9/10 Apgar score by vaginal spontaneous delivery. The mother and the baby who had no problem on postpartum first day were discharged from the hospital. No etiological risk factor was found in the anamnesis of the case, and it was considered as idiopathic fetal gallbladder stone and she was followed up.

Conclusion: Although the ethiology of the fetal gallbladder stone is not known well, maternal and fetal reasons are considered. Among the maternal reasons, there are ablation placenta, increased estrogen level, narcotic use, diabetes mellitus, and drug use (ceftriaxone, furosemide and prostaglandin $\mathrm{E} 2)$. The fetal reasons are $\mathrm{Rh}$ or $\mathrm{ABO}$ inconsistency, congenital anomalies (cardiovascular, gastrointestinal, urogenital), genetic anomalies (Trisomy 21), growth retardation, oligohydramnios, hepatitis, prenatal leukemoid reaction, and idiopathic reasons. Fetal gallbladder stones are generally benign, and most of them usually disappear spontaneously in the first months or within a year at the latest after the delivery.

Keywords: Prenatal diagnosis, fetal gallbladder stone.

\section{PP-022}

\section{Prenatally diagnosed Fryns syndrome}

Bülent Demir ${ }^{1}$, Süreyya Demir ${ }^{1}$, Faruk Demir ${ }^{2}$, Barış Akcan ${ }^{2}$, Selçuk Atalay ${ }^{1}$, Gülser Bingöl ${ }^{1}$, Emel Ataoğlư ${ }^{3}$, Ahmet Çetin

${ }^{1}$ Department of Obstetrics and Gynecology, T.R. Ministry of Health Haseki Training and Research Hospital, Istanbul, Turkey; ${ }^{2}$ Pediatrics Department, Faculty of Medicine, Adnan Menderes University, Aydin, Turkey; ${ }^{3}$ Pediatrics Department, T.R. Ministry of Health Haseki Training and Research Hospital, Istanbul, Turkey

Fryns syndrome is a rare condition which characterized by autosomal recessively inherited multiple congenital anomalies. Its incidence rate is $0.7 / 10,000$ births. Our aim was to present the case diagnosed with Fryns syndrome. Twenty-five-yearold foreign woman referred to our clinic with the complaints of pain and water-breaking. It was her first pregnancy and it was found that she did not had her antenatal follow-up regularly. It was seen in the obstetric US of the patient who had one finger sized orifice that amniotic fluid increased and there was advanced level of polyhydramnios with $15 \mathrm{~cm}$ single pocket vertical measurement. In the fetal biometric measurements, single fetus with breech presentation consistent with BPD: 34w1d, HC: 34w2d, AC: 29w4d and FL: 33w5d. In the fetal ultrasonographic examination, low ear and micrognathia were observed. In the transverse cross-section examination of abdominal region, collapse was observed on the anterior wall which was not in a normal regular structure. Compared to the previous measurements of AC, it was about 4 weeks smaller. Diaphragmatic hernia was seen where abdominal organs moved towards thorax cavity. In the extremities, there was pes equinovarus deformity in the right foot, and the toe of left foot had advanced flexion deformity. In the hands, the fingers were contracted in the flexion. Since the pains of the patient increased, cesarean section was carried out due to breech presentation. With the c-section, $1450 \mathrm{~g}-41 \mathrm{~cm}$ baby was delivered, and intubated just after the birth. On the 13th postnatal day, baby has still been followed-up and treated in the newborn intense care unit as being intubated. In the examination carried out after the birth, highly arched palate, hypertelorism, undescended testicle, micro-penis, shortness of hand fingers and hypoplasia in the nails were observed in addition to the prenatal findings. The most significant and classical findings of Fryns syndrome are congenital diaphragmatic hernia, craniofacial dysmorphism, cleft palate and lip, extremity anomalies, nail hypoplasia and various internal variations. It is a syndrome generally with fatal progress. In its differential diagnosis, Pallister-Killian syndrome, trisomy 18, Cornelia de Lange syndrome and isolated diaphragmatic hernia should be considered. Frnys syndrome should be remembered in the differential diagnosis of cases found to have diaphragmatic hernia or extremity anomaly, and additional anomalies that may accompany should be investigated.

Keywords: Prenatal diagnosis, Fryns syndrome.

\section{PP-023}

\section{Amniotic band syndrome: a case report}

$\underline{\text { Süreyya Demir }}{ }^{1}$, Bülent Demir ${ }^{1}$, Gülser Bingöl ${ }^{1}$, Merve Çalışkan ${ }^{1}$, Faruk Demir², Mehmet Nafi Sakar ${ }^{3}$, Deniz Balsak

${ }^{1}$ Department of Obstetrics and Gynecology, T.R. Ministry of Health Haseki Training and Research Hospital, Istanbul, Turkey; ${ }^{2}$ Pediatrics Department, Faculty of Medicine, Adnan Menderes University, Aydin, Turkey; ${ }^{3}$ Diyarbakur Obstetrics, Gynecology and Pediatrics Hospital, Diyarbakır, Turkey

Amniotic band syndrome (ABS) is a condition which occurs due to the constrictive bands formed by the early rupture of amnion membrane, and may cause different disorders depending on the organ involved. It is especially characterized with the deformation, malformation, amputation and craniofacial anomalies in the extremities. Its incidence rate varies between $1 / 1234$ and 1/15,000 live births in different series. Although the etiopathogenesis of ABS is not known well, there have been many theories. In the etiology, infection, ischemia, trauma, amniocentesis, vasoconstrictive substance use decreasing uterine blood flow, antimitotic drug 
use during the first trimester and connective tissue tissues are suspected. Twenty-year-old patient with her first pregnancy had first degree kin marriage. The patient had no disease or surgery in her medical history, and she was not using alcohol or smoking. She had no characteristics in her family history. It was found in the fetal obstetric US of the patient referred to our clinic with external hydrocephaly pre-diagnosis that she was on 24 weeks of gestation. AFI was normal, placenta was on anterior, amnion membrane was ruptured and in direct contact with fetal tissues freely. In the fetal head examination, hydrocephaly, frontal encephalocele, and cleft palate and lip were observed. There was pes equinovarus deformity in both feet. After required information was provided to the patient, she decided to maintain the pregnancy and was transferred to a tertiary center. In the external follow-up of the patient, it was learnt that she had c-section delivery close to the term, and the baby was ex on postpartum 15 th minute. Consequently, ABS should be remembered in cases with extremity anomaly and craniofacial defects.

Keywords: Amniotic band, encephalocele, cleft palate and lip, pes equinovarus.

\section{PP-024}

\section{Encephalocele: a case report}

Süreyya Demir ${ }^{1}$, Bülent Demir', Faruk Demir' ${ }^{2}$, Gülser Bingöl' ${ }^{1}$, Ecem Kaya ${ }^{1}$, Deniz Balsak ${ }^{3}$, Mehmet Nafi Sakar ${ }^{3}$

${ }^{1}$ Department of Obstetrics and Gynecology, T.R. Ministry of Health Haseki Training and Research Hospital, Istanbul, Turkey; ${ }^{2}$ Pediatrics Department, Faculty of Medicine, Adnan Menderes University, Aydin, Turkey; ${ }^{3}$ Diyarbakur Obstetrics, Gynecology and Pediatrics Hospital, Diyarbakır, Turkey

Encephalocele is a congenital anomaly in which intracranial structures protrude out of cranium in a "sac" form from a calvarial and dural defect as a result of the union defect of cranial bones. It is a midline defect and frequently seen in occipital region, and called as "cephalocele". Meningocele is considered if there are meninges filled with cerebrospinal fluid in the sac, and encephalocele is considered if there is also brain tissue in the sac in addition to the meninges and cerebrospinal fluid. The incidence rate of encephalocele is 1/5000 live birth. Most of them are (85\%) are occipital located fetuses, of which $70 \%$ are male. Encephalocele mostly results with spontaneous abortion. Cranial defects can easily be diagnosed during early period fetal examination, and prenatal consultancy can be given to the family. The case was 28 years old with 6 pregnancies, 4 living and 1 abortion and she did not have prenatal follow-up. She was in a first degree kin marriage. There were no particular characteristics in her medical history; however, there was anencephaly delivery in her family history. She was using no drug.
In the fetal examination, it was found that she was on 17 weeks of gestation and there was an appearance compatible with cephalocele in sizes of $14 \times 12 \mathrm{~mm}$, protruding posterior from occipital region. No additional anomaly was found. The patient was informed about the possible risks, and she decided to maintain the pregnancy. It was seen in her follow-ups that cephalocele increased progressively. Since her gestational pains started on 36 weeks of gestation, she had c-section in a tertiary center and her baby was ex on postpartum 12th hour. It is possible to diagnose encephalocele by first trimester US. Early diagnosis can be established and required consultancy can be provided to the family.

Keywords: Occipital encephalocele.

\section{PP-025}

\section{Prenatally diagnosed unilateral undescended testicle and hydrocele case}

Süreyya Demir ${ }^{1}$, Faruk Demir ${ }^{2}$, Bülent Demir ${ }^{1}$, Barış Akcan ${ }^{2}$, Lale Vuslat Bakır', Selçuk Atalay ${ }^{1}$, Hilal Aşık ${ }^{1}$, Mehmet Nafi Sakar ${ }^{3}$

${ }^{1}$ Department of Obstetrics and Gynecology, T.R. Ministry of Health Haseki Training and Research Hospital, Istanbul, Turkey; ${ }^{2}$ Pediatrics Department, Faculty of Medicine, Adnan Menderes University, Aydin, Turkey; ${ }^{3}$ Diyarbakır Obstetrics, Gynecology and Pediatrics Hospital, Diyarbakır, Turkey

Hydrocele is a fluid collection reaching from abdomen to scrotum. Even it is rare, hydrocele may accompany with undescended testicle cases. Our aim was to present prenatally diagnosed unilateral undescended testicle case with concomitant bilateral hydrocele. The case was 32 years old, on her 37 weeks of gestation and G 4, P 3, A 3 who did not have her antenatal follow-up regularly. In the obstetric US, 37 weeks old live single fetus with placenta on anterior and sufficient amnion fluid. In the US, bilateral hydrocele and unilateral undescended testicle were found in the scrotum. No other anomaly was observed in the fetus. The baby who was born as $3100 \mathrm{~g}$ and with 8-10 APGAR score by spontaneous vaginal delivery was followed up and treated by consulting with pediatrics surgery. In the fetal ultrasonographic examination, genital anomalies found when examining the fetal genital organs may be helpful in the differential diagnosis of some syndromes. The diagnosis of the pathologies of male fetal genital organs in particular may be established more easily compared to the female fetuses. Undescended testicle in newborn is defined as an abnormal finding. The presence of isolated hydrocele is mostly a benign condition; however, the association of these two pathologies is very rare. In conclusion, testicles should be seen bilaterally in fetal scrotum in the last weeks of gestation. Absence of either one or two testicles, being in abnormal sizes or the detection of hydrocele presence is very critical. It should be remembered that the early diagnosis of undescended testicle cases in partic- 
ular is very important in terms of malignity and fertility potential in further periods.

Keywords: Prenatal diagnosis, undescended testicle, hydrocele.

\section{PP-026}

\section{Prenatally diagnosed cystic hygroma and hydrops fetalis case}

Sürevya Demir ${ }^{1}$, Faruk Demir' ${ }^{2}$ Bülent Demir ${ }^{1}$, Lale Vuslat Bakır', Gülser Bingöl', Tuğba Atalay ${ }^{1}$, Mehmet Nafi Sakar ${ }^{3}$, Deniz Balsak

${ }^{1}$ Department of Obstetrics and Gynecology, T.R. Ministry of Health Haseki Training and Research Hospital, Istanbul, Turkey; ${ }^{2}$ Pediatrics Department, Faculty of Medicine, Adnan Menderes University, Aydin, Turkey; ${ }^{3}$ Diyarbakur Obstetrics, Gynecology and Pediatrics Hospital, Diyarbakur, Turkey

Cystic hygroma is also called as cystic lymphangioma. They are cystic lymphatic lesions that may arise in any location of the human body. It is a congenital malformation caused by incomplete connections between lymph veins and venous system, with or without septa, localized or common. It is frequently seen in head and neck region, mostly $(75 \%)$ on left side. Although its incidence rate is $1 / 6000$ births, it is $1 / 875$ in aborted fetuses. The prognosis depends on many factors such as the karyotype, mass localization, week of gestation when diagnosed, depth of invasion, presence of septa. While it can be isolated, it is also frequently associated with chromosomal anomalies, and Turner syndrome is the most frequent concomitant chromosomal anomaly. Besides, it is also associated with trisomies, cardiac anomalies and hydrops fetalis. Progressive skin edema, pleural effusion, pericardial effusion, ascites and placental edema can be observed. In $43-75 \%$ of the cases may develop non-immune hydrops fetalis. In this case, we aimed to present non-immune hydrops fetalis associated with cystic hygroma which was prenatally diagnosed. Twenty-eight-year-old patient with G4P2A1 referred to our clinic and in the fetal examination, 17 weeks old live single fetus was observed. The case first referred to our clinic at 7 weeks of gestation and in her second visit at 17 weeks of gestation, cystic hygroma with septation in size of $60 \times 48 \mathrm{~mm}$ originating from the posterior area of the neck was observed in the fetal ultrasonographic examination. No other systemic anomaly was observed in the fetus. There were no characteristics in the medical history of the case. The patient was recommended to refer a tertiary center for prenatal diagnosis and cardiac evaluation, but the patient did not follow any recommendation and decided to maintain the pregnancy. In her follow-ups, it was found in the fetal examination carried out on 23 weeks of gestation that hydrops fetalis developed and there was no fetal cardiac activity. The pregnancy of the patient was terminated in a tertiary center. Since the family refused, no fetal autopsy was performed. The diagnosis of cystic hygroma and non-immune hydrops fetalis can e established by ultrasonography easily. Fetal ultrasonographic examination including fetal cardiac evaluation should be done in case with cystic hygroma and hydrops fetalis. The patient should be evaluated in terms of family syndromes and karyotyping should be recommended.

Keywords: Prenatal diagnosis, cystic hygroma, hydrops fetalis.

\section{PP-027}

\section{Fetal magnetic resonance imaging of congenital diaphragmatic hernia}

Onur Erol, Cemil Gurses, Ozgur Ozdemir, Selahattin Kumru, Mert Koroglu

Antalya Training and Research Hospital, Antalya, Turkey

Objective: Fetal magnetic resonance (MR) imaging plays a number of roles in the evaluation and management of congenital diaphragmatic hernia (CDH). Fetal MR imaging has proved valuable for anatomic assessment, determination of the specific type of $\mathrm{CDH}$ on the basis of which organs are involved and the effect of the hernia contents on adjacent structures, evaluation and exclusion of hernia-related complications and associated malformations. In addition, fetal MR imaging plays a role in guiding experimental fetal therapy (eg, tracheal balloon occlusion).

Method: We present a case of $\mathrm{CDH}$ that was diagnosed in the 30 week of pregnancy by two-dimensional ultrasonography (USG) in association with fetal MR.

Case: A 31-year-old nulliparous woman with unremarkable past medical history and no significant prenatal risk factor was referred to our department at 30 weeks' gestation for detailed ultrasound examination, which revealed a fluid-filled structure in the thoracic cavity. Ultrasonographic examination showed a fluid-filled stomach and intestinal peristalsis in the left thorax with the heart displaced to the right in the axial scan. Fetal MR confirmed the ultrasonographic findings, and herniated organs and mediastinal shift were clearly visible. There was no associated anomaly in central nervous system, heart, both kidneys and extremities in ultrasonography. The couple was informed of the diagnosis and patient was followed-up fortnightly. At 36 weeks of gestation, planned cesarean section was performed. The newborn girl had signs of severe respiratory distress and required extracorporeal membrane oxygenation support. The $\mathrm{CDH}$ was successfully repaired at 3 days of life. Surgical results confirmed the prenatal diagnosis.

Conclusion: Prenatal sonographic detection of this rare anomaly may allow planned delivery at a tertiary center and early correction. Prenatal MR imaging can confirm the diagnosis of a $\mathrm{CDH}$ when sonographic findings are equivocal or atypical. 
Keywords: Fetal MR, congenital diaphragmatic hernia, prenatal diagnosis.

\section{PP-028}

\section{Prenatal diagnosis of parietal encephalocele: a case report}

Salih Serin, Deniz Cemgil Arıkan, Murat Bakacak, Önder Ercan, Bülent Köstü, Fazıl Avcı

Department of Obstetrics and Gynecology, School of Medicine, Kabramanmaraş Siitçii İmam University, Kabramanmaraş, Turkey

Objective: Most NTDs occur sporadically and are multifactorial in origin. Encephalocele involves defective closure of the anterior neural tube. Encephalocele is characterized as a protrusion of the brain and/or meninges through a defect in the skull that is covered with skin.

Case: In this case report, we aimed to present a case of parietal encephalocele which diagnosed in prenatal period. 26 year-old patient, having second pregnancy.she had single alive fetus of 18 weeks from her last menstrual period. In the results obtained from two-dimensional ultrasound scan, it was detected that the fetus had encephalocele sac with the approximate sizes of $49^{*} 41 \mathrm{~mm}$, possibly originating from the right parietal region of the fetus, and concomitant hydrocephalus (lateral ventricle $10 \mathrm{~mm}$ ). After abortion, it was observed that the exfetus weighing about 300 grams had parietal encephalocele mass having apparent neural tissue in it and stretching from the location over the ear on the right side of the head, comprising the right eye, to the border between mouth and nose.

Conclusion: Amongst NTD's, the incidence of encephalocele is reported to be approximately 1-4 per 10,000 live births. Commonest site of encephalocele is occipital, frontoethmoidal and parietal. Prenatal 2D US detects approximately $80 \%$ of encephaloceles. The prognosis for patients with encephalocele depends on the extent of herniated neural tissue in the sac and on the presence of associated anomalies. the prognosis of the parietal encephalocele is worse than occipital.

Keywords: Prenatal diagnosis, parietal, encephalocele.

\section{PP-029}

\section{A rare congenital anomaly: ectopia cordis and Cantrell pentalogy}

Salih Serin, Deniz Cemgil Arıkan, Önder Ercan, Bülent Köstü, Murat Bakacak, Fazıl Avc1

Department of Obstetrics and Gynecology, School of Medicine, Kabramanmaraş Siitşii İmam University, Kabramanmaraş, Turkey

Objective: In this study, we aimed to present two cases of ectopia cordis which diagnosed in the prenatal period.
Introduction: Ectopia Cordis (EC) is a very rare congenital malformation which appears as development of midline defect. EC may be present as an isolated malformation or a component of Cantrell's Pentalogy.

Case 1: A 22-years-old pregnant at 15 weeks 1 day gestational age admitted to our fetal medicine centre. Prenatal ultrasound showed a fetus with bilateral hydrothorax, EC, and a large omphalocele with evisceration of the heart. Cantrell's pentalogy with thoracoabdominal EC was diagnosed and pregnancy was terminated.

Case 2: A 32-years-old pregnant at 11 weeks 3 days gestational age admitted to our fetal medicine centre. Ultrasound done at our fetal medicine centre revealed absent sternum, ectopia cordis, absent diaphragm, and omphalocele. Cantrell's pentalogy with thoracoabdominal EC was diagnosed and pregnancy was terminated at 12 weeks and 3 days of gestational age.

Results: The diagnosis of EC in the prenatal period was established by monitoring of the fetal heart outside the thorax. EC may be associated with intrinsic heart disease and other midline abnormalities. The vast majority of cases has been reported aneuploidy, particularly Trisomy 18, chromosomal analysis is recommended.

Conclusion: The ectopia cordis can be diagnosed with careful ultrasound examination of the early weeks of pregnancy. The ectopia cordis is especially high risk for Trisomy 18 . We suggest that you should keep in mind this condition and amniocentesis should be offered.

Keywords: Ectopia cordis, Cantrell's pentalogy, prenatal diagnosis.

\section{PP-030}

\section{Comparison of Doppler blood flow indices in fetal \& uterine arteries before and after tocolysis for preterm labor}

Alev Atis ${ }^{1}$, Gulden Tuncer ${ }^{2}$, Savas Ozdemir ${ }^{2}$, Nazlı Felek ${ }^{2}$

${ }^{1}$ Department of Obstetrics \& Gynecology, Kanuni Sultan Suleyman Training \& Research Hospital, Istanbul, Turkey; ${ }^{2}$ Department of Obstetrics \& Gynecology, Şisli Etfal Training \& Research Hospital, Istanbul, Turkey

Objective: Preterm labor is the most important cause of neonatal morbidity and mortality in developed countries. The aim of this study was to compare and evaluate the effects,nifedipine and ritodrine, on fetal and maternal parameters and to predict the patient with therapotic succes.

Methods: The study was carried out on 64 patients with diagnosis of preterm delivery, admitted to our unite.The cases were randomly selected singleton pregnancies between 24-36 weeks of gestation who were in the latent phase of 
labor and despite 2 hours of bed rest, 2 or more uterine contractions in 10 minutes were detected with either manual examination or tococardiographic evaluation. Patients with preterm delivery accompanying fetal distress, ablation plasenta, chorioamnionitis, preeclampsia and fetal anomalies were excluded from our study. A total of 64 patients were randomly divided into two groups according to administiration of either ritodrine or nifedipine. Clinical and laboratory parameters, cervical length and early and late doppler measurements of umbilical artery, bilateral uterine arteries, ductus venosus and middle cerebral artery were recorded.

Results: When we evaluated the results of the study there were statistically no difference between two groups doppler values for umbilical artery, middle cerebral artery and ductus venosus. Also there were no statistically difference betwen two groups in terms of prolongation of pregnancy. Only significant difference evaluated in uteroplacental blood flow. In Nifedipine group bilateral uterine arteries PI was significantly decrased after medication.Also there was no difference on Doppler values between patients with and without therapotic success.

Conclusion: Since efficiency and vascular side effects of both drugs were recorded to be similar, the choice of tocolytic agent in preterm labor should be made according to the side effect profile, cost, applicability in clinical settings and patient coherence to treatment.

Keywords: Doppler ultrasonography, nifedipine, ritodrine.

\section{PP-031}

\section{Ratio of middle cerebral artery / umbilical artery Doppler velocimetry and status of newborn in preeclampsia}

$\underline{\text { Ana Daneva Markova }}{ }^{1}$, Marija Hadzi Lega ${ }^{1}$, Milan Stefanovic ${ }^{2}$, Andrijana Sterjovska

${ }^{1}$ University Clinic of Gynecology and Obstetrics, Skopje, Macedonia; ${ }^{2}$ University Clinic of Gynecology and Obstetrics, Nis, Serbia; ${ }^{3}$ Medical Faculty, Stip, Macedonia

Objective: Doppler velocimetry studies of placental and fetal circulation can provide important information regarding fetal well-being providing an opportunity to improve fetal outcome. The present study was undertaken to evaluate the role of middle cerebral to umbilical artery blood velocity waveform's systolic/diastolic ratio (MCA/UA) as a predictor of perinatal outcome in post term pregnant women.

Methods: This prospective case control study included one hundred pregnant women who were stratified into two groups. Fifty pregnant women during the third trimester (control group=group A) and fifty pregnant women with Preeclampsia (case group=group B). The results of the MCA/UA ratio were evaluated with respect to the outcome of the infants and adverse perinatal outcome, defined as perinatal death, cesarean delivery for fetal distress, admission to the neonatal intensive care unit, days in the neonatal intensive care unit (NICU) or low Apgar score.

Results: Twenty nine percent (29\%) had an abnormal CPR $(<1.0)$ while seventy eight percent $(78 \%)$ had a normal CPR $(\geq 1.0)$. Seventy eight percent $(78 \%)$ were delivered via caesarean section while twenty two percent $(22 \%)$ were delivered vaginally. An APGAR score $<7$ was 66 times more often in mothers with $\mathrm{CPR}<1.0$ than mothers with $\mathrm{CPR} \geq 1.0$. Low birth weight was 4.7 times more likely among mothers with $\mathrm{CPR}<1.0$ as compared to those with mothers with $\mathrm{CPR} \geq 1.0$ (95\% CI 2, 11.1; $<<0.001)$. An APGAR score $<7$ was 66 times more likely among neonates delivered vaginally as compared to those born via caesarean section (95\% CI 1.3, 23; $\mathrm{p}=0.02)$.

Conclusion: CPR is significantly predictive of adverse perinatal outcome when used to monitor mothers with hypertensive states of pregnancy than UA RI or BPPS used alone. CPR was predictive of adverse perinatal outcome (live birth, APGAR score and low birth weight). Caesarian section should bethe recommended mode of delivery for hypertensive mothers. Although the sample size of our study was small, our results suggested that the MCA/UA Doppler ratio of less than 1 was a good predictive tool for neonatal outcome in post term pregnant women and could be used to identify fetuses at risk of morbidity.

Keywords: Middle cerebral artery, umbilical artery, preeclampsia.

\section{PP-032}

\section{Doppler flow parameters for uterine, umbilical and mid cerebral arteries at low and moderately high altitudes}

Ayse Nur Aksoy ${ }^{1}$, Gonca Batmaz², Banu Dane², Suna Kabil Kucur ${ }^{1}$, Ilay Gözükara

${ }^{1}$ Department of Obsterics and Gynaecology, Nenehatun Hospital, Erzurum, Turkey; ${ }^{2}$ Department of Obstetrics and Gynaecology, Faculty of Medicine, Bezmialem Vakif University, Istanbul, Turkey

Objective: This study aimed to investigate the differences in maternal and foetal Doppler flow parameters in women with term pregnancy living at moderately high with those of women living at sea level. For this purpose, we compared the pulsatility (PI) and resistance (RI) index values for uterine, umbilical and mid cerebral arteries in term pregnant women at moderately high altitude and sea level. Also, we aimed to investigate the differences in birth and placental weights between moderately high and low altitudes.

Methods: Eighty women between 20-40 years with full-term pregnancies ( $\geq 37$ gestational weeks) admitted to the Obstetric 
Department of two institutes (40 in Nenehatun Hospital, Erzurum Turkey; $1890 \mathrm{~m}$ above the sea level and 40 in Bezmialem Vakif University, Istanbul, Turkey; $31 \mathrm{~m}$ above the sea level) for the control were enrolled in this study. All women were ethnic Turkish and permanently resident at the altitude. Initially, last menstrual period was questioned and ultrasonographic evaluation was performed to confirm gestational age and to detect foetal abnormalities. Eighty women $(n=40$, for each group) underwent Doppler waveform analysis and the pulsatility and resistance index values for uterine, umbilical and mid cerebral arteries were recorded. Also; sex, birth and placental weights in delivery were obtained from the medical records. Data were analysed using SPSS software 12.0 (SPSS Inc., Chicago, IL, USA) and expressed as mean \pm standard deviation, $\mathrm{P}<0.05$ was considered significant. The Kolmogorov-Smirnov test was used to test for normality of variables. If data was not normally distributed, comparisons were determined using Mann-Whitney U-test. Comparisons were determined using the independent samples t-test when the data was normally distributed and Fisher's exact test was used to compare the percentage values.

Results: There were no differences in clinical characteristics between the groups. Similar mean placental weight values were found at the sea level compared to the values at moderately high altitude $(\mathrm{P}>0.05)$. A significant lower birth weight was noted at moderately high altitude in comparison with the sea level $(\mathrm{P}<0.05)$. Both groups had similar $\mathrm{PI}$ and $\mathrm{RI}$ values for umbilical and mid cerebral arteries ( $p>0.05)$. However, PI and RI values for both right and left uterine arteries were higher at the sea level than at moderately high altitude $(\mathrm{p}<0.05$, for right uterine artery PI; $\mathrm{p}<0.01$, for others).

Conclusions: We suggested that altitude appears to increase the uterine artery blood flow bilaterally and these alterations in bilateral uterine artery blood flow may be associated with a physiological adaptation to chronic hypoxia. The inability of this adaptation may result in an increase in the incidence of pregnancy-related complications at high altitude.

Keywords: Doppler, altitude, pregnancy.

\section{PP-033}

\section{Effect of preterm premature rupture of membranes on umbilical artery Doppler indices}

Ertugrul Karahanoglu, Oya Aldemir, Deniz Esinler, Safak Ozdemirci, Erdem Fadıloglu, Serdar Yalvaç, Omer Kandemir

Etlik Zubeyde Hanim Women's Health Education and Research Hospital, Ankara, Turkey

Objective: One of the importatnt aspect of PPROM is subclincal infection and metabolic response of fetus to this infection. Response of fetus to this subclinical infection is know as
FIRS (Fetal Inflammatory Response Syndrome). As a result of FIRS there is detoriation in the cardiac function in fetus. In the case of pprom there is also detoriation in umblical and splenic artery Doppler indices. It has been shown that after amnioinfusion there has been improvement in umblical artery Doppler indices. As a result of subclical infection and mechanical effect of fetus to amniotic vasculature there might be new vascular adaptaion and organization in umblical artery. In our study we examine effect of pprom on umbilical artery doppler indices.

Methods: This was a case control study that was designed in Etlik Zubeyde Hanım Women's Health and Tranining Research Hospital between January 2013 and July 2013. Cases were formed from the 42 patient that have the diagnosis of PPROM and control group formed from 58 pregnancy week matched healthy pregnant. Study group were formed from the pprom patient under 34 week of pregnancy without any know intrauterine growth restriction, clinical chorioamnionitis,olygohydramnios. Umbilical arter resistance and $\mathrm{A} / \mathrm{B}$ indices were collected from the last measurement before the birth.

Results: When the effect of duration of PPROM on umbilical artery Doppler indices evaluated, PPROM patient divided in to two group according to median value of pprom duration. The duration of PPROM have no effect on umbilical artery Doppler indices

Conclusion: Preterm premature rupture of membranes have no effect on umbilical artery hemodynamic indices. Resistance indices and systole/diastole ratio did not diifer between study and control group. Yuce at al showed that in the cases of histological chorioamnionitis umbilical artery resistance increased. In our study we did not do subgroup analysis that compares subclinic chorioamnionitis with control group. In the case of subclinical chorioamnionitis this finding could be changed. There is need to be RCT trail to show exact effect of pprom on hemodynamic parameters of fetal circulation.

Keywords: PPROM, umbilical artey.

\section{PP-034}

\section{Maternal and fetal Doppler velocimetry in women diagnosed with fear of childbirth}

Ayse Nur Aksoy, Fatma Aydın, Suna Kabil Kucur, Ilay Gözükara

Department of Obsterics and Gynaecology, Nenehatun Hospital, Erzurum, Turkey

Objective: We hypothesised that women with fear of childbirth (FOC) may have increased vascular resistance in maternal and foetal vascular beds due to maternal psychological stress. For this purpose, we investigated pulsatility (PI) and resistance (RI) index values for uterine, umbilical and mid cerebral arter- 
ies in term pregnant women who were diagnosed with FOC and we compared these values than those of women without FOC.

Methods: Women between 20-40 years with full-term singleton pregnancies ( $\geq 37$ gestational weeks) were included. All patients were questioned with Turkish form of Wijma Delivery Expectancy/Experience Questionnaire (W-DEQ) version A. Maternal age, gestational week, parity, body mass index and total W-DEQ scores of patients were recorded. Women with $W$-DEQ scores $\geq 85$ was defined as FOC. Forty women diagnosed with FOC (FOC group) and 45 women with W-DEQ scores $<85$ (control group) underwent Doppler waveform analysis and the pulsatility (PI) and resistance (RI) index values for uterine, umbilical and mid cerebral arteries were recorded. Data were analysed using SPSS software 12.0 (SPSS Inc., Chicago, IL, USA) and expressed as mean \pm standard deviation, $\mathrm{P}<0.05$ was considered significant. The normality of variables was tested using the Kolmogorov-Smirnov test. If the data was not normally distributed, Mann-Whitney U-test was used. Comparisons were done using the independent samples t-test when the data was normally distributed and the Fisher's exact test was used to compare the percentage values.

Results: There were no differences between groups in terms of maternal age, parity, body mass index and gestational week values. Control group had lower W-DEQ scores compared with FOC group $(\mathrm{p}<0.001)$. Both groups had similar PI and RI values for umbilical and mid cerebral arteries $(p>0.05)$. However, PI and RI values for both right and left uterine arteries were higher in FOC group than control group $(\mathrm{p}<0.05$, for right uterine artery $\mathrm{PI} ; \mathrm{p}<0.001$, for left uterine artery $\mathrm{RI}$ and $\mathrm{p}<0.01$, for others).

Conclusions: It may be suggested that the presence of FOC in term pregnant women seems to have a negative effect on uterine blood flow parameters. When diagnosed with FOC, the women should be referred to a specialist for psycho-education and psychosomatic support in order to decrease her fear and to minimize the negative impact of fear on the foetus.

Keywords: Fear of childbirth, fetus, Doppler.

\section{PP-035}

\section{Double notches: association of uterine artery notch forms with fetal outcome and severity of preeclampsia}

Ibrahim Polat ${ }^{1}, \underline{\text { Ali Gedikbasi }}{ }^{1}$, Huseyin Kiyak ${ }^{1}$, Bekir Gulac ${ }^{1}$, Alev Atis ${ }^{1}$, Gokhan Goynumer ${ }^{2}$, Oznur Dundar ${ }^{1}$, Cemal Ark ${ }^{1}$

${ }^{1}$ Kanuni Sultan Suleyman Training and Research Hospital, Istanbul, Turkey; ${ }^{2}$ Istanbul Medeniyet University, Göztepe Education and Research Hospital, Istanbul, Turkey
Objective: To assess uterine artery Doppler waveforms and notches performed in the third trimester as a predictor of adverse outcomes.

Methods: Of 490 pre-eclampsia patients between 24 and 34 weeks gestation, 166 were diagnosed with mild pre-eclampsia and 324 were diagnosed with severe pre-eclampsia. Patients with complete fetal data were divided into four groups as patients with no notch (n:53), a unilateral notch (n:78), bilateral notches (n:219) and double notches (n:39).

Results: Bilateral and double notches were predictive for prematurity, lower 1st minute Apgar scores, higher need for neonatal intensive care unit admission, and perinatal mortality.

Conclusion: Double notches represent progressive deterioration in the uterine artery and are predictive of adverse fetal outcomes.

Keywords: Pre-eclampsia, double notches, fetal outcome.

\section{PP-036}

\section{Double notches: association of uterine artery notch forms with maternal outcome}

Ibrahim Polat ${ }^{1}$, Ali Gedikbasi ${ }^{1}$, Huseyin Kiyak $^{1}$, Bekir Gulac ${ }^{1}$, Alev Atis ${ }^{1}$, Gokhan Goynumer ${ }^{2}$, Oznur Dundar ${ }^{1}$, Cemal Ark ${ }^{1}$

${ }^{1}$ Kanuni Sultan Suleyman Training and Research Hospital, Istanbul, Turkey; ${ }^{2}$ Istanbul Medeniyet University, Göztepe Education and Research Hospital, Istanbul, Turkey

Objective: To assess uterine artery Doppler waveforms and notches performed in the third trimester as a predictor of adverse outcomes.

Methods: Of 490 pre-eclampsia patients between 24 and 34 weeks gestation, 166 were diagnosed with mild pre-eclampsia and 324 were diagnosed with severe pre-eclampsia. Patients with complete data were divided into four groups as patients with no notch (n:58), a unilateral notch (n:93), bilateral notches (n:252) and double notches (n:39).

Results: Bilateral and double notches were predictive of shorter follow-up times, adverse laboratory outcomes (mean $24 \mathrm{~h}$ proteinuria, AST, LDH levels) and HELLP syndrome, need for magnesium sulphate treatment, higher systolic and diastolic blood pressure.

Conclusion: Bilateral notches and especially double notches represent progressive deterioration in the uterine artery and are predictive of adverse maternal outcomes.

Keywords: Pre-eclampsia, double notches, maternal outcome. 


\section{PP-037}

\section{The evaluation of the effect of fetal gender on the umbilical artery and middle cerebral artery Doppler findings}

Burcu Artunç Ülkümen, Halil Gürsoy Pala, Yıldız Uyar, Yeşim Baytur, Faik Mümtaz Koyuncu

Division of Perinatology, Department of Obstetrics \& Gynecology, School of Medicine, Celal Bayar University, Manisa, Turkey

Objective: The evaluation of the effect of fetal gender on the umbilical artery and middle cerebral artery doppler findings is aimed.

Methods: 60 singleton healthy pregnancies admitted to the perinatology outpatient clinic during their third trimester between 2013-2014 are included in the study. Their umbilical artery (UA) and middle cerebral artery (MCA) doppler measurements are evaluated retrospectively from the ultrasound files. UA and MCA doppler calculations are performed with 3 consecutive vawe forms. The pregnancies were divided into 2 groups according to the fetal gender (31 female fetus and 29 male fetus). The difference between two groups was analysed with SPSS v.20.

Results: Maternal age was $29.14 \pm 6.21$ in female and $31.88 \pm$ 5.16 in male groups $(\mathrm{p}=0.162)$; mean gestational week was $31.71 \pm 3.77$ in female and $33.88 \pm 4.41$ in male groups $(\mathrm{p}=0.111)$. UA PI was $1.00 \pm 0.24$ and $1.03 \pm 0.21$ in female and male fetuses, respectively $(\mathrm{p}=0.761)$. MCA PI was $2.16 \pm 0.67$ and $1.84 \pm 0.85$ in female and male fetuses, respectively $(\mathrm{p}=0.197)$.

Conclusion: The current concept is not to ignore the fetal gender during the intrauterine life. The decrease in MCA resistance should be confirmed in larger studies.

Keywords: Fetal gender, Doppler, umbilical artery.

\section{PP-038}

\section{Evaluation of the labors in Kanuni Sultan Suleyman Research Hospital according to Robson classification between January and June 2014}

Sebile Güler Cekiç, Levent Harun Gülcüler, Nihan Ilhan, Nazlı Korkmaz, Ibrahim Polat, Alev Atış Aydın, Ali Gedikbaşı

Department of Obstetrics and Gynecology, Kanuni Sultan Siileyman Research Hospital, Istanbul, Turkey

Cesarean sections are the most common performed operations worldwide and are increasing in time. Cesarean costs are higher than vaginal delivery and also may increase maternal morbidity. In order to decrease cesarean ratios we should know the related indications. Robson's - 10 group system classifications, proposed in 2001, and are performed according to the patient and not to the indication. In our clinic we also document the indications of the cesarean sections in the first four groups of Robson. In this study we evaluated the statistics of the labors in our clinic from January 2014 to June 2014. During the first half of 2014 a total of 7428 labors were performed and 7569 babies were born. Of these deliveries, 2779 were performed spontaneous vaginally, 1793 with help of vaginal episiotomy and 2933 via cesarean section. The primary cesarean section rate was 18.2\% (534/2779) throughout this period. According to the Robson classification of cesarean labors, Group 5 (all multipara with previous uterine incision scared uterus) consists $50.9 \%$, Group $1+2$ (all single cephalic nulliparous) consist $16.4 \%$ and Group 3+4 (all single cephalic multiparas without uterine incision) consist $14.0 \%$ of all sections. After subgroup evaluation, we found that fetal distress was the most frequent indication in nulliparous (Groups 1+2) with $16.0 \%$ rate, followed by preeclampsia and over weighted babies with $8.9 \%$ and $7.9 \%$, respectively. In multipara (Groups $3+4$ ) the most frequent indication is preeclampsia with a rate of $9.8 \%$, followed by fetal distress with $7.5 \%$ and over weighted babies with $7.5 \%$, respectively. The Robson classification groups are evaluated generally whereas it is not appropriate for subgroup analysis which is a limitation of the classification. In our study we investigated the Robson classification as well as indication of subgroups. Because of high rates for cesarean sections in Turkey it is important to decrease the primary section rates. This subgroup analysis may be one evaluation and help to decrease primary cesarean section ratios.

Keywords: Robson, cesarian section classification.

\section{PP-039}

\section{Umbilical Doppler: predictive value in acute fetal distress in case of prolonged pregnancy}

Chiraz El Fekih ${ }^{1}$, Chokri Hnifi', Asma Fatnassi ${ }^{1}$, Faouzia Hmila ${ }^{1}$, Mounira Chaabene

${ }^{1}$ Department of Gynecology \& Obstetrics, Mabmoud el Matri Teaching Hospital, Faculty of Medicine of Tunis, Tunisia; ${ }^{2}$ Department of Radiology, Mabmoud el Matri Teaching Hospital, Faculty of Medicine of Tunis, Tunisia

Introduction: To improve the management of prolonged pregnancy, a detailed study of the predictive value of umbilical Doppler in acute fetal distress should allow good behavior and state route of delivery.

Objective: Determine if high index of resistance at the umbilical artery is predictive of adverse neonatal outcome.

Methods: A prospective study was conducted in our department over a period of four months including all women admitted for delivery over a period of 41 weeks gestation or more. Obstetric ultrasound thus measuring the resistance index in the umbilical artery was performed at admission in 
all parturient. A correlation study was conducted to clarify the predictive value of Doppler in fetal distress.

Results: 139 patients were enrolled with a mean age of 29.38 years. The medium-term admission is 41 weeks gestation and 2 days or 289 days. A pathologic admission umbilical Doppler was noted in 33 patients. A total of 13 newborns showed acute fetal distress during labor and 6 among them transferred in neonatology. We found a low sensitivity of Doppler, in the order of $38.46 \%$ and a specificity of $77.77 \%$. The positive predictive value was $15.15 \%$, but the negative predictive value was $92.45 \%$.

Conclusion: Our study has shown the bad predictive value of umbilical Doppler in fetal distress. Given its specificity and negative predictive value, the umbilical Doppler remains a good review monitoring in case of prolonged pregnancy.

Keywords: Fetus, Doppler.

\section{PP-040}

\section{Evaluation of fetal renal artery Doppler indices of pregnancies complicated with polyhydramnios}

Yesim Bayoglu Tekin, Ulku Mete Ural, Senol Senturk, Emine Seda Guvendag Guven, Figen Kur Sahin

Department of Obstetrics and Gynecology, Recep Tayyip Erdogan University, School of Medicine, Rize, Turkey

Objective: The aim of this study was evaluation of fetal renal artery Doppler indices, umbilical artery and ductus venosus indices of pregnancies complicated with polyhydramnios which were diagnosed during third trimester and comparison with gestational age matched control groups.

Methods: This was a cross-sectional study which was conducted in a university antenatal outpatient clinic. Pregnancies at the third trimester complicated with polyhydramnios were included in the study. Gestational diabetes, hypertensive disorders, systemic disorders and fetal anomalies were excluded. Control group was selected from gestational age matched healthy pregnant women. Doppler Ultrasonography was performed using 3,5 MHz convex transabdominal probe. Umbilical artery systole/diastole (S/D), fetal renal artery pulsatility (PI) and resistive index (RI) and ductus venosus PI Doppler indices were evaluated. Variables were compared by using student's t test and $\mathrm{p}<0.05$ was accepted as statistically significant.

Results: Doppler indices for polyhydramnios were detected as umbilical artery S/D: $2.5 \pm 0.4$, renal artery PI: $2.3 \pm 0.9$, renal artery RI: $0.9 \pm 0.2$ and ductus venosus PI:0.9 \pm 0.3 , and for control group $2.7 \pm 0.6,2.0 \pm 0.3,0.8 \pm 0.1,1.1 \pm 0.5$ respectively. There were statistically significant decrease at fetal renal artery Doppler indices in pregnancy complicated with polyhydramnios.

Conclusion: Fetal renal artery resistance decreased at pregnancies complicated with polyhydramnios. This decrease in the resistance may be associated with increased fetal urine production.

Keywords: Doppler, polyhydramnios.

\section{PP-041}

\section{Prenatal diagnosis of fetal intra-abdominal umbilical vein varix}

Salih Serin, Deniz Cemgil Arıkan, Bülent Köstü, Önder Ercan, Murat Bakacak, Fazıl Avc1

Department of Obstetrics and Gynecology, School of Medicine, Kahramanmaraş Siitçii İmam University, Kahramanmaraş, Turkey

Objective: Fetal intra-abdominal umbilical vein varix (FIUV) is aneurysmatic dilatation of umbilical vein, and constitutes approximately $4 \%$ of umbilical cord abnormalities. FIUV varix is defined as a condition in which the diameter of umbilical vein is above $9 \mathrm{~mm}$.

Case: In the detailed anatomy scan of a 26 year-old patient having second pregnancy, varicose enlargements were detected in the umbilical vein of the fetus; the diameter of umbilical vein was measured as $10.2 \mathrm{~mm}$. Varicose enlargement with a diameter of $18 \mathrm{~mm}$ was found under the connection point of umbilical vein to the abdomen in the fetus. Fetal growth retardation was observed after 32nd week of pregnancy. When her last menstrual period was taken into account, five-week intrauterine growth retardation was present in 39th week of pregnancy. The patient underwent cesarean operation. It was observed in the ultrasound and Doppler ultrasonography examinations carried out in the 7th day after the delivery that venous structures in the abdomen of the newborn were normal.

Results: FIUV is a rare complication whose incidence rate has been found to be $1 / 2300$; it constitutes $4 \%$ of approximately all umbilical cord malformations. Although pregnancy prognosis is stated to be generally fine in those patients, it is also indicated that FIUV findings may be used as an indicator for abnormality scan because of the risk of concomitant fetal abnormalities. In our case, no concomitant abnormality was detected in fetal scan. Intrauterine growth retardation was found in the follow-ups of the pregnancy.

Conclusion: The prognosis of FIUV is generally fine. In most cases, close sonographic monitoring is considered to be sufficient until the term and the termination of the pregnancy is not thought to be necessary. The timing of delivery may vary according to the progressing complications.

Keywords: Umbilical vein, varix, prenatal diagnosis. 


\section{PP-042}

\section{Association of an increased nuchal translucency with total agenesia of the ductus venosus}

Anis Dhouaibia, Kaouther Dimassi, Sana Mtimet, Raouia Radhouani, Amel Triki, Mohamed Faouzi Gara

Department of Obstetrics and Gynecology, Mongi Slim Hospital, La Marsa, Tunisia

Looking for the etiology of an increased nuchal translucency in a patient aged of 22 years G1P0, We performed initially a karyotype whose formula was normal: 46xy. A Fetal echocardiography realized at 18 and 22 weeks' gestation was normal and brain MRI was normal also. At 22 weeks' gestation, ultrasonography revealed a hepatic vascular abnormality without other symptoms. The suspected diagnosis was agenesis of the ductus venosus with creation of a high grade arteriovenous shunt between the umbilical vein and the inferior vena cava. The geneticist suspected also a genetic syndrome but the patient refused any investigation. Agenesis of the ductus venosus may be one expression of the different possible systemic-portalumbilical abnormalities. Physiological consequences vary according to the type of substitutive anastomoses. Agenesis of the ductus venosus can be strictly isolated. It can be also one of a manifestation of a genetic syndrome like NOONAN and JOUBERT SYNDROME. In our case, agenesia of the ductus venosus was associated to an increased nuchal translucency. We did not find a similar case in the literature.

Keywords: Nucal translucency, arantius.

\section{PP-043}

\section{Congenital cataract as an only sign in Down Syndome: case report}

Alev Atis ${ }^{1}$, Burak Ozkose ${ }^{1}$, Basak Kaya ${ }^{1}$, Alper Gezdirici ${ }^{2}$

${ }^{1}$ Department of Obstetrics \& Gynecology, Kanuni Sultan Suleyman Training \& Research Hospital, Istanbul, Turkey; ${ }^{2}$ Department of Genetics, Kanuni Sultan Suleyman Training \& Research Hospital, Istanbul, Turkey Istanbul

Case: 42 year old pregnant woman has been sent to perinatology policlinic for double test. Her first trimester combined test result was $1 / 1240$. She was appointed for second trimester detailed sonography for advanced maternal age. Bilateral opacities in orbital examination were seen on sonography. She was given genetic consultation for this but she opted to continue her pregnancy without karyotyping. Planned c/s section was done for previous c/s endication at 39th week. A female 3450 gr fetüs was born with an Apgar score 8-9. Her face was characteristic with upward slanting of the palpebral fissures, congenital cataract and macroglosi. Postnatal karyotype was concordant with Down syndome.
Conclusion: In high risk groups orbital examination should be included in prenatal sonography.

Keywords: Down syndome, eye, cataract.

\section{PP-044}

\section{Ellis-Van Creveld syndrome}

$\underline{\text { Kaan Pakay }}^{1}$, Resul Arısoy ${ }^{1}$, Emre Erdoğdu ${ }^{1}$, Oya Demirci ${ }^{1}$, Oya Pekin ${ }^{1}$, Hicran Acar ${ }^{1}$, Hatip Aydın' ${ }^{2}$, Murat Muhçu

${ }^{1}$ Department of Perinatology, Zeynep Kamil Maternity and Children's Diseases Training and Research Hospital, Istanbul, Turkey; ${ }^{2}$ Department of Genetics, Zeynep Kamil Maternity and Children's Diseases Training and Research Hospital, Istanbul, Turkey

Objective: To present a prenatally diagnosed case of EllisVan Creveld (EVC) syndrome and discussion of management for this case.

Case: A 19 years old gravida 1, para 0 was referred to our unit because of fetus with shortness in all long bones at 21 weeks gestation. Parents had consanguineous marriage. A detailed ultrasound scan revealed a single live fetus with shortness of long bones $(<2.5$ th) severe thoracic hypoplasia with short ribs, postaxial polydactyly of bileteral hands, and aortic hypoplasia with atrioventricular septal defect.After counseling about the fetus and prognosis, cordosentesis was performed and the pregnancy was terminated. Postmortem examination confirmed as a Ellis-Van Creveld Syndrome. Karyotype analyse was revealed a 46,XX karyotype of the fetus.

Conclusion: EVC syndrome can be diagnosed by prenatal sonograpy in the second trimester but EVC should be distinguished from thoracic asphyxiating dystrophy (Jeune syndrome) and the group of short-rib polydactyly syndromes.

Keywords: Ellis-Van Creveld syndrome, prenatal diagnosis.

\section{PP-045}

\section{Early neonatal outcomes of idiopathic polyhdramnios}

Ertugrul Karahanoglu, Safak Ozdemirci, Erdem Fadıloglu, Ayşegül Akyol, Serdar Yalvaç, Ömer Kandemir

Etlik Zubeyde Hanm Women's Health Research and Training Hospital. Ankara

Objective: Polyhdramnios is seen nearly $0.4 \%-\% 1.7$ of the obstetric population after 24th week. About $45 \%$ of these cases etiology can not be defined. Nearly $5 \%$ of the idiopathic polyhdramios post natal structural anomaly is detected. Gastro intestinsl system, urinar system and cardiovascular system anomalies are the most seen ones. Risk of having aneuploidy is higher in idiopathic polyhdramnios. Stuides have showed that early neonatal outcomes is not well when compared with 
healthy one. In this study post natal anaomlies and early neonatal outcomes of idiopathic polyhdramnios were analyzed.

Methods: A case control study was conducted at Etlik Zubeyde Hanım Women's Health Research and Training Hospital. 207 idiopathic polhydramios cases and 336 control group pregnant are included in the study. With postnatal anomaly early neonatal outcomes are also investigated. Early neonatal outcomes are defined as 5 minute apgar score, NICU admission, ventilator requirement, TTS, newborn hypoglycemia.

Results: Rate of post natal structural anomaly is higher in idiopathic polyhdramnios group when compared with control group (\%5.3 vs \%0.6, p=0.001). Patients with I.P. have increased rate of TTN(\%1.9 vs \%0.0, p=0.021), new born ressutation, (\%3.4 vs \% $0.3, \mathrm{p}=0.007)$, need for NICU (\%6.8 vs $\% 0.3, \mathrm{p}=0.00)$, need for ventilator $(\% 2.9$ vs $\% 0.0, \mathrm{p}=0.03)$, new born jaundice (\%6.3 vs \%0.9, p=0.00) and new born hypoglycemia ( $\% 5$ vs $\% 1.2, \mathrm{p}=0.006)$.

Conclusion: In idiopathic polhydramnios,although antenatal follow up do not show any abnormality postnatally, there is higher rate of having structural anomalous fetus. In our study we found that higher rate of structural anomaly at postpartum period. Although prior studies did not find higher rate of early neonatal complication, in our study we found that higher.

Keywords: Idiopathic polyhdramnios, early neonatal outcomes.

\section{PP-046}

\section{Prenatal diagnosis of Smith-Lemli-Opitz syndrome}

Nihal Șahin Uysal ${ }^{1}$, Çağrı Gülümser ${ }^{1}$, Filiz Fatma Yanık ${ }^{1}$, Esra Ünal ${ }^{1}$, Okan Öte ${ }^{2}$, Zerrin Yılmaz ${ }^{2}$, Ulaş Tuğcu ${ }^{3}$, Ayşe Ecevit ${ }^{3}$

${ }^{1}$ Department of Obstetrics and Gynecology, Başkent University Faculty of Medicine, Ankara, Turkey; ${ }^{2}$ Department of Genetics, Baskent University Faculty of Medicine, Ankara, Turkey; ${ }^{3}$ Department of Pediatrics, Başkent University Faculty of Medicine, Ankara, Turkey

Objective: To present a case of Smith Lemli Opitz Syndrome (SLOS) associated with multiple anomalies and to discuss the prenatal diagnosis.

Methods: We present a case of SLOS in which multiple anomalies were detected ultrasonographically. SLOS is an autosomal recessive deficiency of 7-dehydrocholesterol reductase (DHCR7) resulting in an accumulation of 7- and 8-dehydrocholesterol (7- and 8-DHC) in tissues and body fluids. At birth patients have variable malformations of central nervous system, heart, kidney, genitalia, and limbs. These malformations may be life-threatening. Psychomotor and mental retar- dation and behavior abnormalities become evident later. Prenatally SLOS can be suspected with the findings of malformations and intrauterine growth retardation (IUGR) in prenatal ultrasonography and reduced maternal free estriol in serum. The diagnosis is confirmed by sterol analysis in a chorionic villus biopsy or amniotic fluid.

Case: A 36-year-old pregnant woman was referred to our institution at the 27 th week of her fifth pregnancy because of fetal cardiac anomaly. Her first and third pregnancies had ended up with healthy male and female babies delivered vaginally. She had aborted her second pregnancy. The fourth pregnancy was a spontaneous twin pregnancy but at 6th gestational week one of the twins was missed. The surviving twin had short humerus and femur length.This male infant was delivered vaginally with low APGAR scores. He was $3600 \mathrm{~g}$ and had multisystemic anomalies such as thumb duplication, talipes, congenital cardiac anomaly, adrenal hypoplasia, ambiguous genitalia and small kidneys. He lived only a few days. The patient underwent amniocentesis in the current fifth pregnancy because of the high risk in her second trimester screening test. Normal karyotype was reported. Atrioventriculer septal defect (AVSD), aortic interruption, hypoplastic aorta were observed in fetal echocardiographic evaluation. At the first visit in our institution, left ventricular hypoplasia, left atrial hypoplasia, AVSD, hypoplastic aorta and early intrauterine growth restriction (IUGR) were recognized. Genetic consultation was offered because of the similar findings in the previous baby. Her weekly follow-up continued and cesarean section was performed at the 37 th week due to IUGR, oligohydramnios and fetal distress. A $2280 \mathrm{~g}$ female infant was delivered. Cord blood was sampled to be studied at the genetic department to confirm the prenatal diagnosis. The newborn had metabolic disturbances and also dysmorphologic features such as telangiectasia, rhizomelic limbs. Echocardiographic evaluation was compatible with prenatal findings.

Conclusion: Smith-Lemli-Opitz syndrome (SLOS) can be associated with multiple malformations. Due to reduced maternal serum unconjugated estriol (MSuE3) levels, second trimester screening tests may reveal high risk for chromosomal anomaly. Such patients with poor obstetric history should be referred to genetic consultation.

Keywords: Smith-Lemli-Opitz syndrome, prenatal diagnosis.

\section{PP-047}

\section{Prenatal diagnosis of intestinal atresia}

Mustafa Ozturk, Aytekin Aydın

Etimesgut Military Hospital, Ankara, Turkey

We present an unusual case in which diagnosis was made shortly after bowel perforation at 33 weeks of gestation and 
definitive surgery was performed following prompt Caesarean delivery. A 33-year-old woman, gravida 3 para 2, was referred to our center at 33 weeks of gestation because of antenatal control. Ultrasound examination at admission showed presence of an cystic structure in the fetal abdomen, that was consistent with intestinal dilatation. The fetal growth parameters, placental structure and amniotic fluid volume were all normal. Detailed ultrasound examination of fetal anatomy revealed no additional abnormalities. One week later repeat ultrasound scan showed collapse of the bowel dilatation along with the presence of hyperechogenic fluid in the fetal abdominal cavity. Both parents were counseled regarding the possible diagnosis of fetal intestinal perforation and meconium peritonitis. Caesarean section was preferred as delivery mode due to previous Caesareans. A 2400 gram baby boy was delivered. Apgar scores were 8 and 9 at 1 and $5 \mathrm{~min}$, respectively. Laparotomy and bowel resection were performed within the first day following delivery. The operative findings were atresia of terminal ileum, with a perforation in the distal segment of it, and intraabdominal meconium. It is not clear appropriate delivery time and treatment modality after prenatal identification of the problem. But meconium contains digestive enzymes that induce aseptic peritonitis. Extensive inflammation could inhibit spontaneous sealing of the perforation and inflammation-induced bowel edema could aggravate the underlying bowel obstruction. Morbidity and mortality in meconium peritonitis cases depend upon gestational age, the complexity and the nature of the underlying lesion, process interval, presence of the cystic fibrosis or congenital anomalies, and complications of treatment or expectant management.

Keywords: Intestinal atresia, meconium peritonitis.

\section{PP-048}

\section{Fetal cardiac rhabdomyoma is diagnosed in the second trimester: a case report}

Ebru Dikensoy ${ }^{1}$, Osman Başpınar ${ }^{2}$

${ }^{1}$ Department of Obstetrics \& Gynecology, Faculty of Medicine, Gaziantep University, Gaziantep; 'Department of Pediatric Cardiology, Faculty of Medicine, Gaziantep University, Gaziantep

Rhabdomyoma, the most common primary fetal cardiac tumor $(60-86 \%)$ is often associated with tuberous sclerosis (TS). The prevelance of TS associated with fetal cardiac rhabdomyoma is $50-80 \%$, resulting in a perinatal mortality rate of $0-100 \%$. Other cardiac tumors include fibroma, myxoma, teratoma, and hemangioma.Rhabdomyomas appear on ultrasound as round, homogenous, hyperechogenic masses in the ventricles, and they sometimes appear as a multiple foci in the ventricles and septal wall. When the tumor was larger than $20 \mathrm{~mm}$ fetuses has a higher risk of perinatal death.A few cases with extracardiac anomalies such as cleft palate, polycystic kidney and clubfoot. Fetal MRI provides and additional imaging modality for the detection of TS. TS may be caused by the mutation of the tumor suppressor genes TSC1 and TSC2.TS follows an autosomal dominant hereditary pattern with variable expression, and $50-80 \%$ of childhood cases are considered to result from spontaneous mutation. We aimed to show in our case which fetal cardiac rhabdomyoma was diagnosed in the second trimester (28th weeks) by fetal echocardiography. The mother was referred to our clinic for fetal cardiac hyperechogenic mass.A round, hyperechogenis mass $(32 \times 20 \mathrm{~mm})$ was seen in the left vetricule. Aorta and pulmonary artery outflow were seen for excluding the great artery transposition. There was no sign for outflow obstruction of the aorta.Fetal heart rate was $136 \mathrm{beat} / \mathrm{min}$. There was no sign for hydrops.We screened the patient for renal hamartoma, cleft palate and club foot by ultrasonography.Cranial MRI was performed for brain lesion of TS.Cleft palate or lip were not seen. There was no family history for TS.We planned to check TSC1 and TSC2 tumor supressor gene mutation after delivery.We planned to delivery patient in our clinic at 37 th weeks. The baby is going to follow up for great atreies outflow tract obstruction.

Keywords: Fetal cardiac rhabdomyoma, fetal echocardiography.

\section{PP-049}

\section{Left isomerism diagnosed at prenatal period: a case report}

Didem Alkaş, Hakan Kalaycı, Cem Yalçınkaya, Tayfun Çok, Halis Özdemir, Ebru Tarım

Department of Obstetrics and Gynecology, Basskent University Adana Hospital, Adana, Turkey

Objective: Heterotaxy refers to abnormal situs of visceral organs in thorax or abdomen. Clinic is reflected in two ways: left isomerism/polisplenia, right isomerism/asplenia. Left isomerism is both atria of the heart's replace to left side and could include atrioventricular septal defect, or structural heart disease, the inferior vena cava ongoing azygos vein, heart block and viscerocardiac heterotaxy. Because of fetal arrhythmia and bradycardia, fetal non-immune hydrops and intrauterine death rates are common. In this study, left isomerism case diagnosed in early pregnancy is presented.

Case: 24 years old woman, whom has had five abortions and two healthy child, has consulted to our clinic because of fetal nuchal translucency has measured $3.32 \mathrm{~mm}$ and the risks for trisomy 13 and trisomy 18 in combined test has calculated 1/50. Patient was referred to our center at 15 weeks 2 days of gestation. In obstetric ultrasonography; stomach was observed on the right, fetal bradycardia ( 65 beats/min) and 
atrioventricular septal defect (AVSD) were detected. After giving information to parents about the clinical course and prognosis, termination has recommended which patients did not accept. At 23 weeks obstetric ultrasound persistan fetal bradycardia ( 67 beats/min) was observed. Again terminate of the pregnancy is suggested, but the family did not accept. Patient, at gestational of 35 weeks 1 day was admitted to our clinic with complaint of not feeling fetal movements. The absence of the fetal heart beat has observed. Ex fetus, $2210 \mathrm{~g}$ weigh, was delivered vaginally. Family refused an autopsy.

Conclusion: Within the early weeks of gestation, the monitoring of fetal stomach on the right, detection of fetal bradycardia and AVSD is essential in prenatal diagnosis of left isomerism. The fetus with the diagnosis of isomerism may develop non-immune hydrops and fetal death could have been seen and should be kept in mind.

Keywords: Left isomerism, bradycardia, atrioventricular septal defect.

\section{PP-050}

\section{Assesing the effectivity of early fetal cardiac examination on prenatal diagnosis}

Emre Ekmekci', Seçil Kurtulmuş', Serpil Aydoğmuş², Sefa Kelekçi

${ }^{1}$ Perinatology Clinic, Izmir Katip Celebi University School of Medicine, Izmir, Turkey; ${ }^{2}$ Department of Gynecology and Obstetrics, Izmir Katip Celebi University School of Medicine, Izmir, Turkey

Objective: Although advancements happened in ultrasound technologies and intensive studies done about getting fetal DNA from maternal serum, invasive prenatal tests are still preserving their indispensability. Maternal age of 35 years is not accepted as an indication for fetal caryotyping in many centers anymore but sometimes because of maternal anxiety and sometimes by thepreference of the physicians, invasive prenatal tests are still applied to women over 35 years.

Study Design: In our study we assessed the patients who had amniocentesis because of maternal anxiety by fetal echocardiography before the procedure than we compared them as normal echocardiography and abnormal echocardiography according to caryotype results.

Results: In our clinic between january 2012 and july 2014 totally 494 numbers of amniocentesis, chorion villus sampling and chordocentesis were done for fetal caryotyping. Totally 43 abnormal fetal caryotype was diagnosed. The indications for invasive prenatal testing were; abnormal screening test results for 251 patients, abnormal sonographic findings for 127 patients, anamnesis of abnormal caryotype in previous pregnancies for 11 patients, maternal anxiety for 105 patients. Abnormal caryotype was found in 5 of 105 patients (4.7\%) whom had amniocentesis for maternal anxiety. Among these 105 patients fetal echocardiography was performed in 82 of them and abnormal echocardiographic findings were stated in 18 patients $(17.1 \%)$. Of the 64 patients who had normal fetal echocardiography only 1 had abnormal caryotype (1.5\%), but of the 18 patients who had abnormal fetal echocardiography 3 had abnormal caryotype (16.7\%). In 1 patient who had normal fetal echocardiography the caryotype was Trisomy 21 , in a patient who had Trisomy 18 invasive test was performed before 15th week of pregnancy and fetal cardiac assessment was not sufficient in this gestational week and this patient would not be assessed again because she did not come her next prenatal visits. Trisomy 21 was found in 2 patients who had fetal atrioventricular septal defect and Turner syndrome was found in 1 patient who had fetal aort coarctation. Our study is still going on and the preliminary data were presented.

Conclusion: In our study we assessed the patients who had invasive prenatal testing because of maternal anxiety with fetal echocardiography before the procedure and we are searching the effectivity of fetal cardiac examination on prenatal diagnosis in patients who had normal screening test results or who did not perform any screening tests. Till now with the data we get we observed that with the addition of fetal cardiac examination to the screening programs prenatally detection of karyotype anomalies will increase. By the time our study is going on and as the data increases we will publish the results later.

Keywords: Amniocentesis, prenatal diagnosis, fetal echocardiography.

\section{PP-051 \\ Complete congenital fetal cardiac block associated with maternal lupus: a case report}

\section{Ebru Dikensoy', Osman Başpınar ${ }^{2}$}

${ }^{1}$ Department of Obstetrics and Gynecology, Faculty of Medicine, Gaziantep University, Gaziantep, Turkey; ${ }^{2}$ Department of Pediatric Cardiology, Faculty of Medicine, Gaziantep University, Gaziantep, Turkey

Isolated congenital cardiac block (CCB) is the congenital presence of cardiac block in a heart which is structurally normal. The congenital cardiac block in a structurally normal heart is frequently associated with maternal Ro/SSA and $\mathrm{La} / \mathrm{SSB}$ autoantibodies. Ro/SSA women has $2 \%$ risk to deliver children with CCB. CCB has a significant mortality (20$30 \%$ primary fetal/neonatal) and morbidity (67\% requirement for permanent pace before adolescence). During pregnancy, autoantibodies of mother are transferred via placenta and attached to cardiomyocytes, they disrupt atrioventricular conduction system, and create complete AV block by developing calcification and fibrosis. Life-threatening cardiomy- 
opathy is seen in $10-15 \%$ of patients. The most significant risk factors for death are low birth weight, prematurity, hydrops fetalis, endocardial fibroelastosis and decreased ventricular function. The survey is $94 \%$ in patients underwent diagnosis and treatment in neonatal period. Biomarkers that may show advanced block such as extension within PR range in fetal Doppler have not been considered as useful. Current prophylactic treatment strategies for $\mathrm{CCB}$ are maternal steroid, plasmapheresis, sympathomimetics and intrauterine cardiac pace placement. Our case referred to our clinic due to low fetal cardiac rate at 24 weeks of gestation. The mother was 28 years old and it was her first pregnancy. In the fetal echocardiography performed, no structural cardiac disorder was found. Heart rate was $67-70 \mathrm{beat} / \mathrm{min}$. It was seen that atrium and ventricles were incompatible, atrium rate was 80 beat $/ \mathrm{min}$. and ventricle rate was 50 beat $/ \mathrm{min}$., and third degree atrioventricular block was considered. Anti-Ro/SAA values of mother were requested and it was seen that they were positive. The patient was evaluated by fetal echocardiography biweekly; there was no recovery in heart rate but no dysfunction finding was found. Lower segment cesarean was performed due to early rupture of membrane at 35 week of gestation. Single male baby was born which was $2500 \mathrm{~g}$ and had Apgar score as 9. In the ECG, heart rate was 67 beat $/ \mathrm{min}$. Temporary pace was placed by inserting through femoral vein. Heart rate was set as $87 \mathrm{beat} / \mathrm{min}$.

Keywords: Maternal lupus, congenital fetal cardiac block.

\section{PP-052}

\section{Prenatally diagnosed right aortic arch case}

Seçil Karaca Kurtulmuș ${ }^{1}$, Emre Ekmekci², Alkım Yıldırım², Sefa Kelekçi

${ }^{1}$ Perinatology Clinic, Atatiirk Training and Research Hospital, Faculty of Medicine, İzmir Katip Çelebi University, İzmir, Turkey; ${ }^{2}$ Department of Obstetrics and Gynecology, Atatïrk Training and Research Hospital, Faculty of Medicine, İzmir Katip Çelebi University, İzmir, Turkey

Right-sided aortic arch is a rare vascular pathology. Although its progress is asymptomatic, if there is compression on trachea or esophagus, chronic cough, dyspnea or dysphagia may occur. During postnatal period, its diagnosis is frequently established during the differential diagnosis of obstructive pulmonary diseases. Fetal cardiac screening is one of the most significant parts of fetal anomaly screening. Fetal heart should be evaluated in terms of the appearance of four chambers, the appearance of five chambers and the appearance three vein trachea. Thirty-one-year-old G3P1A1 patient who was followed up at an external center referred to our clinic at 24 weeks of gestation for fetal anatomic screening. Her combined test screening was normal in the first trimester. In the sonographic anatomic screening performed, fetal anatomy was evaluated as normal and her biometric measurements were compatible with the week of gestation. In the fetal cardiac examination, 4-chamber and 5 -chamber plans and major vessel outlets were seen as normal. It was seen in the three vein trachea that aorta was located on the right side of the trachea. No additional anomaly associated with right-sided aortic arch was observed in the echocardiography. It was planned to perform fetal karyotyping and DiGeorge syndrome screening to the patient. Karyotype result done by cordocentesis was normal and $22 \mathrm{q} 11$ microdeletion was not found. The perinatal follow-up of the patient has been maintained at our clinic. In this study, we presented the case which had no fetal anomaly other than right-sided aortic arch in the fetal anomaly ultrasound screening. In such cases, fetal karyotyping and second trimester detailed anatomic screening should be done. Since dyspnea, chronic cough and dysphagia may arise in the newborn, the antenatal diagnosis of right-sided aortic arch is important.

Keywords: Fetal echocardiography, right aortic arch.

\section{PP-053}

\section{Ultrasound prenatal diagnosis of holoprosencephaly: a case report}

Najeh Hsayaoui, Chaouki Mbarki, Youcef Cadhy, Banene Hamdi, Hedhili Oueslati

Department of Obstetrics and Gynecology, Hospital of Ben Arous, Ben Arous, Tunisia

Introduction: The holoprosencephaly (HPE) is a severe and complex congenital malformation of the brain associated with evocative facial anomalies. The prevalence is estimated at 1:10,000 live births and stillbirths and 1/250 design pregnancies. Early antenatal diagnosis of this malformation is essential for taking proper and early obstetrical management.

Objective: The aim of this case report is to illustrate the importance of ultrasonic examination in the prenatal diagnosis of holoprosencephaly.

Methods: $\mathrm{HN}$ is a 32 years old patient without particular antecedent, mother of a child in apparent good health. She was seen at $22 \mathrm{WA}$ for systematic sonography examination. The morphological ultrasound discovered with intracranial signs: a large monoventricular cavity, lack of midline structures and fusion of thalamic masses suggestive alobar holoprosencephaly. Glycemic figures in this patient were normal, as well as acquired immunity to toxoplasmosis and rubella. Amniocentesis was performed at 23 weeks of gestation and an abnormal karyotype was diagnosed. The fetus had a trisomy of the 21 st chromosome. The parents decided to terminate the pregnancy on the basis of the ultrasound abnormalities. Eight hours after inducing labor with vaginally administered misoprostol. Autopsy demonstrated further the alobar HPE 
Conclusion: The HPE is a rare and frequently associated with facial anomalies, congenital brain malformation. Prognosis is often poor especially for alobar form. The ultrasound diagnosis is now possible since 14-16 weeks of amenorrhea.

Keywords: Prenatal diagnosis, holoprosencephaly.

\section{PP-054}

\section{Diastematomyelia could be diagnosed on prenatal sonography}

Chaouki Mbarki, Najeh Hsayaoui, Hajer Bettaieb, Abir Karoui, Hedhili Oueslati

Department of Obstetrics and Gynecology, Hospital of Ben Arous, Ben Arous, Tunisia

Introduction: Diastematomyelia is a rare congenital anomaly that results in the "splitting" of the spinal cord in a longitudinal (sagittal) direction.

Objective: We present a case of diastematomyelia diagnosed prenatally in our institution as well as a review of the literature in order to determine the importance of ultrasound prenatal diagnosis of the isolated case of diastematomyelia.

Methods: The diastematomyelia case, was detected at 23 weeks gestation by ultrasonography examination which was performed by suprapubic approach. It was presented with disorganization of bony process of the vertebral column with a midline echogenic bony spur, asymmetrical hemicords. The liveborn fetus was examined by a pediatric neurologist. A search was then conducted using PubMed to review previously reported cases in the literature.

Conclusion: Prenatal diagnosis is generally made in the second trimester. Intrauterine diagnosis of diastematomyelia should facilitate appropriate management of affected cases.

Keywords: Prenatal diagnosis, diastematomyelia.

\section{PP-055}

\section{Incidence of acrania in Hatay}

İlay Öztürk Gözükara, Arif Güngören, Kenan Dolapçıŏlu, Raziye Keskin Kurt, Dilek Benk Şilfeler, Ali Ulvi Hakverdi

Department of Obstetrics \& Gynecology, Faculty of Medicine, Mustafa Kemal University, Hatay, Turkey

Objective: Acrania is a rare congenital disorder characterized with complete or partial absence of cranial plane bones. Facial and cervical bones are generally seen as normal. This condition has $100 \%$ mortality and seen in 1 of 20,000 live births and mostly affect female babies. Anencephaly concordance is too often. Due to low recurrence rate in the following births routine genetic counseling is not recommended.
Methods: We analyzed 10.616 pregnant from the archive of Mustafa Kemal University, Obstetric Department between 2010 and 2014. 19 fetuses with acrania were detected. Mean pregnancy week was $14 \mathrm{w}$ 4d (12-28) and all fetuses with acrania were terminated. The incidence of a crania was found $0.2 \%$ in our region.

Conclusion: Acrania incidence is $0.2 \%$ in our region. This may be reduced to $0.03 \%$ with $0,4 \mathrm{mg}$ folic acid support in reproductive ages.

Keywords: Acrania, incidence, Hatay.

\section{PP-056}

\section{Prenatal diagnosis of diastematomyelia: case report}

Resul Arısoy, Emre Erdogdu, Oya Demirci, Pınar Kumru, Oya Pekin, Murat Muhcu

Department of Perinatology, Zeynep Kamil Maternity and Children's Diseases Training and Research Hospital, Istanbul, Turkey

Objective: To present a prenatally diagnosed case of fetal diastematomyelia and discussion of management fort this case.

Case: A 26 years old gravida 1, para 0 was referred to our unit at 21 weeks gestation. A widening of the spinal canal, echogenic bony spur traversing the spinal canal, intact skin and soft tissues overlying the affected spinal segment were detected upon detailed ultrasonographic examination. Conus medullaris distance was measured as $24 \mathrm{~mm}$ and tethered cord syndrome was excluded. Other system examinations showed no additional anomalies. After counseling about the prognosis of fetus, the pregnancy was followed up. No neurological deficits existed in the baby delivered at 40th gestational weeks by the vaginal delivery. The newborn weighed 3280 grams and the APGAR scores were 9/10. The newborn was discharged from the hospital on the first postpartum day with the advices of regular neurological examination.

Conclusion: The presence of tethered cord syndrome and other anomalies should be investigated for the management of the cases of fetal diastematomyelia.

Keywords: Fetal diastematomyelia, tethered cord syndrome.

\section{PP-057}

\section{Retrocerebellar arachnoid cyst}

Hicran Acar Sirinoğlu, Resul Arısoy, Emre Erdoğdu, Oya Demirci, Kaan Pakay, Oya Pekin, Murat Muhcu

Department of Perinatology, Zeynep Kamil Maternity and Children's Diseases Training and Research Hospital, Istanbul, Turkey 
Objective: To present a prenatally diagnosed case of retrocerebellar arachnoid cyst and discussion of management for this case.

Case: A 24 years old, gravida 1 , parity 0 pregnant woman was referred to our unit because of fetus with retrocerebellar arachnoid cyst at 22 weeks gestation. A detailed ultrasound scan was revealed a single live fetus with cranial retrocerebellar arachnoid cyst that is $28 \mathrm{~mm} * 22 \mathrm{~mm}$ in diameter, cisterna magna that is $13.18 \mathrm{~mm}$ in diameter and normal cerebellum(5th-50thh). After genetic counseling about the fetus prognosis; amniocentesis was performed. The result of fetal karyotype was $46 \mathrm{XX}$.

Conclusion: Cystic anomalies are easily recognizable in the axial transcerebellar plane in the fetus. However, their differential diagnosis can be particularly diffucult. Retrocerebellar arachnoid cyst is a cerebrospinal fluid collection and sonographically it appears as a sonolucent cystic mass. Retrocerebellar arachnoid cyst can be diagnosed by prenatal sonography into second trimester, but it should be distinquished from mega cisterna magna, Blake's pouch cyst, Dandy-Walker malformation

Keywords: Retrocerebellar arachnoid cyst, prenatal diagnosis.

\section{PP-058}

\section{Carbon monoxide poisoning during pregnancy}

Nihal Şahin Uysal ${ }^{1}$, Çăgrı Gülümser' ${ }^{1}$, Filiz Fatma Yanık ${ }^{1}$, Esra Kuşçu', Aslıhan Abbasoğlu², Aylin Tarcan ${ }^{2}$

${ }^{1}$ Department of Obstetrics and Gynecology, Baskent University Faculty of Medicine, Ankara, Turkey; ${ }^{2}$ Department of Pediatrics, Başkent University Faculty of Medicine, Ankara, Turkey

Objective: To present a case of carbon monoxide poisoning during pregnancy and to discuss the maternal and fetal effects of carbon monoxide.

Methods: A 32-year-old pregnant woman was admitted to Başkent University Ankara Hospital as she had a syncope due to carbon monoxide poisoning at the 15 th week of her pregnancy. Her initial evaluation and treatment as well as the perinatal follow-up is presented.

Results: The patient's physical examination was unremarkable at the emergency department. Oxygen was applied with mask immediately and laboratory analyses were performed. Carboxyhemoglobin (CO-Hb) level was 31\%. Complete blood count and liver and renal function tests had normal results. She was hospitalized and followed at the intensive care unit. Sonography revealed a fetal heart rate of $160 / \mathrm{min}$. After several hours, she was referred to another hospital for hyperbaric oxygen therapy. The case was discussed at the perinatology council and it was concluded that her CO-Hb level was higher than $15 \%$ and this might have caused fetal hypoxia leading to death or severe neurological sequelae. Structural screening was normal as well as cranial anatomy in the detailed ultrasonography which was performed at the 20th week of gestation. Fetal magnetic resonance imaging was performed at the 23 th week of gestation and was reported to be normal. The patient and her husband opted for continuing the pregnancy. The patient delivered vaginally a healthy male infant weighing 2,930 $\mathrm{g}$ at the 39th week of gestation in May 2014. The Apgar scores at 1 and $5 \mathrm{~min}$ were 8 and 9 respectively. Blood gas analyses revealed to be normal. Lactate level $(3.6 \mathrm{mmol} / \mathrm{L})$ was higher than the upper limit.

Conclusion: $\mathrm{CO}$ poisoning during pregnancy causes maternal then fetal tissue hypoxia primarily by binding to hemoglobin. It has a higher affinity for fetal hemoglobin thus its transplacental passage may cause fetal harm, predominantly in the brain. Hyperbaric oxygen therapy may reduce the risk to the fetus. Acute maternal CO poisoning is associated with a maternal mortality between 19 and $24 \%$ and a fetal mortality between 36 and $67 \%$. In the literature, some predictors about fetal outcome are defined, such as severity of maternal involvement, gestational week at which the poisoning occurred. Placental CO diffusion capacity increases with gestational age and in proportion to fetal weight. Anatomical malformations, especially skeletal abnormalities such as limb malformations are more frequent if intoxication occurs in early gestation. During the late gestation, fetal brain seems to be more sensitive to CO leading to anoxic encephalopathy. However, involvement at any stage of pregnancy may cause functional defects in psychomotor and mental development. In our case, the newborn did not have any symptoms attributable to CO exposure, but 3 months of age is too early to tell about his psychmotor and mental development.

Keywords: Pregnancy, carbon monoxide, poisoning.

\section{PP-059}

\section{Dandy-Walker variant}

Aytekin Aydın' ${ }^{1}$ Mustafa Öztürk ${ }^{1}$, Uğur Keskin², Kazım Emre Karaşahin', Ulaş Fidan

${ }^{1}$ Etimesgut Military Hospital, Ankara, Turkey; ${ }^{2}$ Department of Obstetric and Gynecology, Gülhane Military Medical Academy, Ankara, Turkey

Objective: Dandy-Walker variant; cystic posterior fossa mass with variable hypoplasia of the cerebellar vermis and no enlargement of the posterior fossa. The prenatal sonographic diagnosis of Walker variant is difficult before 18 weeks of gestation. We report a case of Dandy-Walker variant which was diagnosed during routine antenatal ultrasonography at 20 weeks of gestation.

Case: A 32-year-old primi-gravida was referred for routine antenatal ultrasound at 20 weeks of gestation. Ultrasonography 
revealed a single live intra-uterine 20 weeks of gestation. The fetal posterior fossa was of normal size but with a large anechoic lesion which was communicating with the 4th ventricle. There was a suggestion of hypoplasia of the cerebellar vermis but no evidence of hydrocephalus. Detailed ultrasound examination of fetal anatomy revealed no additional abnormalities except hypoplasia of the cerebellar vermis. Amniocentesis was not performed because patient. Did not want to perform. The patient delivered a male child at term with a birth weight of $2.6 \mathrm{~kg}$. Physical examination of the baby did not reveal any congenital anomaly. There were no other congenital intra or extra-cranial malformations. There was not any congenital cardiac defect. A final diagnosis of Dandy-Walker variant was made.

Conclusion: The Dandy-Walker malformation has an estimated prevalence of about 1:30,000 live births. DandyWalker malformation is frequently associated with other intracranial anomalies, polycystic kidneys, cardiovascular defects, polydactyly and cleft palate. Isolated Dandy-Walker variant has the highest chance of leading to a normal neonate

Keywords: Dandy-Walker variant.

\section{PP-060}

\section{The predictivity of different ultrasonographic estimated weight formulas and their correlations with actual birth weight}

Irfan Özer, Elif Gül Yapar Eyi, Selçuk Erkılınç

Zekai Tabir Burak Women's Health Education of Research Hospital, Ankara, Turkey

Objective: To compare the accuracy of the eight different formulas for 2-dimensional ultrasonographic fetal weight estimations in our Labor Ward.

Methods: This prospective cohort study was carried out at a single branch Zekai Tahir Burak Women's Health Education and Research Hospital, between October 2013 and March 2014. 1000 low pregnant women were enrolled into the study. Pregnant women with maternal obesity, oligohydramnios, premature rupture of membranes and a cervical dilatation of more than $6 \mathrm{~cm}$ in active labor were considered as the factors that might dinterfere with measurements were excluded from the study. Fetal biometric measurements were only used if the birth occurred within 24 hours of the measurement. Only a single operator (Ï̈) performed all measurements. 8 different models "Hadlock 1", "Hadlock 2", "Hadlock 3", "Hadlock 4", "Campbell", "Combs", "Ott", "Warsoff" formulas were used. In the evaluation of the accuracy of these formulas:

- Average Error: Estimated birth weight (EBW) - Actual birth weight (G) of the algebraic sum of average,

- Average Absolute Error: EBW-G average of the sum of the values
- Average Percentage (\%) Error: (EBW-G)/Gx100 of the algebraic sum of the average

- Average Absolute Error: The percentage of the actual birth weights corresponding to the absolute margin of error in IEFW-G) I/S 100 of the sum of the average of the formulas,

Statistical evaluation was performed using SPSS version 17.

Results: Of 1000 low risk pregnant women, biometric measurements of 914 were evaluated as birth occurred within 24 hours of measurements. In an analysis of eight different EBW formulas, a significant difference was detected among formulas ( $\mathrm{p}<0.001)$, and each formula of EBW showed a significant correlation with the actual birth weight $(\mathrm{p}<0.001)$. Of the sonographic fetal weight estimation formulas, the lowest mean absolute percentage error was found to be present in the Hadlock formula $4(0.97 \pm 1.37)$. The narrowest confidence interval were also found to be in Hadlock 4.

Conclusion: Correct estimation of fetal weight may improve maternal and fetal outcomes. Among the eight different formulas, the best results in terms of lowest mean absolute percentage error and the narrowest CI was detected in Hadlock 4 formula. Therefore, in order to obtain the best clinical results in the estimation of fetal weight, the formula determining the lowest absolute error and the lowest percentage absolute error should be determined for each population.

Keywords: Estimated fetal weight, ultrasound.

\section{PP-061}

\section{Prenatal diagnosis of congenital diaphragmatic hernia}

Najeh Hsayaoui ${ }^{1}$, Chaouki Mbarki ${ }^{1}$, Eya Gharbi ${ }^{1}$, Abir Karoui ${ }^{1}$, Hedhili Oueslati' ${ }^{1}$, Saoussen Melliti' ${ }^{2}$, Sana Mezghani ${ }^{2}$

${ }^{1}$ Department of Obstetrics and Gynecology, Hospital of Ben Arous, Ben Arous, Tunisia; ${ }^{2}$ Department of Radiology, Hospital of Ben Arous, Ben Arous, Tunisia

Introduction: Hernia diaphragmatic dome (HCD) affects about one child born alive in 3000. A very early closure defect of the diaphragm by lack of closure of pleuroperitoneal canal is responsible for impaired lung development and physiology. Due to the different pressure between the thorax and the abdomen, the abdominal organs in the thorax moves causing insufficient lung development. The diagnosis of congenital diaphragmatic hernia occurs most often during a routine ultrasound.

Objective: The aim of this study is to describe two cases of Hernia diaphragmatic dome and show the importance of ultrasound examination in its diagnosis. 
Methods: We present two cases of HCD diagnosed by the antenatal ultrasound examination

Case 1: a 32 year -old woman without any antecedent, admitted to our department of Obstetrics and Gynecology at Ben Arous Hospital (tunisia) for morphological ultrasound examination at 24 weeks of amenorrhea. The ultrasound examination was performed by suprapubic approach. It was a left diaphragmatic hernia. We had noted the absence of stomach in the abdomen in the left upper quadrant in addition to the presence of stomach in the left thorax associated with mediastinal shift and right deviated heart. The fetal MRI did not show the left diaphragmatic dome, it showed the rise of stomach digestive handles and spleen occupying the left hemi-thorax. During the ultrasound monitoring, there was no polyhydramnios noted and transverse abdominal diameter was average. The evolution was marked by a premature birth by natural means to $33 \mathrm{SA}$ a newborn male who presented immediate respiratory distress in the labor ward, died in $\mathrm{H} 1$ living child.

Case 2: morphological ultrasound done at 23 weeks of amenorrhea for a 30 year -old woman diagnosed a left diaphragmatic hernia isolated with no other associated malformations. We did not found chromosomal abnormalities. The delivery was programmed in collaboration with the pediatric surgeons, the child was operated but the outcome was unfavorable with the death of the child two months later.

Conclusion: Multiple ultrasound markers have been identified as items of diagnosis and predictive of outcome. Magnetic resonance imaging have been identified as additional imaging modalities that can assist in making the antenatal diagnosis and accurately assessing perinatal outcome.

Keywords: Sonography, antenatal diagnosis, congenital diaphragmatic hernia.

\section{PP-062}

\section{Congenital high airways obstruction syndrome (CHAOS): report of two cases}

Selçuk Yetkinel, Tayfun Çok, Hakan Kalaycı, Halis Özdemir, Huriye Ayşe Parlakgümüş, Ebru Tarım

Department of Obstetrics and Gynecology, Başkent University Adana Hospital, Adana, Turkey

Objective: Congenital high airways obstruction syndrome (CHAOS) is usually caused by complete or partial high airway obstruction as a result of atresia and stenosis of the larynx and trachea. Bilateral enlarged hyperechoic lungs, dilated airways, flattened or inverted diaphragms are observed at prenatal sonoghrapy. Increased intrathoracic pressure decreases venous return. The ascites, plasentomegaly and hidrops fetalis occurs with fetal heart failure. If it hasn't been diagnosed at intra uter- ine life, the fetus usually couldn't survive or die soon after labor. Acute respiratory distress as a result of difficult intubation and the presence of a point at direct laryngoscopy which allowing a narrow passage are the milestones of postnatal diagnosis in CHAOS. In this text, our aim is reporting of two cases, which was diagnosed at our hospital as CHAOS that could have been seen at 1/50,000 birth.

Case1: 24 years old, whom has had 17 weeks gestation, was referred to our clinic due to fetal hidrops. Obstetric ultrasound revealed bilateral hyperechoic lungs, dilated airways, inverted diaphragm and ascites. Increased in the fetal kidney size was observed. Mortality rate of the disease has been told to parents and the option of termination has offered. Parents have chosen to continue the pregnancy and ongoing weeks hidrops of fetus was obviously increased.

Case 2: 19 years old, 14 weeks 5 days gestation, was referred to our clinic due to fetal ascites. In our clinic, we observed bilateral hyperechoic and enlarged lungs, inverted diaphragm and ascites. Tricuspid valve regurgitation and bilateral club foot were the other findings. Parents have chosen pregnancy termination option because of the poor prognosis of CHAOS.

Conclusion: At the early period of pregnancy, in the presence of bilateral hyperechoic and enlarged lungs, inverted diaphragm and ascites, CHAOS should be kept in mind.

Keywords: Congenital high airways obstruction syndrome, case.

\section{PP-063}

\section{Congenital cystic adenomatoid malformation: a case report}

Sevcan Arzu Arınkan, Resul Arısoy, Emre Erdoğdu, Oya Demirci, Oya Pekin, Pınar Kumru, Murat Muhcu

Department of Maternal Fetal Medicine, Zeynep Kamil Women and Children Diseases Research and Training Hospital, Istanbul, Turkey

Objective: It is aimed to present a case of type 1 congenital cystic adenomatoid malformation which is prenatally diagnosed,and to discuss the management in these cases.

Case: A 26-year-old gravida 1 patient was referred to our clinic at 20 weeks gestation. A detailed ultrasound scan was revealed that multiple anechoic cystic lesions at right lung. No additional anomaly was detected during the examinations of other systems. Type 1 congenital cystic adenomatoid malformation was diagnosed. Parents were informed about the fetal prognosis. Patient lost the follow-up and after two months, she applied to emergency with the complaint of pain. There was no fetal heart rate at the ultrasound examination and fetus was delivered vaginally. 
Conclusion: The differential diagnosis of type 1 congenital cystic adenomatoid malformation and the presence of concomitant anomalies are important for the management of these cases. The prognosis is good in cases with type 1 congenital cystic adenomatoid malformation without any other accompanying anomalies. Conservative management should be applied to these patients.

Keywords: Congenital cystic adenomatoid malformation, prenatal diagnosis, management.

\section{PP-064}

\section{Prenatal diagnosis of pentalogy of Cantrell}

Senol Șentürk, Işık Üstüner

Department of Obstetrics and Gynecology, Faculty of Medicine, Recep Tayyip Erdoğan University, Rize, Turkey

Objective: The pentalogy of Cantrell is an extremely rare heterogeneous thoracoabdominal wall closure defect with an estimated prevalence of 1 per 65,000 to 200,000 live births. Here, we aimed to present a rare case of Cantrell pentalogy in a first trimester pregnant woman.

Case: In the ultrasonographic examination of a 26-year-old G1P0 patient who had pregnancy at $13+0$ weeks of gestation according to her last menstrual period (LMP), anterior abdominal and anterior thoracic walls were not seen in the fetus and it was observed that heart and liver protruded through large supraumbilical omphalocele at the midline defect and there were cystic hygroma, extreme deformities of the vertebral column (thoracolumbar). Ultrasonographic findings supported Cantrell pentalogy. Genetic and obstetric counseling were given to the family. The family wanted to terminate the pregnancy due to poor prognosis and low survival rate. The patient was admitted to the clinic to be performed termination of the pregnancy and the induction of the labor was initiated by administration of single dose of misoprostol. The patient had a medically induced late abortion 12 hours after initiation of the induction. Gross examination of the fetus performed after abortion revealed a midline defect including supraumbilical anterior abdominal and anterior thoracic walls was present, heart and intraabdominal organs protruded through this defect and there were cystic hygroma, extreme deformities of the vertebral column (thoracolumbar). A dermal biopsy was performed for evaluation of fetal karyotype and the fetus was determined to be $46 \mathrm{XY}$. The patient not determined to have an abnormal finding during follow-ups performed after abortion was discharged.

Results: Cantrell pentalogy which has been first described by Cantrell et al. in 1958 is a rare thoracoabdominal development disorder including abdominal wall, diaphragmatic, pericardial, sternal and heart defects. As it could be differ- ences in the anomalies described in the syndrome, various accompanying anomalies were also reported in the literature. Toyama et al. divided Cantrell pentalogy into 3 categories in 1972: These were defined as followings: group 1, exact diagnosis with presence of all defects together; group 2, probably diagnosis with presence of only 4 defects together; group 3, incomplete diagnosis with various combinations of defects. In our case, all of five anomalies and malformations specific to the syndrome were determined.

Conclusion: In conclusion, early diagnosis is feasible in the first trimester if ectopia cordis and omphalocele exist. The termination of the pregnancies with fetuses having high mortality will be easier in case of presence of particularly omphalocele and ectopia cordis and when they are detected in earlier gestational weeks.

Keywords: Cantrell pentalogy, omfalosel, ectopia cordis.

\section{PP-065}

\section{Prenatal sonographic detection of fetal adrenal hemorrhage}

Şenol Şentürk ${ }^{1}$, Yavuz Metin², Işı1k Üstüner ${ }^{1}$, Yeşim Bayoğlu Metin ${ }^{1}$, Figen Kır Şahin ${ }^{1}$

${ }^{1}$ Department of Obstetrics and Gynecology, Faculty of Medicine, Recep Tayyip Erdoğan University, Rize, Turkey; '2Department of Radiology, Faculty of Medicine, Recep Tayyip Erdoğan University, Rize, Turkey

Objective: Detection of prenatal finding of a large cystic adrenal mass causes a dilemma regarding the differential diagnosis between adrenal hemorrhage and cystic neuroblastoma. We report a case of adrenal hemorrhage in a newborn first detected by sonography at a menstrual age of 34 weeks 4 days.

Case: A 23-year-old G1P0 pregnant presented to our clinic due to routine follow-up. The patient having a regular menstrual cycle previously was at 34 weeks and 4 days since her last menstrual period (LMP). The patient did not have consanguineous marriage and a hypoechoic cystic lesion not clearly differentiated in diameter of $18.6 \times 17.5 \mathrm{~mm}$ was determined in the right kidney region of the fetus at 34 weeks of gestation in the ultrasonography performed. Fetal adrenal hemorrhage and cystic neuroblastoma prediagnoses were made in the detailed ultrasonography performed and no additional anomaly was determined. It was learned from the history of the patient she had the second trimester screening tests and the third trimester screening tests previously and determined to have normal values. The patient was informed regarding there could be an additional anomaly. Since the patient was in a late gestational week and she did not want to have, amniocentesis was not performed. The routine laboratory and tumor marker levels were normal. It was observed 
that the tumor was reduced in size during the routine followup of pregnancy. She had normal delivery in the 39th gestational week. No pathological finding was encountered in the newborn infant. No pathological finding was observed in the kidney, liver and bile ducts in the ultrasonography and MRI performed. An area of fetal adrenal hemorrhage with a mildly heterogeneous echo texture in diameter of $5.8 \times 4.7 \mathrm{~mm}$ was determined in fetal adrenal region. Since complete blood count results, blood chemistry tests and tumor marker values were within normal ranges, the infant was followed-up. Ultrasonography was performed every two weeks. It was seen that hemorrhagic area was gradually reduced. Since the cyst was no seen and laboratory findings were found to be normal in the infant at the end of the month, the follow-up was ended.

Results: The thought of a neuroblastoma is generally resulted in surgical excision of this lesion. However, to avoid an unnecessary surgery, an adrenal hemorrhage has to be diagnosed in due time. Close postnatal follow-up should be performed with serial ultrasonography in order to make differential diagnosis of such tumors even in large masses. Unless the tumor size does not reduce, surgical treatment is not essential. Nonetheless, it is impossible to make a differential diagnosis between an adrenal hemorrhage and a spontaneously resolved neuroblastoma.

Conclusion: Our case implies that adrenal hemorrhage may develop as early as the second trimester of the pregnancy.

Keywords: Adrenal hemorrhage, fetal adrenal hemorrhage.

\section{PP-066}

\section{Successful first trimester intrauterine treatment with alcohol in a case of acardiac twin pregnancy}

Melih Atahan Güven ${ }^{1}$, Harika Bodur Öztürk², Önder Koç3 Serkan Erkanl1, Deniz Usal', Tayfun Băğş̧

${ }^{1}$ Department of Obstetrics and Gynecology, Acıbadem University, Istanbul, Turkey; ${ }^{2}$ Department of Obstetrics and Gynecology, Acıbadem Kadikoy Hospital, Istanbul, Turkey; ${ }^{3}$ Department of Obstetrics and Gynecology, Memorial Ankara Hospital, Ankara, Turkey

Twin reversed arterial perfusion (TRAP) sequence is a serious condition of monochorionic twin pregnancy. It is an extremely rare anomaly, occurring with a reported incidence of 1 in 35,000 deliveries, 1 in 100 monozygotic twins and 1 in 30 monozygotic triplets. This condition is associated high risk of perinatal death of the pump twin due to cardiac failure and polyhidramnios may induce preterm birth. Several methods have been proposed for intrauterine treatment of acardiac twin pregnancy and selective reduction of the acardiac twin was recently reported to be minimally invasive and effective for intrauterine treatment of acardiac twin pregnan- cy. First trimester treatment of TRAP sequence is controversies with higher incidence of procedure related complications. We present a case of TRAP sequence that has been managed by intrauterine treatment with alcohol injection at 12 weeks of gestation. Prophylactic intervention at 12 weeks of gestation may be resulted with higher survival rate if the early procedure could prevent fetal loss of pump twin before 16 weeks. First trimester prophylactic intervention could be recommended patient with TRAP sequence. Alcohol ablation can be performed in medical center unless more sophisticated methods as invasive procedure are not available.

Keywords: Acardiac twin, twin pregnancy, intrauterine intervention.

\section{PP-067}

\section{Validity of sonographic prediction of fetal weight and weight discordance in twin pregnancies}

Kaouther Dimassi, Abir Karoui, Thouraya Ammous, Raouia Radhouani, Saida Belgacem, Nizar Ben Aissia, Amel Triki, Mohamed Faouzi Gara

Department of Obstetrics and Gynecology, Mongi Slim Hospital, La Marsa, Tunisia

Introducton: Ultrasonography is an essential tool in the management of twin pregnancies. Fetal weight estimation is useful to anticipate neonatal care in case of prematurity, growth restriction or growth discordance.

Objective: The aims of this study were (1) to assess the accuracy of estimated fetal weight (EFW) in twins and (2) to assess the accuracy of sonographic examination to predict birth weight discordance (BWD).

Methods: All twin pregnancies with at least one ultrasound (US) examination within 04 days of delivery were included in this study. EFW was calculated according Hadlock2 formula. Mean of the standardized errors and percentage of newborns with birth weight (BW) within $10 \%$ of EFW were calculated.

Results: Absolute differences between EFW and BW were similar for both twins (187 g [0-850] for T1 and $156 \mathrm{~g}$ [0-600] for T2). Mean absolute percentage error was 7.7\% (0-32 gr) for T1 and $8.2 \%(0-27 \mathrm{gr})$ for T2. Mean absolute percentage error was superior to $10 \%$ for $42 \%$ of $\mathrm{T} 1$ and $46 \%$ of $\mathrm{T} 2$ with no significant difference. Obesity was associated with a better accuracy of ultrasonography. Chorionicity, gestational age as well as fetal presentation did not influence fetal weight estimation. Ultrasonography in the diagnosis of hypotrophy had a sensitivity of $90.32 \%$, a specificity of $78.94 \%$, a positive predictive value (PPV) of $83.5 \%$ and a negative predictive value 
(NPV) of $87.5 \%$. For the prediction of growth discordance, sensitivity was $76.9 \%$, specificity $81.8 \%$, PPV $50 \%$ and NPV $93.5 \%$.

Conclusion: Sonographic prediction of inter-twin BWD within four days of delivery seems to be accurate enough for routine clinical use. Performance and predictive values depend on the threshold chosen to define EFW and BW discordance.

Keywords: Twins, discordance, weight.

\section{PP-068}

\section{Ultrasound assessement of twin anemia polycetemia sequence}

Fatma Douik, Kaouther Dimassi, Mariem Ajroudi, Raouia Radhouani, Nizar Ben Aissia, Amel Triki, Mohamed Faouzi Gara

Department of Obstetrics and Gynecology, Mongi Slim Hospital, La Marsa, Tunisia

Objective: Twin anemia polycythemia sequence (TAPS) is caused by small placental vascular anastomoses leading to chronic anemia in the donor and polycythemia in the recipient. TAPS can result in severe fetal or neonatal hematologic complications, cerebral injury and perinatal death. The aim of this study is to ascertain the most relevant echographic signs that helps to make an early diagnosis so we can improve the outcome of this sparse complication.

Methods: It's about two observations of patients treated in the department of gynecology and obstetrics of the Mongi Slim hospital Tunis in 2013.

Results: The first case is about a 42 years old patient with one miscarriage, one childbirth, blood type $\mathrm{O}$ negative, actual pregnancy a spontaneous monochorionic according to the early first trimester echography, adressed at 31 SA for intra uterine death of one the twins and hydrops fetalis of the second. The second patient is aged of 28 years, first pregnancy hospitalized at 29 SA to explore an hydramnios accidently discovered.The ultrasound exam performed in our service showed for the first twin: no bladder and anamnios, for the second twin: a huge bladder with polyhydramnios. In this too cases, the blood flow in the MCA was superior to $1.5 \mathrm{MoM}$. Furthermore ultrasound allowed the guidance for fetal transfusion.

Conclusion: TAPS is fetal emergency. Ultrasound is the only mean for the diagnosis and for the fetal therapy.

Keywords: Fetal, anemia, twins.

\section{PP-069}

\section{Prenatal diagnosis of cephalothoracoom-} phalopagus: a rare type of conjoined twin

Yasin Ceylan $^{1}$, Yasemin Doğan ${ }^{2}$, Emre Kole $^{3}$, Gulseren Yucesoy ${ }^{4}$, Sebiha Ozkan Ozdemir ${ }^{5}$

Kocaeli University Medical School, Department of Obstetrics and Gynecology, Izmit, Kocaeli

Objective: Conjoined twins are a rare outcome of a monoamniotic and monochorionic gestation. We present a case of cephalothoracoomphalopagus conjoined twin diagnosed by prenatal ultrasonographic examination.

Case: A 26-year-old gravida 2, para 1 woman was referred to our perinatology unit for evaluation because of suspected conjoined twins at 24 weeks of gestation. Her medical history was unremarkable. There was no family history of genetic abnormalities. The diagnosis of conjoined twins was confirmed by prenatal ultrasonographic examination.

Conclusion: Conjoined twins occur when two identical individuals are joined by part of their anatomy and share their vital one or more organs. The incidence of conjoined twins ranges from 1:50,000 to 1:250,000 live births. We present a case of male cephalothoracoomphalopagus conjoined twin, which is extremely rare type of conjoined twins. A prenatal diagnosis of shared organs dictates pregnacy termination or possible surgical separation strategies.

Keywords: Conjoined twins, cephalothoracoomphalopagus twins.

\section{PP-070}

\section{Ultrasound diagnosis and laparoscopic treatment of a heterotropic pregnancy}

Ismet Hortu, Gökay Özçeltik, Deniz Şimşek, Ahmet Mete Ergenoğlu, Ahmet Özgür Yeniel

Department of Obstetrics and Gynecology, Ege University School of Medicine, Izmir, Turkey

Heterotropic pregnancy is a rare condition in which both intrauterine and extrauterine pregnancies are present at the same time. This rare condition is a serious emergency that can be life-threatening due to bleeding in cases of delayed diagnosis. The main goal of treatment is to maintain the intrauterine pregnancy while terminating the extrauterine pregnancy. Termination of extrauterine pregnancy can be carried out using either surgical treatments or non-surgical treatments. The management remains controversial. In case of a diagnosis of heterotopic pregnancy is hemodynamically stable, conservative management may be considered. Nonsurgical treatments consists of administration of several drugs to the extrauterine gestational sac under ultrasonographic or 
laparoscopic guidance. Surgical treatment is warranted when conservative treatment fails or there is accompanying hemoperitoneum. Surgery can be performed either with laparotomy or laparoscopic approach. Since laparoscopic approach has several advantages over laparatomy including reduced recovery time, reduced requirement for antibiotics and analgesics. We report a case of a 31 year old woman who was admitted through emergency department with delayed menstruation and vaginal bleeding. Her ultrasound scan revealed heterotopic pregnancy with one intrauterin fetus of about 7 weeks and the second fetus of about 7 weeks in the left tubal area, both with fetal cardiac activity. She was hemodynamically stable at the time of presentation. After the patient and her husband were given informed consent she underwent laparoscopy and left salpingo-oophorectomy was performed. On the second day after surgery she was discharged from the hospital. Two weeks after the surgery the patient was called for control and her ultrasound revealed an ongoing intrauterine live pregnancy.

Keywords: Heterotopic pregnany, laparoscopic surgery.

\section{PP-071}

\section{Selective reduction in multiple gestations}

Ebru Dikensoy, Emre Akçil, Erdoğan Koca, Reyhan Gündüz

Department of Obstetrics and Gynecology, Faculty of Medicine, Gaziantep University, Gaziantep, Turkey

The frequency of multiple gestation has increased dramatically. Twins and higher order multiple gestations have pregnancies with increased risks for almost every complication of pregnancy, especially preterm labour, and congenital anomalies. Monochorionic twins, by virtue of the unique plasental angioarchitecture, are at risk for additional complications, such as severe discordant malformations, twin reversed arterial perfusion sequence, twin to twin transfusion syndrome or severe selective intrauterine growth restriction. These complications create unique challenges to those who manage multiple pregnancies. Reduction of higher order multiple pregnancies is on option to reduce pregnancy related risks and improve overall outcomes. Selective termination in complex monochorionic pregnancies can be life saving for the cotwin by preventing intrauterine demise or extreme prematurity. It is critical, however, to determine chorionicity before considering any approach to selective reduction. Procedures can carry out between 11 and 14 weeks allow for information to be obtained that can assist in selecting which fetus to terminate. Nuchal translucency screening can also be carried out before a reduction procedure. Risks for selective reduction are depend on many factors. Strong correlations were observed among the starting number of fetuses, the finishing number of fetuses, and the likelihood of poor pregnancy out- come, including both pregnancy losses and prematurity. Although it is clear that reduction of higher order multiples is of significant benefit, it is unclear whether the optimal number of remaining embriyos should be three,two or one. Although long term outcome information is not available, intutively it is reasonable to expect that less prematurity would result in healthier newborns. Reduction of triplets to singletons would not seem to be associated with a significant increased risk of pregnancy loss. We aimed to show our triplet pregnancy case; monochorionic diamniotic twins and monochorionic singleton pregnacy in 12 weeks. It was an IVF pregnancy, 2 embriyos were transferred. Triplet pregnancy occured because of one embriyo was divided two.The parents were infertile for 5 years. They had to much stress about the abortion rate of the reduction procedure. We gave some information about the monochorionic twins possible complications such as twin to twin transfusion syndrome, selective IUGR and preterm labor. Then, they decided to reduction to single fetus. We measure dthe nuchal translucency, nasal bone and ductus venosus flow for each fetuses.Under ultrasound guidance by transabdominal approach, 22 gauge needle is positioned within the heart or thorax of the twins, and potassium chloride is injected. Now, the patient is in 28th weeeks without any complications.

Keywords: Multiple gestations, selective reduction.

\section{PP-072 \\ An isolated omphalocele determined in one fetus of a twin pregnancy}

Senol Șentürk ${ }^{1}$, Ülkü Mete Ural ${ }^{1}$, Nurgül Orhan Metin ${ }^{2}$

${ }^{1}$ Department of Obstetrics and Gynecology, Faculty of Medicine, Recep Tayyip Erdoğan University, Rize, Turkey; ${ }^{2}$ Department of Radiology, Faculty of Medicine, Recep Tayyip Erdoğan University, Rize, Turkey

Objective: Omphaloceles represent a common group of congenital midline abdominal wall defects associated with increased perinatal morbidity and mortality. Most cases occurs sporadically and an isolated omphalocele occurs in approximately one of every 1:5000 births. Herein we aimed to discuss a patient with omphalocele.

Case: A 21-year-old G2P0A1 twin pregnant presented to our clinic due to routine follow-up. The patient having a regular menstrual cycle previously was at 21 weeks and 2 days since her last menstrual period. The patient did not have consanguineous marriage and a dichorionic diamniotic twin pregnancy at 21 weeks was determined in the ultrasonography performed. While one of the fetuses was observed to be normal, an omphalocele was determined in the other fetus. No additional anomaly was determined in the detailed ultrasonography of the fetus observed to have omphalocele. It was 
learned from the history of the patient she did not have the second trimester screening tests and the third trimester screening tests previously. The patient was informed regarding there could be an additional anomaly. Since the patient was in a late gestational week and she did not want to have, amniocentesis was not performed. Routine laboratory test results were normal. The patient was followed-up with normal pregnancy follow-up and she had caesarean section at 37 th week of gestation. Both of the babies were delivered alive. Newborn infant with definite diagnosis of omphalocele was referred to pediatric surgery. Repair of omphalocele defect was performed in the newborn without any additional anomaly.

Results: Concomitant congenital anomalies of the other systems are also seen in more than $40 \%$ of the babies born with an omphalocele. Prognosis is better in the isolated omphaloceles. It is important to make differential diagnosis between omphalocele and gastroschisis. In this case, abdominal visceral organs are floating in the amniotic fluid. Although umbilical cord was normal at birth, abdominal visceral organs protruded through right or left abdominal wall defect. Omphalocele is covered by a membrane consisting of small and large intestines frequently.

Conclusion: Prenatal diagnosis of omphalocele can be made by using ultrasonography and it is important to investigate the presence of additional anomaly for prognosis. In the management of delivery of the cases diagnosed to have omphalocele, gynecologists and pediatric surgeons should collaborate with a multidisciplinary approach to prevent and treat the neonatal complications.

Keywords: Omphalocele, gastroschisis, prenatal diagnosis.

\section{PP-073}

\section{Contribution of fetal weight estimation in twin pregnancies: a prospective study}

Karoui Abir, Dimassi Kawther, Bouriel Ines, Amel Triki, Mohamed Faouzi Gara

Department of Obstetrics and Gynecology, Mongi Slim Hospital, La Marsa, Tunisia

Introduction: Ultrasonography is an essential tool in the management of twin pregnancies. Fetal weight estimation is useful to anticipate neonatal care in case of prematurity, growth restriction or growth discordance.

Objective: The aim of this study was to evaluate the accuracy of ultrasound fetal weight prediction in twin pregnancies.

Methods: Fifty patients with an ultrasonography within 4 days before birth were studied. Estimated fetal weight (EFW) was compared with birth weight (BW). Fetal hypotrophyand growthdiscordance superior or equal to $25 \%$ between the first and the second twin were recorded.

Results: Absolute differences between EFW and BW were similar for both twins (155 g [72-337.5] for T1 and $150 \mathrm{~g}$ [100-266.5] for T2). Mean absolute percentage error was $7.7 \%(2.5-14.76 \mathrm{gr})$ for $\mathrm{T} 1$ and $7.55 \%(3.37-11.85 \mathrm{gr})$ for $\mathrm{T} 2$. Mean absolute percentage error was superior to $10 \%$ for $20 \%$ of T1 and $18 \%$ of T2with no significant difference. Chorionicity, gestational age as well as fetal presentation did not influence fetal weight estimation T1 correlation coefficient is 0.87 ; T2 correlation coefficient is 0.89 . PN de $\mathrm{J} 1=$ $415.57+0.846^{*} \mathrm{PFE}$ de $\mathrm{J} 1$. PN de $\mathrm{J} 2=65.68+0.963 * \mathrm{PFE}$ de $\mathrm{J} 2$. Ultrasonography in the diagnosis of hypotrophy had a sensitivity of $90.32 \%$, a specificity of $78.94 \%$, a positive predictive value (PPV) of $83.5 \%$ and a negative predictive value (NPV) of $87.5 \%$. For the prediction of growth discordance, sensitivity was $76.9 \%$, specificity $81.8 \%$, PPV $50 \%$ and NPV $93.5 \%$.

Conclusion: Fetal weight can be accurately predicted in twin pregnancies. The contribution of ultrasonography in the diagnosis of hypotrophyand growth discordance is mainly due to a high NPV.

Keywords: Twin pregnancies, weight estimation.

\section{PP-074}

\section{Bipolar cord coagulation for neural tube defect and hydrosephaly in monochorionic diamniotic twins: a case report}

Ebru Dikensoy, Yasemin Dokuzoğlu Tanın, Reyhan Gündüz, Emre Akçil, Erdoğan Koca

Department of Obstetrics \& Gynecology, Medical Faculty, Gaziantep University, Gaziantep

The angioarchitecture of a monochorionic placenta is characterised by the presence of vascular connections between the circulations of the fetuses. The combination of number and type of vessels involved are unique to each pregnancy. The net effect is a dynamic bidirectional flow of blood between the co-twins. The presence of vascular connections creates unacceptable risks for using intra-fetal injection as a method for selective termination. When intrauterine death of one fetus occurs, the risk of death or cerebral damage in cotwin increases, likely because of acute exsanguination of the survivor into the lower pressure circulation of the dead twin through the placental anastomoses. Hypotension and hypoxia then lead to under-perfusion of the co-twin, causing tissue damage. In complicated monochorionic pregnancies, selective termination can be advocated as a therapeutic alternative to termination of the entire pregnancy. A variety of occlusive techniques have been used to achieve selective termination in 
monochorionic twin pregnancies, including bipolar cord coagulation. laser cord coagulation, and cord ligation. These techniques require the insertion of a relatively large diameter instrument through a $3.8 \mathrm{~mm}$ operative sleeve into the amniotic sac of the fetus to be terminated, creating a significant risk for membrane complications, haemorrhage, and preterm labor. Bipolar cord coagulation is preferred when enough amniotic fluid allows for insertion sleeve and deployment of the device. Monoamniotic twin cases are best performed with bipolar cord coagulation because of the need for cord transection to prevent complications from cord entanglement once the termination is completed. If the cord segment to the demised fetus is left intact, it can act as a weight that can cause compression of the surviving twins cord. Our patient is monochorionic diamniotic twins in 18th weeks. One fetus has NTD and hydrocephaly. We performed bipolar cord coagulation for that fetus in this week. The easiest nontransplacental access was chosen, with the aim of approaching the umbilical cord at a 45 degree angle at its placental insertion. The cannula with the trocar was inserted into pocket of amniotic fluid that allowed the forceps to be opened and the cord grasped. Coagulation was performed at power settings of $50 \mathrm{~W}$ applied for $10-30$ seconds. The procedure was deemed successful when echogenic bubbles were seen coming from the cord and cord itself appeared hyperechogenic. Confirmation of the occlusion was also provided by the absence of detectable color Doppler flow in the distal part of the cord, with at least $2 \mathrm{~min}$ of persistent asystole. The entire procedure lasted for 15-40 min. Cardiac activity of the co-twin monitored during the entire procedure and immediately afterwards, and MCA-PSV was also recorded to detect fetal anemis. Cerebral MRI of the survivng twin was also normal 2 weeks after the procedure. The patient is in 24.th weeks of pregnancy.

Keywords: Monochorionic twins, fetal discordant anomaly, bipolar cord coagulation.

\section{PP-075}

\section{Cystic hygroma in one gemel: diagnosis and outcome of pregnancy}

Mirjana Bogavac ${ }^{1}$, Stevan Milosevic ${ }^{1}$, žaklina Tatic Stupar ${ }^{1}$, Marijana Šašic ${ }^{2}$, Zoran Novakovic ${ }^{3}$

${ }^{1}$ Department of Obstetrics and Gynecology, Clinical Center of Vojvodina, University of Novi Sad Medical Faculty, Novi Sad, Serbia; ${ }^{2}$ Institute of Railway, Belgrade, Serbia; ${ }^{3}$ University of Novi Sad Medical Faculty, Novi Sad, Serbia

Introduction: Cystic hygroma is seen as abnormally enlarged nuchal thickness mostly with septa inside and filled with liquid-lymph usually seen during late first or second trimester of pregnancy. This finding, especially seen during the first trimester of pregnancy is highly associated with chromosomal abnormalities, most commonly with Turner's syndrome, but however trisomies 21, 18 and 13 are also prevalent.

Objective: The aim was the presentation of successfully completed pregnancy by $\mathrm{C}$-section, in a patient with prenatally diagnosed cystic hygroma in diamnotic-dichorionic twin pregnancy (DCDA) after selective embrioreduction in 15 week of gestation (WG).

Methods: It is a presented case of successfully completed pregnancy by $\mathrm{C}$-section complicated with gestational diabetes, hypertension and embrioreduction in $15 \mathrm{WG}$ due to confirmed anomaly in DCDA twins.

Case: Patient 33 years old and 12WG with confirmed pregnancy of DCDA twins was admitted into the Clinical Center of Vojvodina, Department of Obstetrics and Gynecology Novi Sad due to a suspected anomaly of one fetus. During ultrasouund examination twin pregnancy DCDA in $12 \mathrm{GW}$ was noted wherein CRL of one fetus was $44 \mathrm{~mm}$ with regular heart action and septated cystic hygroma in transversal cross-section to 13 $\mathrm{mm}$. The other fetus: CRL 60mm with normal morphology and regular heart action. After two weeks the patient was admitted into the clinic in $15 \mathrm{WG}$ for a scheduled intervention-selective embrioreduction. The intervention was successful. The patient was disharged home with advise to report in two weeks for early amniocentesis of other vital fetus. The patient did not want amniocentesis to be performed. During ultrasound control in $30 \mathrm{WG}$ polyhydramnion was diagnosed and because of positive family history of diabetes glucose stress test was performed. Diabetes diet was introduced of 2200 $\mathrm{kCal}$. Due to hypertension a therapy with methyldopa was administered in $36 \mathrm{WG}$ to which the patient reacted well. The patient was admitted into the clinic due to regular contractions, and considering the ultrasoundly estimated weight of fetus of $3800 \mathrm{~g}$, gestational diabetes, occurrence of variable decelerations on CTG recordings it was decided on the operative completion of pregnancy. A female baby was born, weight $3760 \mathrm{~g}$ and $21 \mathrm{~cm}$ lenght, Apgar score 9/10. Postoperative course was well, the patient was discharged home four days after the operation together with her child.

Conclusion: Case study points out to the importance of chorionicity being diagnosed as early as possible in twin pregnancies. Case study indicates the importance of prenatally diagnosed anomaly in one twin, and also success of ultrasound invasive procedures in treatment of twin pregnancy with anomaly of one fetus and healthy other fetus. The pregnancy was completed successfully in term with expulsion of a healthy newborn, and after a series of ultrasound examinations and diagnostic procedures.

Keywords: Twins, cystic hygroma, selective embrioreduction. 


\section{PP-076}

\section{Trisomy 21 presenting with megacystis in the first trimester: a case report}

\section{Elif Gül Yapar Eyi, Şahin Özkan, Deniz Oluklu}

Zekai Tahir Burak Women's Health Education \& Research Hospital, Ankara, Turkey

Objective: Fetal megacystis has been reported to occur in $1 / 1500$ pregnancies and defined by a longitudinal bladder diameter of $7 \mathrm{~mm}$ or more. If the longitudinal bladder diameter is $7-15 \mathrm{~mm}$ there is a risk of about $25 \%$ that the fetus will have a chromosomal defect. If the bladder diameter is $>15$ $\mathrm{mm}$, the risk of chromosomal defects is about $10 \%$. We herein present the sonographic and Doppler findings in a fetus with megacystis and trisomy 21.

Case: A 31-year-old woman, an agricultural engineer, at her first pregnancy has had chemical exposure for 5 years had an operation of patent ductus arteriousus at one and a half year of age and having a sibling with Down Syndrome was referred to antenatal clinics at 13 weeks of gestation due to increased risk of combined test. Nuchal translucency at a crown-rump length(CRL) of $51 \mathrm{~mm}$ was reported to be 3.3 . $\mathrm{mm}$ at $11+4$ weeks of gestation. Pregnancy associated plasma protein $\mathrm{A}(\mathrm{PAPP}-\mathrm{A})$ level was $0.35 \mathrm{MOM}$ and free $\beta \mathrm{hCG}$ level was $1.43 \mathrm{MOM}$ Her combined risk was calculated to be under $1 / 50$ at 11 th week. Sonographic examination revealed longutidinal bladder diameter of $16 \mathrm{~mm}$ with echogenic and enlarged kidneys, absent nasal bone, abnormal ductus venosusu flow, echogenic cardiac focus and tricuspid regurgitation. Chorion villus sampling was performed and karyotype analysis revealed trisomy 21 . Patient and her husband were counselled and pregnancy termination with vaginal misoprostol was performed at 14 weeks.

Results: The fetal urinary tract can be visualized ultrasonically from 11 weeks onwards, allowing recognition of megacystis at 11-14 weeks, which warrants comprehensive risk assessment of possible underlying chromosomal aneuploidy. As the evaluations of the nasal bone, ductus venosus, tricuspid valve function, frontomaxillary facial angle, hyperechogenic bowel, intracardiac echogenic focus, and renal pelvis fullness can become part of the 11- to 13 (+6)-week screening test if the imaging protocols are standardized, these markers and detection of fetal megacystitis prompt us to evaluate fetal karyotyping, by using either invasive techniques or fetal DNA from maternal blood.

Conclusion: Fetal megacystis with increased NT is a severe condition when diagnosed in early pregnancy for chromosomal abnormality and this finding may be an early sign of Trisomy 21.

Keywords: Megacystitis, trisomy 21.

\section{PP-077}

First trimester sonographic findings of alobar holoprosencephaly with cyclopia, proboscis, omphalocele, single ventricle in a fetus with trisomy 13

Elif Gül Yapar Eyi, Şahin Özkan, Fatma Salih

Zekai Tahir Burak Women's Health Education \& Research Hospital, Ankara, Turkey

Alobar holoprosencephaly with cyclopia is a rare lethal congenital anomaly frequently accompanied by other malformations and characterized by large variations in incidence. It is included into the disorders of formation of the structures derived from the "mediobasal prosencephalon". The prosencephalon is the anterior end of the neural tube and consists of the telencephalon which gives rise to the cerebral hemispheres and striatum, and the diencephalon which gives rise to thalamus, hypothalamus globus pallidus and eye. Several malformations showing various severity belong to this category and the the most serious defect from this group of anomalies; prosencephalon has not divided into two parts supposed to become the hemispheres is alobar holoprosencephaly with cyclopia: single eye, absent nose, supraorbital proboscis. We herein present the sonographic and postmortem findings of a 13 weeks fetus with alobar holoprosencephaly with cyclopia and prosbiscus from a 37 year old woman G6 P:5 woman. with no known exposure to teratogens and drugs. Single ventricule and omphalocele were also detected and karyotype analysis revealed trisomy 13.

Keywords: Trisomy 13, holoprosencephaly, cyclopia.

\section{PP-078}

The role of ultrasonographic markers for prediction of first trimester pregnancy outcomes

Ebru Ersoy, Ali Özgür Ersoy, Esra Yaşar Çelik, Sibel Özler, Metin Altay, Orhan Gelişen

Etlik Ziibeyde Hanm Women's Health Training \& Research Hospital, Ankara, Turkey

Objective: Examining certain ultrasonographic parameters during the first trimester of pregnancy and determining their role to predict first trimester outcome.

Methods: It's a prospective cohort study including 210 pregnant women that admitted to Ankara Etlik Zübeyde Hanım Women's Health Training and Research Hospital Antenatal Care Unit. Patients' gestational age were calculated according to last menstrual period. Embryonic heart rate and Yolk sac diameter were evaluated ultrasonographically during first 12 weeks of pregnancy and then patients who have lost their conceptus were confronted with non-aborted 
ones at the end of 12 weeks of pregnancy. Mono-directional variance analysis was used to determine the correlation between Yolk sac diameter and menstrual age, also between embryonic heart rate and menstrual age. (Menstrual Age) minus (Mean Sac Diameter related Age)', 'Yolk Sac Diameter/Mean Sac Diameter ratio', '(Mean Sac Diameter) minus (Crown-Rump Length)' were compared between 'the group of first trimester aborted' and 'the group of first trimester non-aborted' with Independent T-Test. Regression analysis was performed for parameters, suitable graphs and curves were drawn. Fisher Exact Test was performed to determine the decisiveness of 'Embrional Heart Rate $<120 /$ minute' and '(Menstrual Age) minus (Mean Sac Diameter related Age)' values.

Results: Yolk sac diameter was decisive to predict abortion except 6-8 weeks of first trimester pregnancy ( $\mathrm{p} \leq 0.001)$. Yolk sac diameters were increasing as gestational sac diameter and CRL (Crown-Rump Length) increased. Embryonic heart rate (lesser than 120 pulse per minute) was substantially decisive to predict abortion in all groups $(\mathrm{p}<0.001)$. The difference between 'Menstrual Age' and 'Mean Sac Diameter related Age' was substantially different between groups of aborted and non-aborted in the first trimester of pregnancy $(\mathrm{p}=0.024)$.

Conclusion: Embryonic heart rate had a progressive rise in women that brought to completion of a healthy first trimester. Embryonic bradycardia can be used as a prognostic factor to predict adverse pregnancy outcomes. Yolk sac diameter and absence of yolk sac parameters needs further investigations. As the difference between 'Menstrual Age' and 'Mean Sac Diameter related Age' increased, the abortion risk also increased. Further investigations should be performed to make a flat decision.

Keywords: Marker, first trimester, embryonic heart rate.

\section{PP-079}

\section{The correlation between gestational age and the length of the clavicle}

Fazıl Avc1, Salih Serin, Murat Bakacak, Önder Ercan, Bülent Köstü, Deniz Cemgil Arıkan

Department of Gynecology and Obstetrics, Faculty of Medicine, Siitçii Imam University, Kabramanmaras, Turkey

Objective: To evaluate correlation between gestational week and fetal clavicle length (CL) until 27 week's gestation.

Methods: This study was cross-sectional study of patients between 14 and 27 weeks' gestation. Inclusion criteria was well-established dates (confirmed with early ultrasound), singleton, non-anomalous fetuses, and intact amniotic mem- branes with enough amniotic fluid. Sonographic measurements such as biparietal diameter (BPD), head circumference (HC), abdominal circumference (AC), femur length (FL), humerus length (HL), estimated fetal weight (EFW), clavicle lenght (CL) and cerebellum diameter. Pearson's correlation and P-values for the relationships between CL and other biometry measurements were estimated.

Results: We evaluated 77 patients in our clinic. All attempts assessing the CL were successful. Mean maternal age was $29.11 \pm 5.85$ years, median gravidity 3 (range $0-10$ ), and median parity 2 (range 0-5). Fetal CL, BPD, HC, AC, HL, FL, fetal weight and cerebellum diameter were correlated significantly and strongly with gestational week and also Pearson correlation values were $0.965,0.951,0.917,0.964,0.959$, $0.965,0.925$ and 0,954 , respectively (all $\mathrm{p}<0.01$ ).

Conclusion: We suggest that the clavicula diameter as millimetres by ultrasonography was found significantly positive correlation with gestational weeks. We suggest the $1 \mathrm{~mm}=1$ week rule should be used because of anomaly of cerebellum and vermis and also for patients had unknown last menstrual day. The lenght of clavicula may use to detect gestational week.

Keywords: Clavicle, fetal biometry, gestational age.

\section{PP-080}

\section{Ultrasound management of uncommon ectopic pregnancy}

Meriem Ajroudi, Kaouther Dimassi, Fatma Douik, Nizar Ben Aissia, Amel Triki, Mohamed Faouzi Gara

Department of Obstetrics and Gynecology, Mongi Slim Hospital, La Marsa, Tunisia

Introduction: With the improvements in ultrasound equipment as well as the easy access to quantitative beta-human chorionic gonadotropin ( $\beta$-hCG), the timing of diagnosis of ectopic pregnancy has moved to the early part of the first trimester. Ectopic pregnancies of unusual location are encountered much less frequently, but are perhaps more morbid. The treatment of these unusual ectopic gestations may not be as common place as treatment of tubal pregnancies, but with early diagnosis and effective planning, their treatment can be equally as effective.

Objective: Describing cases of uncommon ectopic pregnancies which were managed with ultrasound-guided local injection of $\mathrm{KCl}$, followed by intramuscular injection of MTX if appropriate. Explaining the modalities of the conservative treatment and detailing the clinical biological and ultrasound monitoring.

Methods: It's a retrospective study over a period of 3 years which included patients presenting an ectopic pregnancy on 
uncommon implantation site and whose treatment was conservative. The medical treatment consisted in injection of $\mathrm{KCl}$ in the gestational sac by ultrasound guidance when the pregnancy was scalable. Then we proceed to one or more intramuscular Methotrexate injections in order to complete the treatment.

Results: During the study's period we collected 04 observations of unusual ectopic pregnancies treated medically. There was an interstitial pregnancy in 2 cases: a cervical pregnancy in one case and a cesarean scar pregnancy in the other case. The diagnosis was made by ultrasound in all cases and confirmed by MRI in 2 cases. (Details will be shown in the poster). The medium term at diagnosis was 6 weeks of amenorrhea. Pregnancies were evolving with heart activity in 2 cases. The average number of injection of MTX was 1.3. In all of our cases, ectopic pregnancies have been successfully managed without surgical intervention or anesthesia using ultrasoundguided puncture and injection of $\mathrm{KCl}$.

Conclusion: The use of advanced ultrasonography in combination with ultrasensitive serum b-hCG assays should lead to early diagnosis of such pregnancies. Early diagnosis and use of multiple modalities can reduce morbidity and mortality in cases of ectopic pregnancy with unusual location and they can be successfully managed without surgical intervention through local injection of $\mathrm{KCl}$.

Keywords: Ectopic, pregnancy.

\section{PP-081}

\section{Fertility and pregnancy rate in patients with septate uterus like primary sterility and with habitual abortions before and after hysteroscopic interventions}

Aida Kumnova, Qamil Hamza, Luljeta Canhasi, Butrint Kusari, Ilir Kadiri

Regional Hospital Isa Grezda, Gjakova, Kosovo

Introduction: Uterine malformations result from the development of Mullerian ducts throw embryogenesis. Symptoms are ranged from amenorrhea, infertility, habitual abortions. Prevalence of uterine anomalies are $6.7 \%$. Its presence is associated with poor reproductive performance, including high incidence of first and second trimester abortion, preterm delivery (often as a result of premature rupture of the membranes), as well as abnormal presentations and increased caesarean section rates (Heinonen et al., 1982; Buttram, 1983; McShane et al., 1983). Here it will be presented the last uterine classification of uterine anomalies which was reached on 28.08.134 from ESHRE/ESGE Consensus work of two societies of gynecologists and which extended 3 years.
Objective: To evaluate the effectiveness of hysteroscopy resection of uterine septum in patients with primary sterility and habitual abortions.

Methods: Evaluated 25 patients who had the septate uterus, primary fertility and habitual abortions. With habitual abortions are understood two abortions consecutive. In research was included different age of patients. With the mini hysteroscopy Richard Wolf and scissors are resected the septum under the short intravenous anesthesia. Intervention can be done also without anesthesia but the will of our patients was with anesthesia. The intervention procedure extended 20 till $45 \mathrm{~min}$. The work with mini hysteroscopy started on $01 / 01 / 13$ till $31 / 12 / 13$. From the work with hysteroscopy started on 01.06.13 and evaluation of patients was till 31.12.13. From the total number of patients which have done the intervention 6 patients have given birth 6 of them are in the third trimester of pregnancy. The pregnancy rate and the live birth rate is $48 \%$ and if we count the live birth the total success is $24 \%$. From the total number of patients which have given birth are 6 patients and 6 patients are in the third trimester of pregnancy.In percent's are $44 \%$. Two patients of the total number have done the resection of septum to be prepared for IVF because of ovarian insufficiency are 3 patients. The main outcome measures were clinical pregnancy and live birth rates.

Conclusion: From the results which are achieved it is evidenced that the hysteroscopy intervention in patients with septate uterus fertility is increased the clinical pregnancy rate and the live birth rate.

Keywords: Hysteroscopy, uterine septum, habitual abortions.

\section{PP-082}

\section{Extremely large tubal ectopic pregnancy with tubal torsion: an extraordinary case report}

Ibrahim Polat, Ali Ekiz, Burak Ozkose, Batuhan Ustun, Alev Atis Aydin, Ali Gedikbasi

Kanuni Sultan Suleyman Training and Research Hospital, Istanbul, Turkey

Objective: Ectopic pregnancy is defined as the implantation of a fertilized egg anywhere outside the uterine cavity. The incidence of ectopic pregnancy is estimated to be between $1 \%$ to $2 \%$ of all pregnancies. We report a big tubal ectopic pregnancy case with tubal torsion.

Case: A 36-year-old woman, gravida 4, parity 2, curettage 1 admitted to Kanuni Sultan Suleyman Training and Research Hospital emergency room with severe abdominal pain. She had mild vaginal bleeding and nausea. Physical examination revealed tenderness of abdomen. The patient's blood pressure 
was $90 / 60 \mathrm{mmHg}$, pulse rate was $120 \mathrm{beat} / \mathrm{min}$, respiratory rate and body temperature was $16 / \mathrm{Min}, 37.60 \mathrm{C}$ respectively. Generalized abdominal tenderness was noted during palpation and speculum examination revealed slight bleeding through cervical os. Trans abdominal sonography revealed a gestational sac with a live fetus measured at 12 th gestational week, located at the superior surface of the uterine fundus. Ectopic pregnancy mass was measured $8 \times 5 \mathrm{~cm}$ on widest diameter. After the first emergent investigation, decision for an operation had been given with the pre-diagnosis of an abdominal pregnancy or ruptured ampullary pregnancy. Due to hemodynamic instability and gross abdominal bleeding, laparotomy was decided. Intraoperatively 1 liter of hemoperitoneum was seen. In the right fallopian tube, an ectopic pregnancy which is $75 \times 45 \mathrm{~mm}$ in size and with the fallopian tube torsed one complete round. When salpingectomy material was examined, the fetus' crownrump length was measured 59 mm's, which is competible to 12 weeks and 3 days of gestational age.

Conclusion: It is possible for ampullary ectopic pregnancies to progress until 13th week of gestation. Torsional involvement caused by the excessive growing of the mass can contribute to worsening of the pain in the groin. The differential diagnosis with abdominal pregnancies can be supported by MRI but operational diagnosis may be considered as urgent laparotomy is crucial in some cases

Keywords: Ectopic pregnancy, tubal torsion, abdominal pregnancy.

\section{PP-083}

\section{Early second trimester cesarean scar pregnancy presented with preterm premature rupture of membranes: a case report}

İbrahim Polat ${ }^{1}$, Semra Yuksel ${ }^{1}$, Volkan Kasımogulları ${ }^{2}$, Merve Talmac ${ }^{1}$, Sebile Cekic ${ }^{1}$, Ali Ekiz ${ }^{1}$

${ }^{1}$ Kanuni Sultan Suleyman Training and Research Hospital, Istanbul, Turkey; ${ }^{2}$ Bagcular Training and Research Hospital, Istanbul, Turkey

A 23-year-old woman, gravida 2, para 1 was admitted to the emergency department of our institute with preterm premature rupture of the membranes when she was 16 weeks' pregnant. The patient had undergone one prior cesarean delivery 5 years previously. She had an early ultrasound report of 12 weeks' gestation at another hospital. She complained of mild suprapubic pain with irregular per vaginal spotting since 8 weeks' gestation. On sterile speculum examination, amniotic fluid was draining from the cervix. Initial transabdominal ultrasound was performed at our emergency unit showed a live single fetus and reduced liquor (anhidrosis). The patient was hospitalized for antibiotic treatment and follow up. The following day, transvaginal ultrasound in a sagittal position showed clear uterine cavity, empty cervical canal with a live fetus compatible with its gestational age on the uterine scar of a prior pregnancy. When a gentle pressure was applied by endovaginal probe, the fetus didn't displace from its position at the level of the internal os (negative sliding organ sign). Based on these findings, a diagnosis of cesarean scar pregnancy was determined. After that transabdominal sonography was performed with a well-distended bladder confirmed cesarean scar pregnancy, the thickness of the myometrium between the bladder and the sac very thin to an immeasurable extent. There were a loss of hypoechoic appearance of retroplacental zone and lacunes in placenta, placenta accreta was suspected. A laparotomy was performed and the uterus was incised over the ballooning lower uterine segment which was stuck to the bladder. The products of conception were immediately removed from the lower uterine cavity. A placenta previa and focal placenta accreta $(30 \%)$ were observed. The placenta was excised together with the surrounding myometrium and the bleeding area on the lower uterine segment was sutured. The bilateral uterine arteries were ligated due to failing to provide adequate bleeding control with sutures. At the end an intracavitary Foley balloon (30cc) was placed to tamponade the uterine cavity and control minimal bleeding. The hysterotomy incision was closed, and a drain was left in the pelvis in order to monitor potential blood loss. The fully extracted placenta was transferred to the pathology laboratory for further study. Histopathology showed placental tissue within the fibromuscular tissue of the old cesarean section scar. The patient received 4 units of blood transfusion totally and antibiotic therapy. Her drain and intracervical balloon were removed on postoperative day 1 . Her subsequent clinical course was uneventful. She was discharged on postoperative day 7 without any complications and followed for 3 months, and had used oral contraceptives.

Keywords: Cesarean scar pregnancy, placenta accreta, ectopic pregnancy.

\section{PP-084}

\section{Cervical collagen and hydroxy-prolin ratios: physiologic changes of collagen during first trimester}

Asuman Gedikbasi ${ }^{1}$ Ali Gedikbasi ${ }^{2}$, Oguz Arslan ${ }^{2}$, Murat Giris ${ }^{3}$, Semra Dogru Abbasoglu ${ }^{3}$ Ali İsmet Tekirdag

${ }^{1}$ Department of Biochemistry, Istanbul Bakurköy Sadi Konuk Research Hospital, Istanbul, Turkey; ${ }^{2}$ Department of Obstetrics \& Gynecology Istanbul Kanuni Sultan Suleyman Research Hospital, Istanbul, Turkey; ${ }^{3}$ Department of Biochemistry, Istanbul Medical School, Istanbul University, Istanbul, Turkey

Objective: The cervical tissue consists mainly of an extracellular matrix rich in collagen; important fort the biomechani- 
cal properties. During normal gestation, the biomechanical strength of the cervix is determined by the collagen concentration. This study demonstrates the differences and changes of cervical collagen in first trimester abortions and its relation with age and parity.

Methods: Cervical punch biopsies were obtained from 59 patients divided into two groups: first trimester abortion group (study group; $\mathrm{n}=45$ ), and patients with cervical biopsy due to gynecologic reasons (control group; $n=14$ ). According to their gestational weeks, 45 first trimester pregnant women (median age $=28.2)$ were divided into 3 groups $(<7$ weeks, 7-9 weeks, $>9$ weeks). Biochemical testing was performed and collagen quantity (as $\mu \mathrm{g} \mathrm{OH}$-prolin/mg dry weight) was determined. Hydroxyproline was measured in cervix tissue by the method of Switzer. Finally, the results of collagen and its relation with age and parity were investigated.

Results: Collagen quantity was lower in the first trimester pregnant women group $(13.06 \pm 4.17 \mu \mathrm{g} \mathrm{OH}$-prolin $/ \mathrm{mg}$ tissue) $(\mathrm{p}=0.0001)$ compared with the control group $(24.48 \pm 12.87)$. Moreover, when data were adjusted for gestational weeks, no difference in collagen quantity was found between $<7$ weeks and control groups $(17.01 \pm 1.11 \mu \mathrm{g} \mathrm{OH}-$ prolin/mg tissue $)(\mathrm{p}=$ $0.047)$. However the collagen quantities of 7-9 weeks $(12.07 \pm 3.85 \mu \mathrm{g}$ OH-prolin/mg tissue) and $>9$ weeks $(11.16 \pm$ $4.39 \mu \mathrm{g} \mathrm{OH}-$ prolin/mg tissue) groups were statistically lower compared with the control group $(\mathrm{p}=0.0001)$. Furthermore, the results of first trimester pregnancy group were evaluated for age and parity. Lineer regression analyses shows that collagen increases with age and decreases with parity.

Conclusions: Our study shows that, the collagen content of cervix started to decrease as early as first trimester of gestation. We observed that, from the beginning of 7 th gestational week, cervical collagen starts to decrease. In accordance with the literature knowledge, collagen quantity increases with age and with regard to parity.

Keywords: Cervical collagen, first trimester physiologic changes.

\section{PP-085}

\section{The distribution of nuchal translucency measurements in singleton pregnancies}

Burcu Artunç Ülkümen, Halil Gürsoy Pala, Yıldız Uyar, Yeşim Baytur, Faik Mümtaz Koyuncu

Division of Perinatology, Department of Obstetrics \& Gynecology, School of Medicine, Celal Bayar University, Manisa, Turkey

Objective: In this study, the evaluation of the mean values in the NT measurements of low-risk Turkish population is aimed. Also, the effect of gestational week, crown-rump length (CRL), parity and maternal weight on NT measurements is evaluated.

Methods: Between March 2013 and June 2014, 351 singleton pregnancies, who admitted to perinatology outpatient clinic for 11-14 week screening, are included in the study. NT, CRL measurements, gestational week, maternal weight, parity characteristics are analysed. 351 subjects are divided into 4 groups according to the CRL measurements: Group I for CRL 45-54 mm (n=62); Group II for CRL 55-64 mm $(\mathrm{n}=133)$; Group III for CRL 65-74 mm $(\mathrm{n}=115)$ and Group IV for CRL 75-84 mm ( $=41)$. The groups are compared according to maternal age and NT measurements.

Results: The mean maternal age was $28.76 \pm 5.51$, gestational week was $12.29 \pm 0.69$, CRL measurements were $63.69 \pm$ $9.07 \mathrm{~mm}$, mean NT values were $1.23 \pm 0.48 \mathrm{~mm}$. There was no significant difference regarding the maternal age and NT measurements $(\mathrm{p}=0.817$ and 0.072 respectively). NT values were significantly correlated with CRL $(r=0.232 ; \mathrm{p}=0.001)$ and gestational week $(\mathrm{r}=0.203 ; \mathrm{p}=0.001)$. There was no relation between NT and gravida, parity and maternal weight.

Conclusion: First trimester screening has been commonly used in prenatal medicine. NT is a part of first trimester screening. NT measurement must be performed according to the stanrdardised measurement techniques. The management of the results should be organised according to the algorithms.

Keywords: Nuchal translucency, crown rump length, first trimester screening.

\section{PP-086}

\section{Sirenomelia, which was diagnosed in early pregnancy: case report}

Selçuk Yetkinel ${ }^{1}$, Tayfun Çok ${ }^{1}$, Bermal Hasbay ${ }^{2}$, $\underline{\text { Hakan Kalayci }}{ }^{1}$, Halis Özdemir ${ }^{1}$, Ebru Tarım ${ }^{1}$

${ }^{1}$ Department of Obstetrics and Gynecology, Baskent University Adana Hospital, Adana, Turkey; ${ }^{2}$ Department of Pathology, Başkent University Adana Hospital, Adana, Turkey

Objective: Sirenomelia is rare syndrome, which included fusion of the lower extremities, musculoskeletal abnormalities, urogenital and gastrointestinal abnormalities. It develops as result of serious defects in the development of the posterior caudal blastema. It was seen at 1/60,000-1/100,000 births. Usually it is mortal and was seen more often at twin pregnancy and female fetuses. In the literature, alobar holoprosencephaly, lumbar myelomeningocele has been reported in association with sirenomelia. In this text, we report a pregnant with sironemilia, which was examined in our clinics.

Case: 33 years old, 13 weeks of pregnancy. At sonography, CRL was $52 \mathrm{~mm}$ (12 weeks 5 days) and nuchal translucency 
$1,95 \mathrm{~mm}$. Bilateral lower extremities were seen adherent. Fetus had two femurs and continued with one tibial bone. Bilateral kidney and bladder was not seen and we observed one umblical arter. Mortality of this disease was descibed to patient. Termination decision was made at the request of the family. After termination, X-Ray was taken and it supported sonographic findings. In autopsy, fusion of the lower extremities, low-set ears, imperforate anus, absence of internal and external genital organs, dysmorphic kidney tissue, gastroschisis, left foot oligodactyly was observed.

Conclusion: Sirenomelia is a serious clinical entity that is incompatible with life mostly due to severe renal anomalies. Because of mortality, decision-making termination is very important for parents.

Keywords: Sirenomelia, first trimester, ultrasound.

\section{PP-087}

\section{Cesarean scar pregnancy}

Şenol Şentürk, Ülkü Mete Ural, Mehmet Kağııçı, Gülşah Balık, Figen Kır Şahin

Department of Obstetrics and Gynecology, Recep Tayyip Erdogan University School of Medicine, Rize, Turkey

Objective: Cesarean scar pregnancy (CSP) is a rare type of ectopic pregnancy. Without proper treatment in time, CSP may cause major bleeding, uterine rupture, and other lifethreatening complications. Here, it was aimed to present a case of CSP occurring in an adult woman and its management.

Case: A 39-year-old G3P3 patient presented to our clinic with complaint of a delayed menses for 2 weeks. She stated that she had her previous deliveries with cesarean sections. The physical examination demonstrated that vagina and cervix were in normal appearance and bimanual vaginal examination revealed that cervical motions were painless. Transvaginal and suprapubic ultrasound revealed that the 6 week 3 days gestational sac with FHB according to CRL (crown-rump length) was implanted at the site of the previous cesarean section scar. The serum level of the $\beta$-hCG was $12388 \mathrm{mIU} / \mathrm{ml}$ and hemoglobin level was $12,2 \mathrm{~g} / \mathrm{dl}$. A diagnosis of a CSP was made with these findings. The patient was informed. Preoperative preparation of the patient was performed after obtaining the informed consent of her spouse. Dilation and curettage (D\&C) was performed in the operating room. No complication occurred. The patient was discharged after postoperative 3 rd hour.

Results: CSP is one of the rarest forms of ectopic pregnancy, but incidence of CSP has been rising to be about $1 / 2000$ normal pregnancies due to the increasing number of cesare- an section deliveries. Treatment modalities of CSP include methotrexate administration (directly or systemically), wedge resection using either laparotomy or laparoscopy, Dilatation \&Curettage, Curettage with a hysteroscopy and uterine artery embolization.

Conclusion: In the pregnancies of the patients with a history of uterine scar or scar pregnancy, new localizations of pregnancy should be determined earlier by using transvaginal ultrasound and cesarean scar pregnancy should be kept among the differential diagnoses of these risky pregnancies.

Keywords: Cesarean scar pregnancy, ectopic pregnancy.

\section{PP-088}

\section{Contraception failure with an intrauterine device in a grand multipara woman: an undiagnosed septate uteri}

Raziye Keskin Kurt', Nesrin Atc1 ${ }^{2}$, İlay Öztürk ${ }^{1}$, Oğuz Uyar ${ }^{1}$, Arif Güngören'

${ }^{1}$ Department of Gynecology and Obstetrics, Faculty of Medicine, Mustafa Kemal University, Hatay, Turkey; ${ }^{2}$ Department of Radiology, Faculty of Medicine, Mustafa Kemal University, Hatay, Turkey

Objective: Congenital uterine anomalies are usually asymptomatic. Women having undiagnosed uterine anomaly may have contraception failure. In this case report, we aimed to present a woman having intrauterine device(IUD) and intrauterine pregnancy because of undiagnosed uterine septum.

Case: A twenty-eight years old, G7P6Y6 woman was admitted to our outpatient clinic with a complaint of pregnancy and IUD. Her history revealed that she had pregnancy with IUD again before 3 years ago. Except that, her reproductive history was normal and she had term vaginal births without presentation anomaly. She didn't remember her last menstrual period. String of IUD were not seen in gynecological examination. Her TV-USG revealed that dimensions of uterus were increased and a long uterine septation were observed. While IUD and fluid in mixed echoes were seen in left uterine cavity, there were an viable embryo with a crown rump length of $7.7 \mathrm{~mm}(6 \mathrm{w} 5 \mathrm{~d})$ in the right uterine cavity. There was no pathological findings in adnexial region and douglas pouch. She wished to continue her pregnancy and she were taken follow-up.

Results: The exact incidence of congenital uterine anomalies is difficult to determine since many women with such anomalies are not diagnosed. Uterine anomalies occur in 2 to 4 percent of fertile women with normal reproductive outcomes. The type and frequency of abnormalities were septate uteri (90 percent), bicornuate uterus (5 percent), and didelphic uterus (5 percent). They may cause intrauterine growth 
restriction and presentation anomalies. Pregnancy outcomes reported in such women revealed spontaneous abortion in 21-44 percent, preterm delivery in $12-33$ percent, and live birth in 50-72 percent. This patient had normal reproductive history except a pregnancy with IUD. Intrauterine devices (IUDs) which are easily applied, inexpensive and one of the most reliable contraceptive methods have been used worldwide for contraception. They are frequently placed by midwives in the outpatient setting in developing countries due to easy placement, some complications due to its misplacement occasionally can occur. We conclude evaluation of the pelvis by ultrasound prior to placement of IUDs even in asymptomatic patients may be helpful in identifying uterine anomalies that make IUD placement unsuitable. History of contraception failure with IUD should bring to mind uterine anomaly.

Keywords: Uterine anomaly, contraception failure, intrauterine device.

\section{PP-089}

\section{Angular pregnancy with intrauterine device}

Senol Şentürk, Yeşim Bayoğlu Tekin, Gülşah Balık, Ülkü Mete Ural

Department of Obstetrics and Gynecology, Recep Tayyip Erdogan University School of Medicine, Rize, Turkey

Objective: Angular pregnancy is the rare condition in which the gestational sac is implanted in the lateral angle of the uterine cavity. Here, it was aimed to present a case of angular pregnancy occurring in an adult woman and its management.

Case: A multigravida 26-year-old patient presented to our clinic with complaint of delayed menses. At the vaginal examination of the patient using IUD for 2 years, vagina and cervix were in normal appearances and the string of the IUD was not observed. There was no painful cervical motion at vaginal palpation. A transvaginal ultrasound showed an IUD located in the correct position and a 5 weeks gestational sac without fetal pole implanted in the left side of the uterine fundus with myometrial thinning was determined when the probe was moved toward the left side. Interstitial line (ultrasonographic finding seen in cornual pregnancy) was not observed. The minimum myometrial thickness around the gestational sac was measured to be $4.3 \mathrm{~mm}$. BhCG level was $4421 \mathrm{mIU} / \mathrm{ml}$ and hemoglobin level was $12.1 \mathrm{~g} / \mathrm{dl}$. The diagnosis of angular pregnancy was made with these findings. When the patient was informed about her condition, she said that it was an unintended pregnancy and she wanted to terminate her pregnancy. After receiving the consent of her husband, preoperative preparation was made. IUD was removed first in the operating room and then curettage was performed. No complication occurred. The patient was discharged after postoperative $3 \mathrm{rd}$ hour.

Results: Several reports have been published regarding angular pregnancies. Nevertheless, because of a lack of clinical understanding, angular pregnancy seems not to be considered as a clinical entity and most of the cases are presumably not to be diagnosed. Angular pregnancy is a condition in which nidation occurs in just medial portion of the uterotubal junction of uterine cavity and it is not considered as an ectopic pregnancy. In this case, it is worthy of notice not to confuse it with cornual pregnancy. Conservative approach is preferred in angular pregnancy. Pregnancy continues until delivery of a viable fetus in around $60 \%$ of the cases.

Conclusion: It may be difficult to diagnose the ectopic pregnancy of unusual location. To make a differentiation between intact intrauterine and extrauterine pregnancy by taking the area of uterine ostium of the fallopian tube into consideration may be sensitive. Differantial diagnosis should be made carefully and treatment strategies should be determined accordingly.

Keywords: Intrauterine device, angular pregnancy, ectopic pregnancy.

\section{PP-090}

\section{A case of cervical ectopic pregnancy}

Şenol Şentürk, Mehmet Kağıtçı, Halit Arslan, Figen Kır Şahin

Department of Obstetrics and Gynecology, Faculty of Medicine, Recep Tayyip Erdoğan University, Rize, Turkey

Objective: Cervical ectopic pregnancy (CP) is a rare form of ectopic pregnancy and its incidence is less than $0,1 \%$ of all ectopic pregnancies. Improvement in ultrasound resolution and detection of these pregnancies in the early stages has led to the development of more conservative treatments that attempt to limit morbidity and preserve fertility. We present the case of a 38-year old woman (gravida 1, para 0) who was found to have a cervical ectopic pregnancy at six weeks of gestation.

Case: A multigravida 38-year-old patient (gravida 1, para 0) presented to our clinic with complaint of delayed menses. At the vaginal examination of the patient, vagina and cervix were in normal appearances. There was no painful cervical motion at vaginal palpation. A transvaginal ultrasound showed a 5 weeks gestational sac without fetal pole implanted in the cervix. BhCG level was $4023 \mathrm{mIU} / \mathrm{ml}$ and hemoglobin level was $11.8 \mathrm{~g} / \mathrm{dl}$. The diagnosis of cervical pregnancy was made with these findings. When the patient was informed about her condition, she said that it was an unintended pregnancy 
and she wanted to terminate her pregnancy. After receiving the consent of her husband, preoperative preparation was made. Curettage was performed in the operating room. No complication occurred. The patient was discharged after postoperative 6th hour.

Results: Historically, it was difficult to diagnose CPs and they were identified at later gestational ages compared to the tubal ectopic pregnancies. Since the cervical tissue had a relatively large gestational sac and a highly vascular nature, treatment of CP was often associated with massive hemorrhage from the implantation site, frequently requiring hysterectomy. In a study performed by Matteo et al. in 2006, the authors also used hysteroscopy to successfully resect a $\mathrm{CP}$ (after two cycles of methotrexate treatment in this patient) and they found that the hemostasis could be achieved via direct hysteroscopic coagulation of bleeding vessels.

Conclusion: The principal targets in the management of any cervical ectopic pregnancy are to minimize hemorrhage and preserve future fertility. Therefore, these goals should be kept in mind when choosing treatment modalities.

Keywords: Cervical pregnancy, ectopic pregnancy.

\section{PP-091}

\section{Interest of ultrasound measurement of cervical length in the diagnosis and prognosis of preterm labor}

Chiraz Elfekih ${ }^{1}$, Mohamed Chokri Hnifi', Asma Fatnassi ${ }^{1}$, Faouzia Hmila $^{1}$, Mounira Chaabene ${ }^{2}$

${ }^{1}$ Department of Gynecology \& Obstetrics, Mahmoud el Matri Teaching Hospital, Faculty of Medicine of Tunis, Tunisia; ${ }^{2}$ Department of Radiology, Mabmoud el Matri Teaching Hospital, Faculty of Medicine of Tunis, Tunisia

Introduction: The preterm labor is a common pathology in obstetrics. Note that $9 \%$ of births are premature (2010). The problems of prematurity are the importance of a reliable diagnosis. Endo vaginal ultrasound measurement of cervical length is a way more employees for this purpose.

Objective: Compare the diagnostic and prognostic accuracy of the vaginal ultrasound measurement of cervical length. Specify the positive predictive value of spontaneous preterm birth.

Methods: They are 100 cases of MAP with intact membranes seen in the hospital Mahmoud El Matri. Terms of pregnancy vary between 28SA and 36SA 6 days.

Results: The average age of patients was 28.74 years, mean parity was 1.79 . The medium-term pregnancy is $33 \mathrm{WA} 4$ days with extremes in 28WA and 36WA. On admission the vaginal examination showed a greater than 1 finger dilatation in $69 \%$ of cases with a deletion greater than $50 \%$ in $40 \%$ of cases. Cervical length is in $41 \%$ of patients lower or equal to $25 \mathrm{~mm}$ and in $59 \%$ of patients it is less than $25 \mathrm{~mm}$. The average length of the neck is $26.85 \mathrm{~mm}$. For an equal length of neck $25 \mathrm{~mm}$ negative predictive value is equal to 86.27 with good specificity to 68.75 . For cervical length $20 \mathrm{~mm}$ we have a weak VPN. For cervical length $30 \mathrm{~mm}$ we have a low specificity. Of the 100 women admitted for MAP 28 and 72 gave birth prematurely to an end.

Conclusion: The measurement of the cervix by trans-vaginal ultrasound is a part of everyday obstetric practice. Objectivity and low inter-operator variability allowed such additional examination to become an extension of the clinical examination.

Keywords: Ultrasound, cervical length, preterm labor.

\section{PP-092}

\section{A case of complete hydatidiform mole co-existing with a twin pregnancy after intra-uterine insemination}

Ali Taner Anuk ${ }^{1}$, Turab Janbakhishov' ${ }^{2}$ Ferruh Acet ${ }^{3}$, Ufuk Atlihan ${ }^{4}$, Sabahattin Altunyurt ${ }^{4}$

${ }^{1}$ Department of Obstetrics and Gynecology, Dokuz Eylul University School of Medicine, Izmir, Turkey; ${ }^{2}$ Department of Obstetrics and Gynecology, Baku University School of Medicine, Baku, Azerbaijan; ${ }^{3}$ Department of Obstetrics and Gynecology, Gümizşhane State Hospital, Gïmiişhane, Turkey; ${ }^{4}$ Department of Obstetrics and Gynecology, Dokuz Eylul University School of Medicine, Izmir,Turkey

Objective: The aim of this study is to discuss the management of complete hydatidiform mole co-existing with a twin pregnancy after intra-uterine insemination which is clinically quite rare.

Case: A 33-year-old, gravida 1 para 0 woman presented to our clinic; pregnancy following the intra-uterine insemination in another medical center with echogenic mass ultrasound finding which is more appropriate for mole hydatidiform. The first trimester ultrasound examination revealed a normal fetus and a large cystic echogenic mass in the uterine wall near the placenta. Fetal biometry was compatible with 12 weeks gestation and the echogenic cystic mass size was $4 \times 5$ $\mathrm{cm}$ at front of the uterine wall. The patient was asymptomatic. Her quantitative serum human chorionic gonadotropin was $1191602 \mathrm{mIU} / \mathrm{ml}$. After the two days, the control measurement of serum $\beta$-hCG was $911901 \mathrm{mIU} / \mathrm{ml}$. The chest $\mathrm{X}$-ray was evaluated normal. In magnetic resonance imaging, in the uterine cavity there were two gestational sac and a one live fetus with multicystic echogenic mass was demonstrated. Trophoblastic invasion was not dif- 
ferentiated in the MRI. No other pathology was observed radiologically in the other systems. At the perinatalogy council the patient was evaluated accompanied these findings and the pregnancy termination was decided. After the family's approval, the pregnancy was terminated with dilatation and evacuation. The pathologic material's volume had $600 \mathrm{cc}$ which contained chorionic villi,desidua and gestational endometrium. The analysis of the vesicular tissue demonstrated a diploid (46XX) karyotype consistent with a complete mole. In postoperative period two weeks later, $\beta$-hCG measurement was $250 \mathrm{mIU} / \mathrm{ml}$ and 6 weeks later from the operation $\beta$-hCG level was $30 \mathrm{mIU} / \mathrm{ml}$.

Conclusion: Today in the early period diagnosing the hydatidiform mole co-existing with a twin pregnancy is important. The ultrasound examination is preferred mostly. The continuation of pregnancy, there are also some maternal risks increased such as persistent trophoblastic disease, preeclampsia, spontaneous abortion or premature birth. The risk for persistent gestational trophoblastic disease of twin pregnancy with partial hydatidiform mole and complete hydatidiform mole has been reported to be $4-14$ and $20 \%$. In our case, she had a primary infertility diagnosis during the four years and we considered the maternal health firstly, decided to terminate pregnancy appropriately with the low risk of complication. The final pathologic diagnosis was a twin pregnancy with a complete mole. Approaching to the these patients in the postoperative period has not certain yet in the literaure. However Wee and Jauniaux recommend that an ultrasound examination and measure the $\beta$ hCG level should be repeated twice a month.

The management and the pregnancy termination of this rare case should be planned at the tertiary treatment centres.

Keywords: Complete hydatidiform mole, twin pregnancy, termination.

\section{PP-093}

\section{Successful treatment of cesarean scar pregnancy by curettage after methotrexate therapy}

Yesim Bayoglu Tekin, Ulku Mete Ural, Senol Senturk, Emine Seda Guvendag Guven, Figen Kur Sahin

Department of Obstetrics and Gynecology, Faculty of Medicine, Recep Tayyip Erdoğan University, Rize, Turkey

Objective: In this study, we presented a case which was found to have cesarean scar pregnancy, applied suction curettage under ultrasonography when gestational material within cavity was not regressed after methotrexate administration, and treated without complication.
Case: Twenty-seven-year-old G2P1A1 patient referred to our clinic with spotting complaint after 6 weeks of delayed menstruation. It was found in the transvaginal ultrasonography that there was an image consistent with the gestational sac with the size of $57 \times 45 \mathrm{~mm}$ on isthmus level. It was observed that the gestational sac was localized in cesarean scar region and thinned down the myometrium in this region. Myometrial thickness was measured as $4.6 \mathrm{~mm}$ in the region adjacent to the bladder. The patient having $\beta \mathrm{HCG}$ value as 1670 was administered $1 \mathrm{mg} / \mathrm{kg}$ methotrexate intramuscularly. On the 21 st day after methotrexate administration, suction curettage was applied under ultrasonography to the patient whose $\beta \mathrm{HCG}$ value dropped to 0 but no regression was observed in the mass within the cavity. After curettage, placental tissue in size of $24 \times 22 \mathrm{~mm}$ with severe bleeding in scar area was observed. Due to possible uterine rupture and bleeding risk, the mass was not intervened again and methotrexate was applied for the second time. Two months after the treatment, it was seen that the mass was regressed completely, and the patient started to menstruate spontaneously.

Conclusion: If cesarean scar pregnancy is not diagnosed early and treated with an appropriate method, serious complications such as abundant bleeding, uterine rupture and bladder perforation may occur. There are two treatment options as medical and surgical methods. However, leading the treatment by considering the clinical presentation of patient, size of mass, distance from bladder and fertility request of patient is the most significant key to a successful treatment.

Keywords: Scar pregnancy, ultrasonography.

\section{PP-094}

\section{Cesarean scar pregnancy: a case report}

Süreyya Demir ${ }^{1}$, Bülent Demir ${ }^{1}$, Gülser Bingöl', Sahra Çavuşoğlu ${ }^{1}$, Mehmet Nafi Sakar ${ }^{2}$, Deniz Balsak

${ }^{1}$ Department of Obstetrics and Gynecology, T.R. Ministry of Health Haseki Training and Research Hospital, Istanbul, Turkey; ${ }^{2}$ Diyarbakur Obstetrics, Gynecology and Pediatrics Hospital, Diyarbakır, Turkey

Cesarean scar pregnancy is a rare type of ectopic pregnancy occurring by the invasion of the pregnancy created in the cesarean scar into the myometrium. Its incidence rate is $1 / 1800-1 / 2216$ in all pregnancies and $0.15 \%$ for those with cesarean history. The greatest risk factor is the cesarean history. It is a life-threatening condition due to its complications. Early diagnosis and treatment is mostly lifesaving. In cesarean scar pregnancy, many treatment alternatives may be applied such as non-invasive treatment, dilatation and curettage, local or systemic methotrexate, surgical resection of trophoblastic 
tissue or uterine artery embolization. In this case, we aimed to present cesarean scar pregnancy treated by Foley catheter method after dilatation and curettage. Thirty-six-year-old G6P4A1 case referred to our clinic for delayed menstrual period. In the ultrasonography examination performed, we observed that the gestational sac compatible with 5 weeks of gestation was located in cesarean scar on lower uterine segment. We found from the medical history of the patient, she had cesarean section for 3 times and underwent D C once after abortion. All possible complications were explained to the patient, cervical dilatation was done first in the operating room by Hegar dilator accompanied with US, and the pregnancy product was aspirated by Karman's cannula. Upon the moderate bleeding of the patient, intracavitary Foley catheter was applied. The operation was ended by inflating the balloon of the catheter by 25-30 cc SF. Foley catheter was removed after 24 hours and when there was no postoperative bleeding, and she was discharged in health condition.

Keywords: Cesarean scar pregnancy, dilatation and curettage, ectopic pregnancy.

\section{PP-095}

\section{Prenatal exencephaly diagnosis at first trimester: a case report}

Süreyya Demir ${ }^{1}$, Bülent Demir ${ }^{1}$, Lale Vuslat Bakır ${ }^{1}$, Gülser Bingöl ${ }^{1}$, Sahra Çavuşoğlu, Mehmet Nafi Sakar², Deniz Balsak

${ }^{1}$ Department of Obstetrics and Gynecology, T.R. Ministry of Health Haseki Training and Research Hospital, Istanbul, Turkey; ${ }^{2}$ Diyarbakur Obstetrics, Gynecology and Pediatrics Hospital, Diyarbakur, Turkey

Objective: Neural tube defects are the second most frequent congenital anomalies after cardiac anomalies. Its prevalence has been reported as 3/1000 in a study carried out in Turkey. Since ultrasonography is a common practice, the diagnosis can be established mostly at first trimester.

Case: The case was 38 years old and G7, P6, A0 and Y6, and her first trimester fetal US revealed live single pregnancy compatible with CRL 14 weeks. Exencephaly diagnosis was established when it was observed that cranium's integrity was lost and brain tissue had an irregular appearance on the region where fetal head developed. No other anomaly was detected in the fetus. There were no characteristics in her medical history or drug use (she did not use folic acid). She had nothing in her family history. The parent was informed in detail about the anomaly. The parent decided termination. The pregnancy was terminated at a tertiary center.

Conclusion: Although anencephaly is defined as the deficiency or absence of the development of brain tissue, it starts as exencephaly (defective development of cranium, Mickey
Mouse appearance) or acrania (absence of cranium) and brain tissue contacts directly with amniotic fluid as the week of gestation increases. Cranial bones ossify as of 10 weeks of gestation and they can be seen in the ultrasonography beginning from 11 weeks of gestation. Since anencephaly has fatal outcomes, diagnosing in the fetal ultrasonography examination at first trimester allows parents to have termination option and helps to decrease possible trauma on parents.

Keywords: First trimester, exencephaly, prenatal diagnosis.

\section{PP-096}

\section{Ectopic pregnancy-ultrasound diagnosis and minimal invasive treatment in 10 years at our general hospital}

Boris Divic, Dragan Malobabic, Slavko Arbanas, Bratislav Mitrovic

Department of Gynecology and Obstetrics, General Hospital Sremska Mitrovica, Sremska Mitrovica, Serbia

Objective: The term is applied to pregnancy following implantation of fertilized ovum on any tissue other than endometrium. The incidence $0.94-2.6 \%$ of all pregnancies and is increasing. The tubal presentation is the most common one.The aim of the paper is to prove that with transvaginal ultrasound development and with earlier detection of free betaHCG in our department the diagnosis is getting better and it is possible to recognize an ectopic pregnancy at earlier stages.

Methods: We were following our diagnostic and therapeutic abilities in dealing with ectopic pregnancies in the time frame of 10 years-01.01.2001-31.12.2010. The tables and graphics will show the numbers and locations of ectopic pregnancies in the last 10 years among our hospitalized patients. We shall demonstrate the numbers of ultrasound examinations per person, the average number of days in bed before and after the treatment. Correlation of transvaginal ultrasound and the levels of free beta subunit HCG were also examined. The treatment was operative in all cases-minimal invasive procedures were method of choice in most occasions.

Results and Conclusions: In our work, the ten year period in dealing with ectopic pregnancies was depicted. The increasing trend in the incidence of the condition was observed in our department,also the diagnosis of ectopic pregnancies is improved thanks to transvaginal ultrasound development. Getting new machines and continuing in striving to be more skilled in transvaginal ultrasound technique will ensure the results to be even better.

Keywords: Ectopic pregnancies, transvaginal ultrasound, levels of beta subunit HCG. 


\section{PP-097}

\section{Observation of uterine, radial and spiral artery Doppler parameters in MIRENA applied patients due to abnormal uterin bleeding}

Hanifi Şahin, Arif Güngören, Kenan Dolapçıŏlu, Raziye Keskin Kurt, Orhan Nural, Oğuz Uyar

Department of Gynecology and Obstetrics, Faculty of Medicine, Mustafa Kemal University, Hatay, Turkey

Objective: The aim of this study was to investigate the effect of levonorgestrel secreting intrauterine device (LNG-RIA) on uterin, radial and spiral artery doppler parameters in one year follow-up.

Methods: The study included 117 fertile patients who had complaint of menometrorrhagia and who were applied LNG-RIA in Mustafa Kemal University Hospital. We observed uterine, radial and spiral artery Doppler changes during one year.

Results: Of 117 patients, 91 cases comleted 1 year follow-up. While uterine artey resistivity index (RI) and pulsatility index(PI) were not changed statistically significiant, radial artery and spiral artery resistivity indices were increased. İn addition to that, endometrial thickness was decreased and levels of hemoglobine and hematocrite increased. Coogulation parameters(PT, PTT, INR) were not changed.

Conclusion: LNG-RIA did not change significiantly uterine artery doppler parameters. İncrease in radial, spiral artery resistivity indices and decrease in endometrial thickness may be due to local progesteronic effect of LNG-RIA. No change in coogulation parameters may indicate that LNG-RIA does not change intrinsic and extrinsic coogulation pathways and doesn`t decrease vaginal bleeding via systemic effect.

Keywords: LNG-RİA, Doppler of artery.

\section{PP-098}

\section{Use of transperineal ultrasonography in preterm labor}

Helmi Temessek, Kaouther Dimassi, Narjess Karmous, Nizar Ben Aissia, Amel Triki, Mohamed Faouzi Gara

Obstetrics and Gynecology Department, Mongi Slim Hospital, La Marsa, Tunisia

Introduction: In the management of preterm labor (PL), transvaginal ultrasound (TVU) remains the gold standard in terms of diagnosis and prognosis. The transperineal ultrasound (TPU) can be a reliable alternative.

\section{Objective:}

- Present the use of transperineal ultrasound technique in preterm labor.
- Compare results of TVU and TPU on cervical length measurements and visualization of the opening of the internal os.

Methods: It is about a preliminary prospective study, including study patients between 14 and 36weeks' gestation with a preterm labor. All the patients underwent transperineal and transvaginal cervical length assessment. The Pearson correlation coefficient and Lin concordance coefficient were used. Acceptable concordance was defined as $>0.82$, with an acceptable correlation of $>0.9$.

Results: 59 patients underwent the protocol. The Pearson correlation coefficient was 0.64.Close agreement between transperineal and transvaginal measurements was observed across the full range of cervical lengths.

Conclusion: Transperineal ultrasound is a as reliable as transvaginal ultrasound. Moreover, this technique is, fast, precise, trivial and providing more comfort for anxious patients.

Keywords: Preterm labor, cervix length, transperineal ultrasound .

\section{PP-099}

\section{Comparison of the clitoral artery Doppler indices before and after hysterectomy}

Yesim Bayoglu Tekin, Senol Senturk, Ulku Mete Ural, Emine Seda Guvendag Guven, Figen Kur Sahin

Department of Gynecology and Obstetrics, School of Medicine, Recep Tayyip Erdogan University, Rize, Turkey

Objective: We aimed to evaluate clitoral artery Doppler indices of women who underwent hysterectomy for benign lesions of uterus and to compare the alterations with female sexual function index (FSFI)

Methods: Twenty women enrolled in this study. Inclusion criteria were pre-menopausal women with benign uterine lesions. Clitoral artery Doppler ultrasonography evaluation was performed by 13.5 Mhz linear probe. The examinations were done in the lithotomy position without exerting any pressure on the genital tissue. Pulsatility (PI), resistive (RI) indices and systole/diastole ratio (S/D) were calculated and FSFI scores were assessed before and 6 months after surgery.

Results: The mean age of women was $45.2 \pm 31$. PI, RI and S/D indices were calculated as $1.25 \pm 0.41,0.65 \pm 0.10,3.31 \pm 1.53$ before surgery and $1.01 \pm 0.41,0.59 \pm 0.10,2.69 \pm 1.01$ after surgery, respectively. There were statistically significant difference between pre and post-surgery evaluation of Doppler indices $(\mathrm{p}<0.001$ for PI, RI and S/D). FSFI scores were $28.3 \pm 5.4$ prior hysterectomy and $20.5 \pm 8.6$ six months after surgery and FSFI score was significantly decreased after surgery $(\mathrm{p}<0.05)$. 
Conclusion: Our results show that clitoral artery blood flow changes after hysterectomy and these changes are significantly affected female sexual functions.

Keywords: Clitoral artery Doppler, sexual function, hysterectomy.

\section{PP-100}

\section{Accuracy of power Doppler ultrasonography for detecting intrauterine focal lesions: a correlation with doppler ultrasound and hysteroscopic hystopathology}

Ebru Cöğendez ${ }^{1}$, Meryem Eken ${ }^{1}$, Osman Temizkan², Ecmel Işsk Kaygusuz ${ }^{3}$, Dilşad Herkiloğlư ${ }^{1}$, Mustafa Eroğlu', Murat Muhçu

${ }^{1}$ Department of Obstetrics and Gynecology, Zeynep Kamil Training and Research Hospital, Istanbul, Turkey; ${ }^{2}$ Department of Obstetrics and Gynecology, Sisili Etfal Training and Research Hospital, Istanbul, Turkey; ${ }^{3}$ Department of Pathology, Zeynep Kamil Training and Research Hospital, Istanbul, Turkey

Objective: To compare power Doppler flow mapping characteristics of endometrial polyps and submucosal fibroids and analyze whether different power Doppler characteristics can help to differentiate these focal endometrial lesions.

Methods: Fifty-eight women (median age, 37 years; range, $25-51$ years) presenting with abnormal uterine bleeding and infertility on transvaginal ultrasund suggested focal endometrial lesions underwent sonohysterography were included in this prospective study. Three different vascular patterns were defined: Pattern A: single-vessel pattern, Pattern B: rim-like vessel pattern $C$ : multiple vessel pattern. These were compared with the final histopathological diagnosis.

Results: Histological diagnoses were as follows: Endometrial polyp 40 (69\%), submucousal myoma 18 (31\%). Power Doppler signals were observed in 53 of these; they were not observed in five patients with endometrial polyps. We find out $75 \%$ pattern $\mathrm{A}, 2.5 \%$ pattern $\mathrm{B}$ and $7.5 \%$ pattern $\mathrm{C}$ in vascularized polyps, and also submucous myomas we find out $5.6 \%$ pattern A, $66.7 \%$ pattern B and $27.8 \%$ pattern C. The sensitivity, specificity and positive and negative predictive values for single vessel pattern in diagnosing endometrial polyps were $80,100,100$, and $69.23 \%$; for multiple vessels pattern in diagnosing submucousal myomas were 27.78, 92.5, 62.5 and $74 \%$; for rim-like vessel pattern in diagnosing submucosal fibroids, they were $72.22,100,100$ and $88.9 \%$, respectively.

Conclusion: Power Doppler blood flow mapping is reasonable in the diagnosis of intrauterine focal lesions and is practical in distinguishing endometrial polyps and submucosal fibroids.
Keywords: Power Doppler, hysteroscopy, focal intrauterine lesions.

\section{PP-101}

\section{Radiologists intra-rater agreement and category distinguish ability in diagnosis of ovarian mass by ultrasonography}

Gholamreza Babaei Rouchi

Islamic Azad University, Karaj-Branch, Karaj, Iran

Objective: Intra-rater agreement in observing and decision making in diagnosis of any disease is of great importance. This investigation is to observe and read ultrasound pictures of ovarian cysts and distinguish its category for any radiologist. Distinguish ability is one of the related entities in this matter and radiologists' ability in correct diagnosis is of great concern. In this study, we evaluated radiologist's distinguish ability of ordered categories of ovarian cyst diseases (benign, borderline and malignant) in ultrasonography. To do this, we measured intra-rater agreement of radiologists by Weighted Kappa coefficient, and then by the help of "square scores association model" we evaluated their distinguish ability in diagnosis of the severity of the ovarian cyst's diseases.

Methods: In this analytical cross-sectional study, two radiologists and there radiology residents assessed ultrasounds of 40 patients separately and independently in two periods (with the interval of one week). Patients selected from those who were referred to Mirza Koockk Khan Hospital in January 2012. Ultrasounds were performed by an expert radiologist and by a single apparatus.

Result: Data from radiologists was evaluated by "square scores association model" due to their superior result of distinguish ability. Mean of Weighted Kappa coefficient was 0.81 and intra-rater agreement was 0.99 for our radiologists, but due to weaker results of our residents, we used "agreement plus square scores association model" for analyzing and mean of Weighted Kappa coefficient was 0.65 and intra-rater agreement was 0.97 for them.

Conclusion: Although radiologists had a better function than their residents, all of them showed appropriate distinguish ability and intra-rater agreement in diagnosis and categorizing of the ovarian cyst's disease. To distinguish benign category from borderline was more difficult than to distinguish malignant category from borderline and radiologists showed better result in this than their residents did.

Keywords: Ovarian cyst, ultrasonography, reliability. 


\section{PP-102}

\section{Hyperreactio luteinalis presented with abdominal pain during third trimester: a case report}

Harika Bodur Öztürk ${ }^{1}$, Gül Telci ${ }^{1}$, Deniz Usal', Tayfun Bağış ${ }^{2}$

${ }^{1}$ Department of Obstetrics and Gynecology, Acıbadem Kadiköy Hospital, Istanbul, Turkey; ${ }^{2}$ Department of Obstetrics and Gynecology, Acıbadem University, Istanbul, Turkey

Hyperreactio luteinalis is a rare bening condition presented with cystic enlargement of both ovaries. This condition is generally associated with trophoblastic disease, fetal hydrops and multiple pregnancies. A 28 years old G1 P0 woman has admitted to hospital at 33 week of spontaneous twin pregnancy with bilateral pelvic pain. Ultrasound examination demonstrated multiple anechoic cystic lesions in both ovaries. The patient underwent primary cesarean section delivery at 34 weeks 4 days due to twin pregnancy. Intraoperative inspection of the pelvis revealed that the ovaries were distinctly enlarged due to multiple cysts 2 to 4 $\mathrm{cm}$ in diameter. Perioperative follow up was uneventfull. We performed pelvic ultrasound 6 weeks after delivery and we confirmed normal ovaries without residual cyst. Hyperreactio luteinalis usually regress after pregnancy. Surgery may be necessary in case of ovarian torsion or uncontrolled hemorrhage. Postpartum follow-up is recommended in all presumptive cases in which histological confirmation has not been established. In the presented case, conservative management allowed preservation of both ovaries.

Keywords: Adnexal mass, hyperreactio luteinalis, twin pregnancy.

\section{PP-103}

\section{Prenatal diagnosis of a fetal ovarian cyst}

Şenol Şentürk, Gülşah Balık, Zeynep Serdaroğlu Uzuner, Figen Kır Şahin

Department of Obstetrics and Gynecology, Faculty of Medicine, Recep Tayyip Erdoğan University, Rize, Turkey

Objective: Fetal ovarian cysts are the most common prenatally diagnosed abdominal tumors. Fetal ovarian cysts are usually unilateral, diagnosed in the third trimester and they are uncommon. In this article, antenatal detection of a fetal ovarian cyst is reported by reviewing the available literature.

Case: A 20-year-old primigravid patient was referred to our prenatal center at 24 weeks of gestation after detection of a fetal cystic mass in the abdomen by prenatal sonography. Her past medical history was unremarkable and her antenatal course was uneventful. Ultrasound examination confirmed the cyst measured to be $73 \times 65 \mathrm{~mm}$ in diameter had anechoic content and the thin wall of the cyst was located in the lower abdomen of the fetus. These findings are suggestive of a simple ovarian cyst. The patient has been informed of her condition and then serial ultrasonographic scans were performed to follow the cyst every 2 weeks until delivery. The diameter of the cyst increased to $58 \times 50 \mathrm{~mm}, 69 \times 53 \mathrm{~mm}$ and $75 \times 60 \mathrm{~mm}$ at 34,37 and 39 weeks of gestation, respectively. Due to breech presentation at term, caesarean section was performed and a healthy female infant was delivered. The baby was weighing 3040 grams with Apgar scores of 8 and 10 (after 5 and 10 minutes, respectively). A cystic mass of $80 \times 78 \mathrm{~mm}$ in diameter was shown at abdominal ultrasound scanning performed on the first postnatal day. Due to determination of severe abdominal distension and respiratory distress, it was recommended to perform laparotomy on the second postnatal day. A yellow cystic structure arising from the right ovary was seen in the lower right quadrant of the abdomen during the surgical procedure. The pedicle of the cyst was not twisted and the left ovary and adnexal structures were normal in appearance. Laparoscopic right ovarian cystectomy was perfomed. The histopathological examination of the sample demonstrated a large yellowish cystic mass with a diameter of 80x80 mm filled with serous fluid. Final pathological report confirmed the diagnosis of a serous cystadenoma of the right ovary. The newborn had an uneventful and uncomplicated postoperative course and she was discharged with her mother on the 5 th postoperative day.

Results: While the etiology still remins unknown, it is generally considered that the hormonal stimulation is responsible for the disease (fetal gonadotropins, maternal estrogen and placental human chorionic gonadotropin). Maternal and fetal ovarian cysts may co-exist and they could potentially have a similar hormonal etiology. Neonatal ovarian cysts are almost always benign simple cysts and they are self-limiting, and many of them go unreported.

Conclusion: In general, a fetal ovarian cyst is not a lifethreatening condition. These cysts are usually simple cysts and they are small in size. After diagnosis, they have to be followed by serial ultrasonographic examinations.

Keywords: Fetal ovarian cyst, ovarian cyst, prenatal diagnosis.

\section{PP-105}

\section{Transvaginal drainage of tubo-ovarian abscess under ultrasonography}

Yesim Bayoglu Tekin, Ulku Mete Ural, Senol Senturk, Emine Seda Guvendag Guven, Figen Kır Sahin

Department of Obstetrics and Gynecology, Faculty of Medicine, Recep Tayyip Erdoğan University, Rize, Turkey 
Objective: In our study, we aimed to represent a case with successful endovaginal drainage of a tubo-ovarian abscess under ultrasonography which failed to recover by intravenous antibiotic treatment.

Case: Our case was 45-year-old G6P5 premenopausal patient. The patient using intrauterine device for 7 years had abdominal pain and high fever for a week. In the ultrasonography of the patient who referred to the emergency service with acute abdominal complaint, it was observed that there were conglomerated masses consistent with tubo-ovarian abscess in sizes of $105 \times 97 \mathrm{~mm}$ in the right side of pelvis and of $76 \times 62 \mathrm{~mm}$ on the left side, and free fluid $50 \mathrm{~mm}$ deep in the Douglas cavity. WBC was 23,000 and CRP was 16.8 in the patient together with $38.5{ }^{\circ} \mathrm{C}$ body temperature. The abdomen was sensitive and there were rebound and defense. It was observed in the vaginal examination that posterior fornix was filled and revealed fluctuation. Collum movements were painful. The patient was administered $2 \times 1$ metronidazole $1 \mathrm{~g}$ and $2 \mathrm{x}$ IV ceftriaxone $1 \mathrm{~g}$ for 5 days. Under ultrasonography, endovaginal drainage was applied to the patient whose WBC and CRP values did not decrease, and about $700 \mathrm{cc}$ purulent fluid was discharged. After the drainage, drain was inserted into Douglas. When pelvic masses were decreased after drainage, the drain was removed from the patient after her WBC and CRP values decreased and she was discharged one week later.

Conclusion: Transvaginal discharge of pelvic abscess under ultrasonography is a safe and effective procedure. It can be used as an alternative treatment option in patients with failed intravenous antibiotic treatment.

Keywords: Tubo-ovarian abscess, ultrasonography.

\section{PP-106}

\section{Abnormal elevated CA 19-9 in the dermoid cyst: a sign of the ovarian torsion?}

Burcu Artunç Ülkümen, Aslı Göker, Halil Gürsoy Pala, Serçin Ordu

Department of Obstetrics and Gynecology, Celal Bayar University School of Medicine, Manisa, Turkey

Dermoid cyst is the most common germ cell tumor of the ovary containing various tissue elements. Ovarian torsion is a common complication of which ultrasonographic diagnosis is confusing. A 14-year-old virgin adolescent was admitted to our clinic because of pelvic pain lasting for 1 week. Abdominopelvic ultrasonography revealed a lobulated cystic lesion with a diameter of $11 \mathrm{~cm}$ in the right adnexa. Abdominopelvic MR revealed a $16 \mathrm{~cm}$ cystic lesion consisting of heterogeneous solid structures. The left ovary and other intra-abdominal structures were normal. Tumor markers were as follows: CEA: $1.90 \mathrm{U} / \mathrm{mL}, \mathrm{AFP}: 0.94 \mathrm{U} / \mathrm{mL}$, CA 15-3: $13.4 \mathrm{U} / \mathrm{mL}$, CA 19.9: $1983 \mathrm{U} / \mathrm{mL}$, and CA 125: 217 $\mathrm{U} / \mathrm{mL}$. Another possible gastrointestinal system pathology was ruled out by imaging modalities. Pfannenstiel incision was made, and right ovarian torsion with necrosis was detected. Right salpingooophorectomy was performed, and frozen section revealed dermoid cyst. Pathological evaluation was compatible with dermoid cyst and the ovarian torsion. High levels of CA 19-9 and CA-125 and the rapid increase in the diameter of the cyst are not always associated with malignancy. However, a detailed preoperative evaluation is needed. Due to the need of early detection of ovarian torsion, CA 199 may be a good marker particularly for ovarian torsion and the extensity of ovarian necrosis. However, larger studies are needed to confirm this hypothesis.

Keywords: CA 19-9, dermoid cyst, ovarian torsion.

\section{PP-107}

\section{The case of ovarian serous cystadenofibroma confused with postmenopausal malign adnexial mass}

Ergul Demircivi Bor ${ }^{1}$, Kadir Güzin ${ }^{1}$, Şeyma Özkanlı ${ }^{2}$, Gökhan Göynümer

${ }^{1}$ Department of Obstetrics and Gynecology, Istanbul Göztepe Research and Training Hospital, Istanbul, Turkey; ${ }^{2}$ Department of Pathology, Istanbul Göztepe Research and Training Hospital, Istanbul, Turkey

Introduction and Objective: Ovarian cystadenofibroma is quite rare benign ovarian tumor including both epithelial and fibrous stromal contents and seen between 25 and 65 years old. Ultrasonographic appearance of cystadenofibroma is frequently a cystic adnexial mass with solid content, and it is generally confused with malign ovarian tumor. In our study, we operated our case with the pre-diagnosis of postmenopausal malign adnexial mass by radiological imaging, and we found serous cystadenofibroma by intraoperative pathological diagnosis. In the patients operated due to the pre-diagnosis of malign adnexial mass, cystadenofibroma should also be considered as a differential diagnosis even it is rare.

Case: Our case referred to our clinic with the complaint of inguinal pains. Seventy-five-year-old multipara patient who was in menopause for 25 years have had no gynecologic disease so far. In the ultrasonography performed, a total of 15 $\mathrm{cm}$ cystic mass including bilobular solid papillary areas were found within right adnexal area. Ca 125 value of the patient lies within normal ranges. In the MRI examination, right adnexial mass was observed causing suspicion for solid cystic 
malignity which is hypointense in $\mathrm{T} 1$ and hyperintense in T2. When serous papillary cyst adenofibroma was found after the intraoperative pathology, total hysterectomy and bilateral salpingo-oophorectomy were carried out, and the patient was discharged with healthy posteoperative condition.

Discussion and Conclusion: Ovarian cystadenofibroma is a rare benign tumor with epithelial and fibrous contents. Its incidence rate is $1.7 \%$ in all benign ovarian tumors. These tumors are cystic masses with solid or papillary components and therefore, they can be evaluated as malign masses in preoperative ultrasonographic or MR imaging. In our patient, both ultrasonographic and MR pre-diagnoses were against malign adnexial mass. Cystadenofibromas are grossly similar to malign tumor during operation and therefore, intraoperative pathological diagnosis by frozen should be established to get the proper diagnosis. Although our patient was in postmenopausal period, these cysts may be seen during reproductive period, and radical surgical intervention may be planned due to preoperative malign appearance. Serous papillary cystadenofibroma which is benign ovarian cystic tumor rarely seen in cases with clinically negative tumor markers should be remembered although preoperative imaging findings supports malignity in the differential diagnosis of malign adnexial masses.

Keywords: Adnexial mass, cystadenofibroma, ovary.

\section{PP-108}

\section{Peritoneal pseudo and ovarian cysts are frequent ultrasonic dilemma: an Egyptian experience}

Mohammad Ahmad Emam

Department of Obstetrics \& Gynecology, Mansoura Faculty of Medicine, Mansoura, Egypt

Introduction: Peritoneal pseudo cysts (PPCS) are formed due to trapping and collection of the fluid arising from the ovary into post inflammatory or postoperative adhesive pockets in peritoneal cavity. These appear as complex multicystic adnexal masses on sonography. Unfortunately, although fairly common-due to increased pelvic surgery like caesarean section, many gynecologists and ultrasonographers are not aware of them, leading to less recognization on imaging of the female pelvis or falsely diagnosed as true ovarian cysts. This can lead to unnecessary surgical interference.

Objective: To highlight Egyptian (Mansoura) experience regarding, the guidelines needed for diagnosis of (PPCs), and to distinguish them from true ovarian cysts.
Methods: A total of 223 women with ovarian cysts were subjected to transvaginal sonography (TVS), combined with power Doppler and plasma concentrations of CA 125 before surgery. 62 women with (PPCs) were diagnosed on surgical intervention and correlated to (TVS). Case series study regarding the diameters of the cysts, the shape, margins, content, location, presence of septa and echogenicity were analyzed.

Results: The (PPCs) were unilateral in 40 (65\%) and bilateral in $22(35 \%)$ women. A well-defined cystic structure was found in only 12 (19\%) women, while in the other 50 (81\%) women the (PPCs ) showed blurred, undefined margins and a bizarre morphology, giving them lumpy shape. The ipsilateral ovary was identified in $52(84 \%)$ cases, either external to the cyst or entrapped within it.

Conclusion: Peritoneal pseudo cysts are presented with a variety of imaging appearances which can be confused with a long list of differential diagnoses, including ovarian cancer. Preoperative diagnosis depends on the presence of normal ipsilateral ovary with surrounding loculated fluid conforming to the peritoneal space. Although TVS is sufficient for diagnosis, but the normal CA125 and power doppler increase the sensitivity of TVS.

Keywords: Peritoneal pseudo cysts, ovarian cysts, ultrasonic.

\section{PP-109}

\section{The importance of ultrasound examination in the diagnosis of a rare form of molar pregnancy: a case report}

Chaouki Mbarki ${ }^{1}$, Najeh Hsayaoui ${ }^{1}$, Ines Bouriel ${ }^{1}$, Hajer Bettaieb $^{1}$, Saoussen Melliti', Salma Gharbi ${ }^{2}$, Sana Mezghani ${ }^{2}$, Hedhili Oueslati ${ }^{1}$

${ }^{1}$ Department of Obstetrics and Gynecology, Hospital of Ben Arous, Ben Arous, Tunisia; ${ }^{2}$ Department of Radiology, Hospital of Ben Arous, Ben Arous, Tunisia

Introduction: A cornual pregnancy is a rare type of ectopic pregnancy which occurs when the fertilised egg implants in that part of the fallopian tube buried deep in the wall of the uterus. Hydatidiform mole (molar pregnancy) is a rare mass or growth. Molar cornual ectopic pregnancy is extremely rare.

Objective: The aim of this work is to describe a rare form of molar cornual pregnancy and show the importance of ultrasound examination in its diagnosis.

Methods: In this study, we present a case of molar cornual pregnancy diagnosed by ultrasound examination, serial serum beta subunit of human chorionic gonadotropin and 
diagnostic laparoscopy. A 32 year -old woman with an antecedent of asthma, admitted to our department of Obstetrics and Gynecology at Ben Arous Hospital (tunisia) for ultrasound examination at 8 weeks of amenorrhea. The ultrasound examination was performed by suprapubic and endovaginal approach.

Results: At the ultrasound examination the uterus was empty and We demonstrated an ectopic gestational sac embryonated of $0.96 \mathrm{~cm}$ cranio caudal length (that is to say 7 weeks of amenorrhea). The sac was surrounded by placenta, Which was enlarged and contains areas of multiple, diffuse anechoic lesions. The diagnosis of cornual pregnancy was made from data of the ultrasound examination. It was confirmed by the $\beta$-hCG (85843.4mUI/ml), diagnostic laparoscopy and Pathologic analysis (placental tissue with features consistent with a partial molar pregnancy). the patient had a successful laparotomy.

Conclusion: Molar cornual pregnancy occurs rarely. Its diagnosis is not often made.Its discovery is made frequently at the rupture stage. Endovaginal ultrasound examination helps discover cornual pregnancy at an early stage.

Keywords: Molar pregnancy, ultrasound examination, cornual pregnancy.

\section{PP-110}

\section{Bilateral ectopic pregnancy: a case report}

Najeh Hsayaoui, Chaouki Mbarki, Youcef Cadhy, Banene Hamdi, Hedhili Oueslati

Department of Obstetrics and Gynecology, Hospital of Ben Arous, Ben Arous, Tunisia

Introduction: Bilateral tubal pregnancy is the rarest form of ectopic pregnancy. It occurs frequently at women after undergoing assisted reproduction procedures.

Objective: The aim of this study is to insist at importance of ultrasonography exam on bilateral ectopic pregnancy diagnosis.

Case: We present a case of a 23 years primigravida with previous history of right tubal pregnancy treated conservatively. Patient presented as 6 weeks ectopic pregnancy with abdominal pain for 2 days. Serial serum beta subunit of human chorionic gonadotropin was at $3206 \mathrm{mUI} / \mathrm{ml}$. The diagnosis of bilateral ectopic pregnancy was made from data of the ultrasound examination: trans-vaginal ultrasound revealed empty uterus with left and right tubo-ovarian hypoechoeic masses. There was also minimal collection of fluid in cul-desac. A laparoscopic surgery had been performed. It concluded at a bilateral ectopic pregnancy. It was done a conservative treatment for left ectopic pregnancy and and a salpingectomy for the right one.

Conclusion: The diagnosis of the bilateral ectopic pregnancy is difficult.A high index of suspicion for pregnancy is required to avoid missing an ectopic bilateral pregnancy. Ultrasound examination could help the diagnosis.

Keywords: Ectopic pregnancy, ultrasound examination.

\section{PP-111}

\section{Postpartum diagnosed spontaneous rupture of an unscarred multigravid uterus with vaginal omentum expulsion: case report}

Alev Atis, Burak Ozkose, Verda Alpay, Aysegul Atalay, Ali Gedikbasi

Department of Obstetrics \& Gynecology, Kanuni Sultan Suleyman Training \& Research Hospital, Istanbul, Turkey

Introduction: Spontaneous rupture of an unscarred uterus is an obstetrical emergency. Its diagnosis is often concealed, leading to maternal and fetal mortality. Many risk factors and clinical presentations been identified.

Case: In this case report, we describe 34 years old pregnant woman with postpartum diagnosed uterine rupture with a very rare presentation of omental expression and discuss appropriate management of this presentation.

Conclusion: Delay in the diagnosis of uterine rupture will lead in maternal and fetal mortality.

Keywords: Uterine rupture, postpartum.

\section{PP-112}

\section{Obstetric and postpartum result of elongatio colli during pregnancy}

Ergul Demircivi Bor ${ }^{1}$, Orhan Sahin ${ }^{3}$, Gokhan Goynumer ${ }^{1}$, Cemal Ark ${ }^{2}$

${ }^{1}$ Istanbul Goztepe Training and Research Hospital, Istanbul, Turkey; ${ }^{2}$ Istanbul Kanuni Sultan Suleyman Training and Researcb Hospital, Istanbul, Turkey; ${ }^{3}$ Trabzon Kanuni Sultan Suleyman Training and Research Hospital, Trabzon, Turkey

Objective: Uterine prolapsus is a gynecologic problem that seen in elderly and multiparous women. In literature it is mentioned that occasionally uterine prolapsus with elonga-tion colli is seen after delivery. Etiology of uterine prolapsus after delivery is increased hormone levels (esp. progesterone and cortizole) during pregnancy may cause relaxation of uter-ine supporting ligaments (cardinal, uterosacrale).We follow our patient pre and post partum period and observe sponta- 
neous recovery of uterine prolapsus and elongation colli at post partum period.

Case: Our case is 37 years old, multiparous woman who is complaining about pain in her 33 th week of gestation. At her history, she delivered 2850 gr term healthy baby with normal vaginal delivery and after the labor her complains about the mass protruding from introitus was started. But she did not get any treatment about this mass after the labor. Patients elongation colli was protruded from intraitus about $10-12 \mathrm{~cm}$ and reductable by hand (POP Q 3 ) and her cervical examination was multiparous and also heavy erosion due to the mechanical trauma was seen. We treated her preterm labour condition fistly and than gave her pesser treatment with antibiotheraphy and get cervical cytology because of her cervical erosion. we followed the patient at bed rest due to the failure of pesser treatment.. She delivered 3050 gr healthy baby with cesarian section. She has no complication at postpartum period. We recommended surgery for her condition bu she refuse the surgery.

Conclusion and Results: In most cases, women were multiparous and their prolapsus condition was seen before the pregnancies. Pregnancy complications as abortion, preterm labour and urinary infection are seen in these women. Also labour complications as arrestment of labour and dystocia due to cervical hypertrophia because of edema and infection of cervix are also seen. Due to the fact thas elective cesarian section is recommended for these patients. Psotpsrtum atonia bleeding is also seen often in this prolapsus patients and its morbidity is also very high. In literature, spontaneous recovery of uterine prolapsus and elongation colli was seen rarely. But mostly the spontaneous recovery of the condition is not seen and surgery at postpartum period is recommended. In our patient, due to the Kegel exercise the prolapsus and ellongatio colli degree was not recovered, and difficulty in reduction was occurred. We offered surgery but she refused it due to financial issues.

Keywords: Pregnancy, uterine prolapsus, elongatio colli.

\section{PP-113}

\section{Honokiol decreases intra-abdominal adhesion formation in a rat model}

Elif A ğaçayak ${ }^{1}$, Senem Yaman Tunç ${ }^{1}$, Mehmet Sait İçen ${ }^{1}$, Ulaş Alabalık ${ }^{2}$, Fatih Mehmet Fındık ${ }^{1}$, Hatice Yüksel ${ }^{3}$, Talip Gül ${ }^{1}$

${ }^{1}$ Department of Obstetrics \& Gynecology, Dicle University School of Medicine, Diyarbakur, Turkey; 'Department of Pathology, Dicle University School of Medicine, Diyarbakur, Turkey; ${ }^{3}$ Department of Biochemistry, Dicle University School of Medicine, Diyarbakur, Turkey
Objective: The purpose of this study was to investigate the effectiveness of honokiol, a natural molecule that was shown to have antioxidant effects, in prevention of intra-abdominal adhesion formation in a rat model.

Methods: This study was conducted on a total of 40 nonpregnant Sprague-Dawley rats which were divided into 4 groups as follows: sham, control, saline and honokiol groups. Both uterine horns of the rats in control, saline and honokiol groups were exposed and a $2 \mathrm{~cm}$ segment of the antimesenteric surface of both uterine horns was traumatized by a scalpel. The saline group was administered $2 \mathrm{ml}$ of saline/day intraperitoneally for 5 days following the operation. The honokiol group, on the other hand, was administered honokiol intraperitoneally at a dose of $1 \mathrm{mg} / \mathrm{kg} /$ day for 5 days following the operation. On postoperative day 14, 3 $\mathrm{mL}$ of intracardiac blood sample was taken from the rats for biochemical analyses, and the rats were sacrificed this way. From the blood samples Total antioxidant status (TAC) and Total oxidant status (TOS) levels were studied. The adhesions were evaluated according to the microscopic adhesions classification of Zuhlke et al. Skin tissues were also evaluated for the presence of inflammation, granulation tissue and fibrosis.

Results: Adhesion and inflammation scores were all significantly lower in the honokiol group compared to the saline and control groups $(\mathrm{p}<0.008)$. Similarly, fibrosis score was significantly lower in the honokiol group compared to the saline group $(\mathrm{p}<0.008)$. However, in comparison of TAS and TOS levels; there was no significant difference between groups.

Conclusion: Honokiol was found to be effective in prevention of intra-abdominal adhesion formation in a rat model. However, larger studies are needed to shed light on the exact role of honokiol in intra-abdominal adhesion formation and determine the molecular aspects of the promising results found in this study.

Keywords: Honokiol, intra-abdominal adhesions, rat.

\section{PP-114 Imperforate hymen case causing globe vesicale}

Süreyya Demir ${ }^{1}$, Bülent Demir ${ }^{1}$, Faruk Demir ${ }^{2}$,

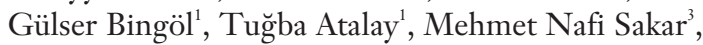
Deniz Balsak

${ }^{1}$ Department of Obstetrics and Gynecology, T.R. Ministry of Health Haseki Training and Research Hospital, Istanbul, Turkey; ${ }^{2}$ Pediatrics Department, Faculty of Medicine, Adnan Menderes University, Aydin, Turkey; ${ }^{3}$ Diyarbakur Obstetrics, Gynecology and Pediatrics Hospital, Diyarbakır, Turkey 
Imperforated hymen is a rare congenital anomaly due to the non-completion of Mullerian development. Although its exact incidence is not known, it is approximately $0.014-$ $0.01 \%$. Its progress is asymptomatic until menstrual cycle starts. When menstruations start, different symptoms may arise depending on the cyclic pelvic pains and pelvic compression of hematometrocolpos. The cases mostly refer due to the primary amenorrhea. In the physical and US examinations of 13-year-old patient who referred to the emergency clinic with the complaint of abdominal ache, she was diagnosed with globe vesicale. In the gynecologic examination, extremely cambered imperforated hymen was observed. In the pelvic ultrasonography we performed, there was an appearance compatible with hematocolpos with the size of $11 \times 12 \mathrm{~cm}$ in the pelvis. The patient was applied hymenotomy, and she was discharged without any problem on the postoperative first day. In conclusion, imperforated hymen should be remembered in the differential diagnosis when investigating the reason of acute urine retention in adolescent girls.

Keywords: Globe vesicale, imperforated hymen, hematocolpos. 


\section{1th Congress of the Mediterranean Association for Ultrasound in Obstetrics and Gynecology 9th-12th October 2014, Belek, Antalya, Turkey 9th Congress of Obstetrical and Gynecological Ultrasonography Author Index}

\begin{tabular}{|c|}
\hline A \\
\hline Abbasoğlu A. \\
\hline Abir K. \\
\hline Acar H. \\
\hline Acar Şirinoğlu H. \\
\hline Acet F. \\
\hline Adalı E. \\
\hline Ağaçayak E. \\
\hline Ajroudi M. \\
\hline Akberova A. \\
\hline Akcan B. \\
\hline Akçil E. \\
\hline Aksoy A.N. \\
\hline Akyol A. \\
\hline Alabalık U. \\
\hline Alanbay I. \\
\hline Aldemir O. \\
\hline Alkaş D. \\
\hline Alpay V. \\
\hline Altay M. \\
\hline Altunyurt S. \\
\hline Ammous T. \\
\hline Anuk A.T. \\
\hline Arat Ö. \\
\hline Arbanas S. \\
\hline Arıkan S.A. \\
\hline Arısoy R. \\
\hline Ark C. \\
\hline Arslan $\mathrm{H}$. \\
\hline Arslan O. \\
\hline $\begin{array}{l}\text { Artunç Ülkümen B. } \\
\text { Asık H. }\end{array}$ \\
\hline
\end{tabular}

PP-058
PP-073
PP-044
PP-057
PP-092
PP-014
PP-003, PP-113
OP-08, PP-068, PP-080
OP-07
PP-021, PP-022, PP-025
PP-071, PP-074
PP-032, PP-034
PP-045
PP-113
PP-004
PP-033
PP-049
PP-111
PP-078
OP-07, PP-092
PP-017, PP-067
PP-092
PP-011
PP-096
PP-010, PP-012, PP-063
PP-009, PP-010, PP-012, PP-013, PP-044,
PP-056, PP-057, PP-063
PP-035, PP-036, PP-112
PP-090
PP-084
OP-05, OP-06, PP-002, PP-037, PP-085, PP-10
PP-025

\begin{tabular}{|c|c|}
\hline Atabek C. & OP-02 \\
\hline Atalay $\mathrm{T}$. & PP-026, PP-114 \\
\hline Atalay A. & PP-111 \\
\hline Atalay S. & PP-021, PP-022, PP-025 \\
\hline Ataoğlu E. & PP-022, PP-021 \\
\hline Atc1 $\mathrm{N}$ & PP-088 \\
\hline Atış Aydın A. & PP-038, PP-082 \\
\hline Atis A. & OP-10, PP-030, PP-035, PP-036, PP-043, PP-111 \\
\hline Atlihan U. & PP-092 \\
\hline Avc1 F. & PP-028, PP-029, PP-041, PP-079 \\
\hline Aydın A. & PP-047, PP-059 \\
\hline Aydın F. & PP-034 \\
\hline Aydın H. & PP-009, PP-044 \\
\hline Aydoğmuş S. & PP-016, PP-019, PP-020, PP-050 \\
\hline \multicolumn{2}{|l|}{ B } \\
\hline Băğ & PP-066, PP-102 \\
\hline Bakacak M. & PP-028, PP-029, PP-041, PP-079 \\
\hline Bakır L.V. & PP-025, PP-026, PP-095 \\
\hline Balık G. & PP-087, PP-089, PP-103 \\
\hline Balsak D. & $\begin{array}{l}\text { PP-023, PP-024, PP-026, PP-094, PP-095, } \\
\text { PP-114 }\end{array}$ \\
\hline Başaranoğlu S. & PP-003 \\
\hline Başpınar O. & PP-048, PP-051 \\
\hline Batmaz G. & PP-032 \\
\hline Bayoglu Tekin Y. & PP-040, PP-089, PP-093, PP-099, PP-105 \\
\hline Bayoğlu Metin Y. & PP-065 \\
\hline Baytur Y. & OP-05, OP-06, PP-002, PP-037, PP-085 \\
\hline Belgacem S. & PP-067 \\
\hline Belghith C. & OP-12 \\
\hline Ben Aissia N. & PP-067, PP-068, PP-080, PP-098 \\
\hline Ben Amor A. & OP-12 \\
\hline
\end{tabular}


Benk Şilfeler D.

Bettaieb H.

Bingöl G.

Bodur Öztürk H.

Bogavac M.

Bor E.D.

Bouriel I.

\section{C}

Cadhy Y.

Canhasi L.

Cekic S.

Cemgil Arıkan D.

Ceylan Y.

Chaabene M.

Chelli D.

\section{Ç}

Çalışkan M. PP-023

Çavuşoğlu S. $\quad$ PP-094, PP-095

Çekiç S.G. PP-038

Çelik E.Y. PP-078

Çelik T. PP-014

Çetin A. PP-021, PP-022

Çok T.

Çöğendez E.

\section{D}

Dane B.
Daneva Markova A.

Dede $M$.

Demir B.

Demir F.

Demir S.

Demirbağ S.

Demirci O.

Dhouaibia A.

Dikensoy E.

Dimassi K.

Divic B.

Dogru Abbasoglu S.

Doğan Y.

Dokuzoğlu Tanın Y.

Dolapçığlu K.

Douik F.

Dundar O.
PP-049, PP-062, PP-086

PP-100

PP-015, PP-055

PP-095, PP-114

PP-107, PP-112

PP-109

PP-053, PP-110

PP-083

PP-028, PP-029, PP-041, PP-079

PP-039, PP-091

OP-08

PP-032

OP-11, PP-031

PP-004

PP-021, PP-022, PP-023, PP-024, PP-025, PP-026, PP-094, PP-095, PP-114

PP-021, PP-022, PP-023, PP-024, PP-025, PP-026, PP-114

PP-021, PP-022, PP-023, PP-024, PP-025, PP-026, PP-094, PP-095, PP-114

OP-02

PP-009, PP-010, PP-012, PP-013, PP-044, PP-056, PP-057, PP-063

OP-12, PP-042

PP-048, PP-051, PP-071, PP-074

OP-08, OP-12, PP-017, PP-042, PP-067,

PP-068, PP-080, PP-098

PP-096

PP-084

PP-069

PP-074

PP-006, PP-015, PP-055, PP-097

PP-068, PP-080

PP-035, PP-036
E

Ecevit A. PP-046

Eken M. PP-100

Ekiz A. PP-082, PP-083

Ekmekci E. PP-019, PP-008, PP-016, PP-020, PP-050, PP-052, PP-007

El Fekih C. $\quad$ PP-039, PP-091

Emam M.A. $\quad$ PP-108

Energin $\mathrm{H} . \quad$ OP-01

Ercan Ö.

Erdogdu E.

PP-028, PP-029, PP-041, PP-079

PP-009, PP-010, PP-012, PP-013, PP-044, PP-056, PP-057, PP-063

Ergenoğlu A.M. PP-070

Ergin Bayık R.N. OP-09

Ergün A. OP-02

Erkanlı S. PP-066

Erkılınç S. PP-060

Eroğlu $M . \quad$ PP-100

Erol O. PP-018, PP-027

Erol Türkyılmaz Ş. $\quad$ PP-013

Ersoy A.Ö. PP-078

Ersoy E. PP-078

Eser B. PP-014

Esinler D. PP-033

F

Fadıloglu E. $\quad$ PP-033, PP-045

Fatnassi A. PP-039, PP-091

Felek N. PP-030

Findik F.M. PP-003, PP-113

Fidan U. PP-004, PP-059

G

Gara M.F. OP-08, OP-12, PP-017, PP-042, PP-067, PP-068, PP-073, PP-080, PP-098

Gedikbasi A. OP-10, PP-035, PP-036, PP-038, PP-082,

PP-084, PP-084, PP-111

Gelișen O. PP-078

Gezdirici A. PP-043

Gharbi E. PP-061

Gharbi S. PP-109

Giris M. PP-084

Goynumer G. $\quad$ PP-035, PP-036, PP-107, PP-112

Gökçe H. PP-006

Göker A. PP-106

Gözükara I. PP-032, PP-034

Gulac B. PP-035, PP-036

Gunduz O.D. $\quad$ OP-10

Gurses C. PP-027

Guvendag Guven E.S. PP-040, PP-093, PP-099, PP-105

Gül T.

PP-003, PP-113

Gülcüler L.H. PP-038

Gülümser Ç. $\quad$ PP-046, PP-058

Gündüz R. PP-071, PP-074 
Güngören A.

Güven M.A.

Güzin K.

\section{$\mathbf{H}$}

Hadzi Lega M.

Hakverdi A.U.

Hamdi A.

Hamdi B.

Hamza Q.

Hasbay B.

Herkiloğlu D.

Hmila F.

Hnifi C.

Hnifi M.C.

Hortu I.

Hsayaoui N.

\section{I}

Ines B.

I

İçen M.S.

İlhan N.

İlhan R.

İsenlik B.S.

\section{J}

Janbakhishov T.

PP-092

\section{K}

Kabil Kucur S.

Kadiri I.

Kağıtçı M.

Kalaycı H.

Kandemir O.

Kandemir Ö.

Kaplan S.

Karaca Kurtulmuş S.

Karacan T.

Karahanoglu E.

Karasahin K.E.

Karmous N.

Karoui A.

Kasımogulları V.

Kavak E.

Kavak S.B.

Kawther D.

Kaya B.

Kaya E.

Kaygusuz E.I.

Kelekçi S.

PP-066

PP-107

OP-08

PP-081

PP-086

PP-100

PP-039

PP-091

PP-070

PP-073

PP-038

PP-011

PP-018

PP-081

PP-033

PP-045

PP-011

OP-10

PP-083

PP-011

PP-011

PP-073

$\mathrm{PP}-043$

PP-024

PP-100
PP-006, PP-015, PP-055, PP-088, PP-097

OP-11, PP-031

PP-006, PP-015, PP-055

PP-053, PP-110

PP-039, PP-091

PP-053, PP-054, PP-061, PP-109, PP-110

PP-003, PP-113

PP-032, PP-034

PP-087, PP-090

PP-049, PP-062, PP-086

PP-019, PP-020, PP-052

PP-033, PP-045

OP-02, PP-004, PP-059

PP-017, PP-098

PP-054, PP-061, PP-067

PP-007, PP-008, PP-016, PP-019, PP-020, PP-050, PP-052
Keskin Kurt R.

Keskin U.

Kır Sahin F.

Kiyak H.

Koca E.

Koç Ö.

Kole E.

Koledin S.

Korkmaz N.

Koroglu M.

Koyuncu F.M.

Köse S.

Köstü B.

Kublay A.

Kumnova A.

Kumru P.

Kumru S.

Kurtulmuş S.

Kusari B.

Kuşçu E.

\section{M}

Malobabic D.

Mbarki C.

Melliti S.

Mete Ural U.

Metin Y.

Mezghani S.

Milosevic S.

Mitrovic B.

Mladenovic Segedi L.

Mtimet S.

Muhcu M.

\section{$\mathbf{N}$}

Novakovic Z. PP-075

Nural O. PP-097

\section{O}

Oluklu D. PP-076

Ordu S. PP-106

Orelj Popic M. PP-005

Orhan Metin N. PP-072

Oueslati H. PP-053, PP-054, PP-061, PP-110, PP-109

Ozdemir O. PP-027

Ozdemir S. PP-030

Ozdemirci S. PP-033, PP-045

Ozkan Ozdemir S. PP-069

Ozkose B. PP-043, PP-082, PP-111

Ozturk M. PP-047 
Ö

Öte $\mathrm{O}$.

Özçeltik G.

Özdemir H.

Özdemir Ö.

Özer I.

Özkan Ş.

Özkanlı Ş.

Özler S.

Öztürk Gözükara I.

Öztürk I.

Öztürk M.

Öztürk Ş.

\section{$\mathbf{P}$}

Pakay K.

Pala H.G.

Parlakgümüş H.A.

Pekin O.

Polat I.

Polat M.

\section{$\mathbf{R}$}

Radhouani R.

Rouchi G.B.

Sahin O.

Sak S.

Sakar M.N.

Salih F.

Sapmaz E.

Šašic $M$.

Serdaroğlu Uzuner Z.

Serin S.

Sezik M.

Soylu Karapinar O.

Stanojevic M.

Sterjovska A.

\section{Ş}

Şahin H.

Şahin Uysal N.

Şentürk Ş.

Şimşek D.
PP-046

PP-070

PP-049, PP-062, PP-086

PP-018

PP-060

PP-076, PP-077

PP-107

PP-078

PP-006, PP-055

PP-088

OP-02, PP-059

PP-014

PP-044, PP-057

OP-05, OP-06, PP-002, PP-037, PP-085, PP-106

PP-062

PP-012, PP-013, PP-044, PP-056, PP-057, PP-063

PP-035, PP-036, PP-038, PP-082, PP-083

PP-010, PP-012

PP-017, PP-042, PP-067, PP-068

PP-101

PP-112

PP-003

PP-023, PP-024, PP-025, PP-026, PP-094, PP-095, PP-114

PP-077

PP-011

PP-075

PP-103

PP-028, PP-029, PP-041, PP-079

OP-03, OP-04, PP-001

PP-006, PP-015

OP-11, PP-031

PP-031

PP-015, PP-097

PP-046, PP-058

PP-040, PP-064, PP-065, PP-072, PP-087, PP-089, PP-090, PP-093, PP-099, PP-105, PP-103

PP-070
$\mathbf{T}$

Talmac M. PP-083

Tarcan A. PP-058

Tarım E. PP-049, PP-062, PP-086

Taşkın M.İ. PP-014

Tatic Stupar Ž. PP-075

Tekirdag A.İ. PP-084

Telci G. PP-102

Temessek H. PP-017, PP-098

Temizkan O. PP-100

Toyran Sezik H. OP-04

Tozkır E. PP-010

Triki A.

OP-08, OP-12, PP-067, PP-017, PP-042, PP-068, PP-073, PP-080, PP-098

Tugrul S. PP-009, PP-010

Tuğcu U. PP-046

Tuncer G. PP-030

Türkyılmaz G. PP-013

$\mathbf{U}$

Ulubay M. PP-004

Usal D. PP-066, PP-102

Ustun B. PP-082

Uyar O. PP-088, PP-097

Uyar Y. OP-05, OP-06, PP-002, PP-037, PP-085

\section{$\ddot{\mathbf{U}}$}

Ünal E. PP-046

Üreyen E. $\quad$ PP-014

Üstüner I. $\quad$ PP-064, PP-065

Y

Yalçınkaya C. PP-049

Yalvaç S. PP-033, PP-045

Yaman Tunç S. PP-003, PP-113

Yanık F.F. PP-046, PP-058

Yapar Eyi E.G. $\quad$ OP-01, PP-060, PP-076, PP-077

Yayla $M . \quad$ OP-09

Yazıc1 S. PP-014

Yenen M.C. PP-004

Yeniel A.Ö. PP-070

Yetkinel S. PP-062, PP-086

Yildırım A. PP-019, PP-020, PP-052

Yilmaz Z. PP-046

Yucesoy G. PP-069

Yuksel S. PP-083

Yüksel H. PP-113 


\title{
PERINATAL JOURNAL
}

www.perinataljournal.com

\begin{abstract}
The Official Publication of Perinatal Medicine Foundation, Turkish Perinatology Society and Turkish Society of Ultrasound in Obstetrics and Gynecology
\end{abstract}

\section{Publication Ethics and Malpractice Statement}

Perinatal Journal is committed to upholding the highest standards of publication ethics and observes the following principles of Publication Ethics and Malpractice Statement which is based on the recommendations and guidelines for journal editors developed by the Committee on Publication Ethics (COPE), Council of Science Editors (CSE), World Association of Medical Editors (WAME) and International Committee of Medical Journal Editors (ICMJE).

All submissions must be original, unpublished (including as full text in conference proceedings), and not under the review of any other publication synchronously. Each manuscript is reviewed by one of the editors and at least two referees under double-blind peer review process. We reserve the right to use plagiarism detecting software to screen submitted papers at all times. We check for plagiary and fraudulent data; falsification (fabrication or manipulation of research data, tables, or images) and improper use of humans or animals in research. All manuscripts not in accordance with these standards will be removed from the publication. This also contains any possible malpractice discovered after the publication. In accordance with the code of conduct we will report any cases of suspected plagiarism or duplicate publishing.

We follow the COPE Ethics Flowcharts for dealing with cases of possible scientific misconduct and breach of publication ethics.

\section{Author Responsibilities}

Authors should ensure that submitted work is original. They must certify that the manuscript has not previously been published elsewhere or is not currently being considered for publication elsewhere, in any language. Applicable copyright laws and conventions should be followed. Copyright material (e.g. tables, figures or extensive quotations) should be reproduced only with appropriate permission and acknowledgement. Any work or words of other authors, contributors, or sources should be appropriately credited and referenced.

The author(s) of the original research articles (including short communications) must declare that they were involved in at least 3 of the 5 stages of the study as "designing the study", "collecting the data", "analyzing the data", "writing the manuscript" and "confirming the accuracy of the data and the analyses". All authors should disclose all issues concerning financial relationship, conflict of interest, and competing interest that may potentially influence the results of the research or scientific judgment. All financial contributions, supports or sponsorship of projects should be clearly explained.

When an author discovers a significant error or inaccuracy in his/her own published paper, it is the author's obligation to promptly cooperate with the Editor-in-Chief to provide retractions or corrections of mistakes.

\section{Responsibility for the Reviewers}

Reviewers evaluate manuscripts based on content without regard to ethnic origin, gender, sexual orientation, citizenship, religious belief or political philosophy of the authors. They should have no conflict of interest with respect to the research, the authors and/or the research funders. Their judgments should be objective.

Reviewers should identify relevant published work that has not been cited by the authors. They must ensure that all the information related to submitted manuscripts is kept as confidential and must report to the Editor-in-Chief if they are aware of copyright infringement and plagiarism on the author's side.

A reviewer who feels unqualified to review the topic of a manuscript or knows that its prompt review will be impossible should notify the Editor-in-Chief and excuse himself from the review process.

\section{Editorial Responsibilities}

Editors evaluate manuscripts for their scientific content without regard to ethnic origin, gender, sexual orientation, citizenship, religious belief or political philosophy of the authors. They provide a fair double-blind peer review of the submitted articles for publication. They ensure that all the information related to submitted manuscripts is kept as confidential before publishing.

Editors are responsible for the contents and overall quality of the publication. They should publish errata pages or make corrections when needed.

Editor-in-Chief does not allow any conflicts of interest between the authors, editors and reviewers. Only he has the full authority to assign a reviewer and is responsible for final decision for publication of the manuscripts in Perinatal Journal. 


\section{PERINATAL JOURNAL}

Volume 22 | Supplement | October 2014

11th Congress of the Mediterranean Association for Ultrasound in Obstetrics and Gynecology

9th-12th October 2014, Belek, Antalya, Turkey

9th Congress of Obstetrical and Gynecological Ultrasonography

Program Schedule

Oral Presentations SE1

(OP-01 - OP-12)

Poster Presentations

(PP-01 - PP-114)

Author Index 